ARGONNE NATIONAL LABORATORY

9700 South Cass Avenue

Argonne, Illinois 60439
MLLESS-TI- -228

DEo3 014390

ANL/EES-TM-228

\title{
INDIAN POINT NUCLEAR POWER STATION: VERIFICATION \\ ANALYSIS OF COUNTY RADIOLOGICAL \\ EMERGENCY-RESPONSE PLANS
}

by

J. Nagle and R. Whitfield

Energy and Envirommental Systems Division

Integrated Assessments and Policy Evaluation Group

May 1983

\section{DISCLAIMER}

This report was prepared as an account of work sponsored by an agency of the United States Government. Neither the United States Government nor any agency thereof, nor any of their employees, makes any warranty, express or implied, or assumes any legal liability or responsibility for the accuracy, completeness, or usefulness of any information, apparatus, product, or process disclosed, or represents that its use would not infringe privately owned rights. Reference herein to any specific commercial product, process, or service by trade name, trademark, manufacturer, or otherwise does not necessarily constitute or imply its endorsement, recommendation, or favoring by the Unitud States Government or any agency thereof. The views and opinions of authors expressed herein do not nec.:ssarily state or reflect those of the United States Government or any agency thereof.

work sponsored by

FEDERAL EMERGENCY MANAGEMENT AGENCY

Region II 
1 INTRODUCTION. ........................................

1.1 Purpose and Scope of Analysis.......................... 1

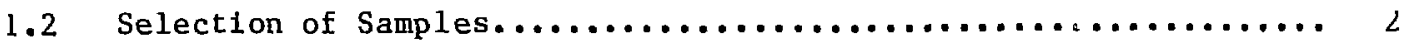

1.3 Surveying Procedures.................................

1.4 Significance of the Results............................. 3

2 RESULTS OF THE SURVEY.................................... 5

$2.1 \quad B^{-1}=$ Companies...................................... 5

$2.2 \quad \mathrm{~K}$. ption Centers.................................. 10

2.3 Congregate Care Centers................................ 14

2.4 Public Schools within the EPZ...........................18

2.5 Nonpublic Schools, Nursery Schools, and Day Care Centers

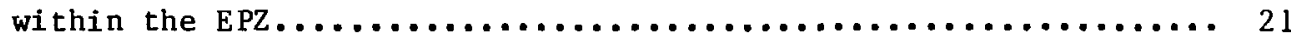

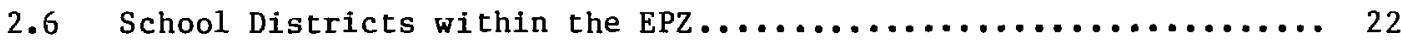

2.7 Hospitals and Nursing Homes within the EPZ............... 28

2.8 Hospitals Capable of Treating Radiologically Contaminated Patients......................................... 32

$2.9 \quad$ Ambulances......................................... 37

2.10 Personnel Monitoring Centers..........................4

APPENDIX A: QUESTIONNAIRES USED IN THE SURVEY................... 43

APPENDIX B: CONFIDENCE INTERVALS ........................... 77

APPENDIX C: INDIVIDUAL AND CUMULATIVE PROBABILITIES FOR THE HYPERGEOMETRIC DISTRIBUTION........................ 85

TABLES

1 Population and Sample Sizes,.............................4

2 Results of the Survey of Bus Companies...................... 6

3 Results of the Survey of Reception Centers.....................1

4 Results of the Survey of Congregate Care Centers............... 15

5 Results of the Survey of Public Schools within the EPZ............ 19 


\section{TABLES (Cont' $d$ )}

6 Results of the Survey of Nonpublic Schools, Nursery Schools, and Day Care Centers within the EPZ......................... 23

7 Results of the Survey of School Districts within the EPZ......... 26

8 Results of the Survey of Hospitals and Nursing Homes to be Evacuated ..................................... 29

9 Results of the Survey of Hospitals Capable of Treating Radiologically Contaminated Patients..................... 33

10 Results of the Survey of Ambulance Companies................. 38

\section{FIGURES}

1 Choice of Confidence Intervals for the Bus Company Category --

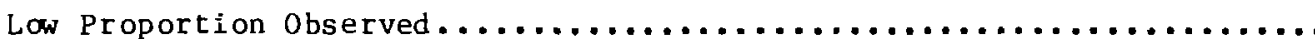

2 Choice of Confidence Intervals for the Bus Company Category --

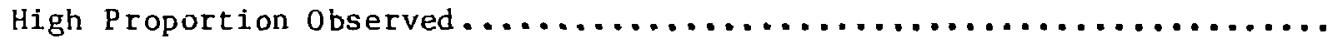

3 Choice of Confidence Intervals for the Ambulance Companies Category.... 83 
This study was prepared for the Federal Emergency Management Agency, Region II. The direction and support provided by Roger B. Kowieski, Chairman of the Regional Assistance Commitiee for Region II, is gratefully acknowledged. Stewart M. Glass, Regional Counsel for Region II, also played a key role in the development of the report.

Many Argonze National Laboratory personnel were involved in the verification effort. Thomas E. Baldwin was instrumental in managing Argonne's work with Region II staff and reviewing the report. Susan Barisas, Karen Guziel, Donald Hulet, Yehuda Klein, Elliott Levine, and Dee Wernette made the telephone calls that were the basis of the study. Mark Jusko assisted in the statistical analysis of the results. Kenneth Lerner reviewed and commented on an earlier draft of this report. Jacqueline Dzingel and the entire word processing staff of the Energy and Environmental Systens Division typed and retyped earlier drafts of this report. The report was edited by Donna Kenski.

Deficiencies or errors that remain in spite of the assistance of these individuals are the responsibility of the authors. 
1 INTRODUCTION

\subsection{PURPOSE AND SCOPE OF THE ANALYSIS}

This report was developed as a management tool for use by the Federal Emergency Manageinent Agency (FEMA) Region II staff. The analysis summarized in this report was undertaken to verify the extent to which procedures, training programs, and resources set forth in the County Radiological Emergency Response Plans (CRERPs) for Orange, Putnam, and Westchester counties in New York had been realized prior to the March 9, 1983, exercise of the Indian Point Nuclear Power Station near Buchanan, New York. To this end a telephone survey of county emergency response organizations was conducted between January 19 and February 22, 1983. Nine categories of emergency response organizations were contacted:

- Bus companies,

- Reception centers,

- Congregate care centers,

- Public schools within the 10-mile plume exposure emergency planning zone (EPZ) to be evacuated,

- Nonpublic schools, nursery schools, and day care centers within the EPZ to be evacuated,

- School districts within the EPZ to be evacuated,

- Hospitals and nursing homes within the EPZ to be evacuated,

- Hospitals capable of treating radiologically contaminated patients, and

- Ambulance companies.

This report presents the results of responses obtained from this survey of county emergency response organizations.

Time, manpower, and financial constraints prohibited a comprehensive survey of all the emergency response organizations with responsibilities assigned in the CRERPs. Therefore emergency response organizations within the nine categories listed above were sampled randomly instead. Emergency response organizations designated in CRERPs that were available on January 19 , 1983, were inventoried and lists of organizations to be contacted by telephone were then randomly sampled from these inventories. 
At the time of the verification analysis, Rockland County had not adopted a radiological emergency preparedness plan. For this reason, Rockland County was not included in this study.

\subsection{SELECTION OF SAMPLES}

The following guidelines were used to determine the size of the sample taken for each category of emergency response organization within each county*:

No. of Organizations
1
$2-4$
$5-6$
$7-20$
$21-54$
55 and up

Sample size

1
2
3
4
5

$10 \%$ of organizations

(rounded to nearest

integer)

These guidelines were constructed with the help of FEMA Region II staff. The guidelines were influenced by the time, manpower, and financial constraints mentioned above. As the number of organizations in a category decreases, a larger percentage of the total must be included in the sample to adequately estimate the parameters (variables) under study. Accordingly, the proportion of organizations sampled ranges from $100 \%$ (where the organizations of interest number two or less) to $10 \%$ (where the organizations of interest number 50 or greater). To avoid introducing undue bias into the sample, a simple randomizing technique was used to select the emergency response organizations to be sampled.

\section{3 SURVEYING PROCEDURES}

The questionnaires used in the verification analysis were developed by FEMA Region II staff with the assistance of personnel from Argonne National Laboratory. These questionnaires can be found in Appendix A. Argonne National Laboratory personnel telephoned each sampled emergency response organization and queried the person in charge of the organization or that persun's representative.

*All bus companies and hospitals capable of treating radiologically contaminated patients were surveyed. 
of the 98 emergency response organizations randomly selected to be sampled, sis responded to the survey. The other emergency response organizations either declined to answer any questions, were not available for comment, or did not respond for other reasons.

\subsection{SIGNIFICANCE OF THE RESULTS}

Table 1 summarizes the population (number of organizations in a category) and sample sizes for the study. The statistical significance of the responses to selected questions is included in Sec. 2. Confidence intervals and confidence levels are calculated for responses that were considered to be the most important, including responses on the training of emergency response personnel, the level of involvement with state and county authorities, and other particularly relevant topics. For example, where one out of five schools sampled from a population of 36 schools (see Table 1 and Tabie f, question 4 for Westchester (ounty) had been trained in evacuation procedures, the confidence interval is the range 0.03 to 0.56 for the proportion trained, and the confidence level is $89 \%$. A more detailed description of the confidence intervals and their selection is included in Appendix B. 
Table 1 Population and Sample Sizes

\begin{tabular}{|c|c|c|c|c|c|c|c|c|c|c|c|c|}
\hline \multirow[b]{2}{*}{ Factlfty Type } & \multicolumn{3}{|c|}{ Hestchester Co. } & \multicolumn{3}{|c|}{ Putnam Co. } & \multicolumn{3}{|c|}{ Orange Co. } & \multicolumn{3}{|c|}{ A1I CountfeB } \\
\hline & $\begin{array}{l}\text { Population } \\
\text { size }\end{array}$ & $\begin{array}{l}\text { Sample } \\
\text { S1ze }\end{array}$ & $\begin{array}{l}\text { Completed } \\
\text { Surveys }\end{array}$ & $\begin{array}{l}\text { Population } \\
\text { stze }\end{array}$ & $\begin{array}{l}\text { Sample } \\
\text { size }\end{array}$ & $\begin{array}{l}\text { Completed } \\
\text { Surveys }\end{array}$ & $\begin{array}{l}\text { Population } \\
\text { slze }\end{array}$ & $\begin{array}{l}\text { Sample } \\
\text { Size }\end{array}$ & $\begin{array}{l}\text { Completed } \\
\text { Surveys }\end{array}$ & $\begin{array}{l}\text { Population } \\
\text { Size }\end{array}$ & $\begin{array}{l}\text { Sample } \\
\text { S1ze }\end{array}$ & $\begin{array}{l}\text { Coupleted } \\
\text { Surveys }\end{array}$ \\
\hline Dus compantes & 7 & 7 & 5 & 5 & 5 & 3 & 3 & 3 & 1 & 15 & 15 & 9 \\
\hline Reception centers & 39 & 5 & 4 & 6 & 3 & 3 & 8 & 4 & 4 & 53 & 12 & 11 \\
\hline $\begin{array}{l}\text { Congregate care } \\
\text { relocation centera }\end{array}$ & 77 & 8 & g & 30 & 5 & 5 & 12 & 4 & $\dot{4}$ & 119 & 17 & 17 \\
\hline $\begin{array}{l}\text { Public schools within } \\
\text { the EPZ }\end{array}$ & 41 & 5 & 4 & 4 & 2 & 2 & 5 & 3 & 3 & 50 & 10 & 9 \\
\hline $\begin{array}{l}\text { Nonpublic achools, } \\
\text { nursery schools, and } \\
\text { day care centers } \\
\text { within the EPZ }\end{array}$ & 36 & 5 & 5 & 3 & 2 & 2 & 2 & 2 & 2 & 41 & 9 & 9 \\
\hline $\begin{array}{l}\text { School diatricts } \\
\text { within the EPZ }\end{array}$ & $\mathbf{B}$ & 4 & 4 & 3 & 2 & 2 & 2 & 2 & 2 & 13 & B & 8 \\
\hline $\begin{array}{l}\text { Hogpitals and nursing } \\
\text { hoseg within the EP2 }\end{array}$ & 20 & 4 & 4 & 2 & 2 & 2 & 1 & 1 & 1 & 23 & 7 & 7 \\
\hline $\begin{array}{l}\text { Hoapitals treating radio- } \\
\text { logically contaminated } \\
\text { patients }\end{array}$ & 3 & 3 & 3 & 1 & 1 & 1 & 2 & 2 & 2 & 6 & 6 & 6 \\
\hline Ambulance compantea & 51 & 5 & 4 & 11 & 4 & 4 & 27 & 5 & 4 & 89 & 14 & 12 \\
\hline
\end{tabular}

The nuaber of surveys actually completed is smaller than the number in the sample hecause some organizations elected not to reapond to queations over the telephone or could not be contacted despite repeated attempts. 


\section{RESULTS OF THE SURVEY}

of the total 409 emergency response organizations with responsibilities assigned in the CRERPs, 98 were included in the sample. However, the number of surveys actually completed is smaller than the number of emergency organizations selected for the sample because some organizations elected not to respond to questions over the telephone or could not be contacted despite repeated attempts. The analysis that follows is based on the 88 completed interviews.

The following results are organized by type of emergency sesponse organization. For each type of organization, a narrative summary presents results for the three counties combined and then for each county separately. Following this narrative is a table that contains the numerical results of each question asked.

\subsection{BUS COMPANIES}

Nine bus companies -- $60 \%$ of the companies listed in the CRERPS -responded to the survey. Of these nine companies,

- Seven (78\%) had been contacted by tine state or county concerning the CRERP,

- Five (55\%) had garases located within the EPz,

- One (11\%) had at least one driver who had been trained in radiological emergency response preparedness, and

- Two (22\%) had such training scheduled.

Table 2 lists the numerical results of the bus company survey.

Orange County

Three bus companies in Orange County are designated to assist in an evacuation, and all three were included in the sample. The CRERP, however, is organized so that one company is responsible for contacting the other two companies. The survey respondent at the company responsible for contacting the other two companies was not aware of this system. Argonne personnel were unable to contact the other two companies. The one company that was questioned had been contacted by the county concerning the CRERP. Personnel at this company had not received any training for radiological emergency response preparedness, but such training was scheduled. The company did not have information on evacuee pick-up locations or dosimeters available for drivers. 
Table 2 Results of the Survey of Bus Companies

2a. How many buses do you have in your garage? Orange Putnam

Westchester All Counties

$\begin{array}{lcccc}\text { Range } & 65 & 17-163 & 10-250 & 10-250 \\ \text { Mean } & 65 & 78 & 84 & 80\end{array}$

2b. How many vans do you have in your garage?

Orange Putnam Westchester All Counties

$\begin{array}{lcccc}\text { Range } & 2 & 8-20 & 0-23 & 0-23 \\ \text { Mean } & 2 & 16 & 12 & 12\end{array}$

3a. On an average day, how many buses do you have in working condition?

Orange Putnam Westchester A.l1 Counties

$\begin{array}{lcccc}\text { Range } & 63 & 15-147 & 10-225 & 10-225 \\ \text { Mean } & 63 & 70 & 80 & 75\end{array}$

3b. On an average day, how many vans do you have in working condition? Orange Putnam Westchester All Counties

$\begin{array}{lcccc}\text { Range } & 2 & 8-18 & 0-18 & 0-18 \\ \text { Mean } & 2 & 14 & 11 & 11\end{array}$

4a. What is the average capacity of the buses that you have in working condition on an average day?

Orange Putnam Westchester All Counties
Range
43
$60-77$
Mean
43
67
$42-66$
58
$42-77$
59

4b. What is the average capacity of the vans that you have in working condition on an average day?

Orange Putnam Westchester All Counties
Range
$8 \quad i-15$
$12-16$
$7-16$
Mean
811
15
12

5. How many of your vehicles are equipped to transport handicapped, nonambulatory individuals?

Orange Putnam Westchester All Counties

Range

$0 \quad 2-9$

$0-86$

$0-86$

Mean

$0 \quad 5$


Table 2 (Cont'd)

6. How many 1 icensed bus and van drivers do you employ?

Orange Putnam Westchester All Counties

$\begin{array}{lcccc}\text { Range } & 80 & 25-225 & 30-316 & 25-316 \\ \text { Mean } & 80 & 107 & 115 & 108\end{array}$

7. How many vehicles do you use on an ordinary daily basis when schools are in session?

Orange Putnam Westchester All Counties
Range
$6123-180$
61
192
$22-220$
$22-220$
Me an
80
82

8. How many vehicles do you use on an ordinary daily basis when schools are not in session? (weekends, vacation, summer, etc.)

Orange Putnan Westchester All Counties

$\begin{array}{lcccc}\text { Range } & 13 & 0-13 & 0-196 & 0-196 \\ \text { Mean } & 13 & 5 & --\end{array}$

9. Approximately how many vehicles are equipped with mobile commuications equi pment?

Orange Putnam Westchester All Counties

$\begin{array}{lcccc}\text { Range } & 67 & 8-183 & 0-118 & 0-183 \\ \text { Mean } & 67 & 79 & 44 & 58\end{array}$

11). Have you or someone in your organization been contacted by state or county representatives to discuss your role in the Indian point Radiological Emergency Response Plan?

Orange Putnam Westchester All Counties

$\begin{array}{lllll}\text { Yes } & 1^{\mathrm{a}} & 2^{\mathrm{b}} & 4^{\mathrm{c}} & 7^{\mathrm{d}} \\ \text { No } & 0 & 0 & 1 & 1 \\ \text { Don't know } & 0 & 1 & 0 & 1\end{array}$

10a. If yes, when was the company contacted regarding the plan? Orange Putnam Westchester

All Counties

1983

1982

1981

Don't know

$\begin{array}{ll}0 & 1 \\ 1 & 1 \\ 0 & 0 \\ 0 & 0\end{array}$

0
2
1
2

1
4
1
2


Table 2 (Cont'd)

12. Who would contact you and tell you to deploy your vehicles in the event. an evacuation became necessary?

Orange Putnam Westchester All Counties

County

Superintendent of schools

Civil defense

$\begin{array}{llll}1 & 0 & 3 & 3 \\ 1 & 2 & 2 & 5 \\ i & 1 & 0 & i\end{array}$

13. How would you be contacted? (a-g., telephone, radio, etc.)

Orange Putnam Westchester All Counties

Telephone

Don't know

$0 \quad 2$

25

$5 \quad 7$

$\begin{array}{llll}1 & 1 & 0 & 2\end{array}$

14. How would you notify your vehicledrivers to report to the garage in the event they were needed for an evacuation?

Orange Putnam Westchester All Counties

Telephone

Rad io

$\begin{array}{llll}1 & 3 & 4 & 8 \\ 0 & 1 & 3 & 4\end{array}$

15. Is your garage located within the 10-mile Emergency Planning Zone? Orange Putnam Westchester All Counties

$\begin{array}{lllll}\text { Yes } & 1^{\mathrm{f}} & 1 & 3 & 5^{\mathrm{f}} \\ \text { No } & 1^{\mathrm{f}} & 2 & 2 & 5^{\mathrm{f}}\end{array}$

16. If the garage is witin the EPZ, how will you commicate with your drivers if there is a total evacuation and your dispaccher must leave the garage?

Orange Putnam Westchester All Counties

Radio

Don't know

Move headquarters

$0 \quad 0$

$\begin{array}{lll}0 & 1 & 0\end{array}$

3

10001

17. Do you have maps or lists of evacuee pick-up locations available for distribution to your vehicle drivers?

Orange Putnam Westchester Ail Counties

Yes

No

og $\quad 1^{\mathrm{h}}$

$4^{c}$

$5^{i}$

12

1

4 
Table 2 (Cont'd)

18. How many of your vehicie drivers have received formal training in radiological emergency response preparedness (including dosimetry, evacuation routes, etcs)?

$\begin{array}{cccccc}: & \text { Orange } & \text { Putnam } & \text { Westchester } & \text { all Counties } \\ \text { Onedriver } & 0^{g} & 0^{j} & & 1^{k} & 1^{1} \\ \text { Nodrivers } & 1 & 3 & & 4 & 8\end{array}$

19. Are your vehicle drivers scheduled to receive radiological emergency response training in the future?

Orange Putnam Westchester All Counties

$\begin{array}{lllll}\text { Yes } & 1 & 1 & 0 & 2 \\ \text { No } & 0 & 2 & 5 & 7\end{array}$

20. How many dosimeters do you have available for distribution to your drivers?

Orange Putnam Westchester All Counties

Une dosineter

No dosimeters

Don't know

$\begin{array}{ll}0 & 0 \\ 1 & 3 \\ 0 & 0\end{array}$

$\begin{array}{ll}1 & 1 \\ 3 & 7 \\ 1 & 1\end{array}$

${ }^{\mathrm{a}}$ Confidence interval $=(0.33,1.00)$, confidence level $=100:$.

$\mathrm{b}_{\text {Confidence interval }}=(0.40,0.80)$, confidence level $=100 \%$.

${ }^{c}$ Confidence interval $=(0.57,0.85)$, confidence level $=100 \%$.

${ }^{\mathrm{d}}$ Confidence interval $=(0.60,0.87)$, confidence level $=88 \%$; confidence

interval $=(0.47,0.87)$, confidence level $=100 \%$.

Multiple responses were given by same companies.

E One company had garages located both within and outside the EPZ.

g Confidence interval $=(0.00,0.67)$, confidence level $=100 \%$.

$\mathrm{h}_{\text {Confidence interval }}=(0.20,0.60)$, confidence level $=100 \%$.

${ }^{i}$ Confidence interval $=(0.40,0.73)$, confidence level $=83 \%$; confidence interval $=(0.33,0.73)$, crnfidence level $=100 \%$.

$\mathrm{j}_{\text {Confidence }}$ interval $=(0.00,0.40)$, confidence level $=100 \%$.

${ }^{k}$ Confidence interval $=(0.14,0.43)$, confidence level $=100 \%$.

${ }^{1}$ Confidence interval $=(0.07,0.27)$, confidence 1 evel $=86 \%$; confidence

interval $=(0.07,0.47)$, confidence level $=100 \%$. 


\section{$\underline{\text { Putnam County }}$}

of the five bus companies chosen to be surveyed in Putnam County, the respondent at one refused to answer questions without compensation and surveyors ware not able to contact a second company. Two of the remaining companies tiat completed the survey had been contacted by the state or county concernins the CRERP. None of these three companies had personnel trained in radiological emergency response preparedness, but one indicated that such training ras scheduled. One company had information on evacuee pick-up locations : railable for drivers. No companies bad dosimeters available for drivers.

\section{Westchester County}

Seven bus companies in Westchester County were included in the CRERP and all were selected to be surveyed. Argonne surveyors were unable to contact one company, and another company refused to answer the questionnaire. Four of the five companies that completed the survey had been contacted by the state or county concerning the CRERP. The survey indicated that one driver in one company had been trained in radiological emergency response preparedness. No training sessions were scheduled for any company. Four companies had information on evacuee pick-up locations available for drivers, and one had dosimeters available for drivers.

\subsection{RECEPTION CENTERS}

Twelve of the 53 facilities designated to serve as reception centers were included in the sample, and 11 responded to the survey. of these facilities,

- All (100\%) were schools, and

- Seven (78\%) had plans for students if the buildings were to be used as reception centers.

Nine ( $82 \%$ ) of the respondents were aware that their buildings were designated as reception centers, but none knew who would be in charge of reception center operations. Table 3 lists the questions and numerical results of the reception center survey.

\section{Orange County}

Respondents at all four of the schools sampled in Orange County were aware that their buildings had been designated as reception centers. One respondent knew who would notify the school if it became necessary to activate the building as a receptiol center. None of the respondents knew who would be in charge of reception center operations. Three of the schools had plans (e.g., dismissal of school) for the students if the butldings were to be used as reception centers. 
Table 3 Results of the Survey of Reception Centers

1. Are you aware that your building is designated as a Reception

Center in the Indian Point Radiological Emergency Response Plan?

Orange Putnam Westchester A11 Counties

$\begin{array}{lllll}\text { Yes } & 4^{a} & 3^{b} & 2^{c} & 9^{d} \\ \text { No } & 0 & 0 & 2^{e} & 2^{e}\end{array}$

2. Who would notify you that your building is to be activated as a Reception Center?

Orange Putnam Westchester A11 Counties

Superintendent

Don't know

10

3

2

$\begin{array}{llll}1 & 3 & 1 & 7\end{array}$

3. Huw would you be notified that your building is to be activated as a Reception Center?

Orange Putnam Westchester All Counties

Telephone

Don't know

2

$1 \quad 1 \quad 4$

$\begin{array}{llll}2 & 2 & 1 & 5\end{array}$

4. Is your building utilized 12 months a year?

Orange Putnam Westchester All Counties

Yes

$\mathrm{so}$

23

$2 \quad 7$

5. Who is authorized to open the building after working hours (and weekends, vacations, summers if applicable) in case it is needed as a Reception Center during a Kadiological Emergency?

Orange Putnam Westch'iter All Counties

Custodian

Principal

Superintendent

Other

$\begin{array}{llll}2 & 1 & 1 & 4 \\ 0 & 1 & 0 & 1 \\ 1 & 1 & 0 & 2 \\ 1 & 0 & 1 & 2\end{array}$

b. Is there a backup person name available in case the regular person isn't available?

Orange Putnam Westchester All Counties

Yes

No

43

1

8

$0 \quad 0$

1

1 
Table 3 (Cont'd)

7. What is the normal daily occupancy of your building?

$\begin{array}{lccccc} & \text { Orange } & & \text { Putnam } & \text { Westchester } & \text { All Counties } \\ \text { Range } & 660-2400 & 400-1850 & 80-750 & 80-2400 \\ \text { Mean } & 1343 & 883 & 415 & 983\end{array}$

8. What is the capacity of your parking lot? (automobiles)

$\begin{array}{lccccc} & \text { Orange } & & \text { Putnam } & \text { Westchester } & \text { All Counties } \\ \text { Range } & 75-100 & 40-50 & 80-300 & 40-300 \\ \text { Mean } & 103 & 45 & & 190 & 82\end{array}$

9. Are there showers in your building?

Orange Putnam Westchester All Counties

$\begin{array}{lllll}\text { Yes } & 3 & 2 & 2 & 7 \\ \text { No } & 1 & 1 & 0 & 2\end{array}$

9a. How many showers are there in the building? $\mathrm{f}$

Orange Putnam Westchester All Counties

\begin{tabular}{|c|c|c|c|c|c|}
\hline \multirow{2}{*}{ Male } & fRange & $7-15$ & --- & $1-6$ & -- \\
\hline & Mean & 11 & --- & 4 & --- \\
\hline \multirow{2}{*}{ Female } & fRange & $0-15$ & --- & $2-6$ & --- \\
\hline & Mean & 8 & --- & 4 & --- \\
\hline Male or Female & $\left\{\begin{array}{l}\text { Range } \\
\text { Mean }\end{array}\right.$ & $\begin{array}{l}--- \\
---\end{array}$ & $\begin{array}{c}6-10 \\
8\end{array}$ & -- & -- \\
\hline
\end{tabular}

10. Approximately how many toilets are there in the building? Orange Putnam Westchester All Counties

\begin{tabular}{|c|c|c|c|c|c|}
\hline \multirow[t]{2}{*}{ Male } & \{range & $11-35$ & $10-35$ & $6-10$ & $6-35$ \\
\hline & Mean & 18 & 21 & 8 & 16 \\
\hline Female & Range & $11-35$ & $10-35$ & $6-10$ & $6-35$ \\
\hline & Mean & 18 & 21 & 8 & 16 \\
\hline
\end{tabular}

11. In the event of a radiological emergency at the Indian Point Nuclear Generating Station, who is in charge of operations at the Reception Center to be located in your building?

Orange Putnam Westchester All Counties

Don't know

other

$\begin{array}{llll}4 & 3 & 2 & 9 \\ 0 & 0 & 0 & 0\end{array}$


Table 3 (Cont'd)

12. Do you have any plans for your own students if you are notified that your school will be used as a Reception Center? (Asked only for Reception Centers located in schools.)

$\begin{array}{cccc}\text { Orange } & \text { Putnam } & \text { Westchester } & \text { All Counties } \\ 3 & 2 & 2 & 7 \\ 1 & 0 & 0 & 1 \\ 0 & 1 & 0 & 1\end{array}$

${ }^{\mathrm{a}}$ Confidence interval $=(0.62,1.00)$, confidence level $=92 \%$; confidence interval $=(0.50,1.00)$, confidence level $=100 \%$.

${ }^{\mathrm{b}}$ Confidence interval $=(0.66,1.00)$, confidence level $=80 \%$; confidence interval $=(0.50,1.00)$, confidence level $=100 \%$.

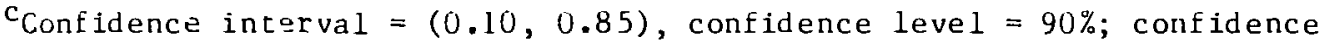
iriterval $=(0.05,0.35)$, confidence level $=100 \%$.

${ }^{d}$ Confidence interval $=(0.60,0.96)$, confidence 1 evel $=90 \%$; confidence interval $=(0.17,0.96)$, confidence level $=100 \%$.

encludes one school that has been closed and one school that has not accepted the responsibility of being a reception center.

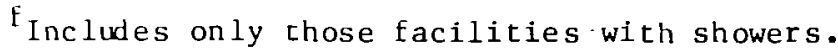

$\underline{\text { Putnam County }}$

Kespondents at each of the three schools questioned ir. Putnam County were aware that their buildings had been designated as reception centers, but did not know who would notify them if it became necessary to activate their buildings as reception centers or who would be in charge of reception center operations. All of those schools responding had plans (e.g., dismissal of school) for their students if the buildings were to be used as a reception centers.

Westchester County

Five schools designated as reception centers in the CRERP were chosen for the sample in Westchester County. Of these schools, one was closed in 1979, and one refused to accept the responsibility of serving as a reception center. The respondent at the third school wuld not answer the questionnaire by telephone. Respondents at the two schools participating in the survey were aware that their buildings had been designated as reception centers. One of these knew who would notify the school if it became necessary to activate the building as a reception center. Neither knew who would be in charge of 
reception center operations, but both schools had plans (e.g., dismissal of school) for the students if the buildings were to be used as reception centers.

\subsection{CONGREGATE CARE CENTERS}

Seventeen or the 119 facilities designated to serve as congregate care centers were sampled. of those questioned,

- Eleven (65\%) of the respondents were aware that their buildings were designated as congregate care centers,

- Ten (59\%) of the respondents did not know wto would notify them that their buildings were to be activated as congregate care centers, and

- Nine (56\%) of the schools had plans for their students if the buildings were to be used as congregate care centers.

Table 4 lists the questions and numerical results of the congregate care cencer survey.

\section{Orange County}

Four schools designated to serve as congregate care centers in orange County were included in the sample. Each of these schools responded to the survey. Respondents at three of the schools were aware of their inclusion in the CKERP, but each respondent had a different idea as to who would notify the school if it became necessary to activate the building as a congregate care center. All of the schools had plans for their students if the buildings were activated as congregate care cencers.

\section{Putnam County}

In Putnam County, five facilities were sampled. Respondents at two were aware that their buildings had been designated as congregate care centers. Four did not know who would notify them if it became necessary to activate their buildings as congregate care centers. Two of the schools (there was one hospital in the sample) had plans for their students if it became necessary to activate the buildings as congregate care centers. 
Table 4 Results of the Survey of Congregate Care Centers

1. Are you aware that your building is designated as a congregate care center?

\begin{tabular}{ccccc} 
Orange & Putnam & Westchester & All Counties \\
\cline { 1 - 1 } $3^{\mathrm{a}}$ & $2^{\mathrm{b}}$ & $6^{\mathrm{c}}$ & & $11^{\mathrm{d}}$ \\
0 & 3 & 2 & 5 \\
1 & 0 & 0 & 1
\end{tabular}

2. Who would notify you that your building is to be activated as a congregate care center?

Orange Putnam Westchester All Counties

Civil defense

Health department

Red Cross

Superintendent of schools

other

Don't know

1
0

10

10

$0 \quad 0$

$\begin{array}{ll}1 & 1 \\ 0 & 1 \\ 0 & 0 \\ 0 & 0 \\ 0 & 1 \\ 4 & 5\end{array}$

3

1

0

5

3. How would you be notified that your building is to be activated as a congregate care center?

Orange Putnam Westchester All Counties

Telephone

Rad io

In person

Don't know

$\begin{array}{ll}3 & 1 \\ 1 & 0 \\ 1 & 0 \\ 1 & 4\end{array}$

4

8

1

0

0

4

1

4. Is your building utilized 12 months a year?

Orange Putnam Westchester All Counties

Yes

No

No answer
4

0

0

4
1
0

6 
Table 4 (Cont'd)

5. Who is authorized to open the building after working hours (and weekends, vacations, summers if applicable) in case it is needed as a congregate care center during a radiological emergency? ${ }^{e}$

Orange Putnam Westchester All Counties

Superintendent
Priccipal
Custodian
Secretary
Board of Education
Teacher
Don't know
Not applicable (open
$24 \mathrm{hr} / \mathrm{day}$ )

6. Is there a backup person in case the regular person isn't available? Orange Putnam Hestchester All Counties

$\begin{array}{llllr}\text { Yes } & 4 & 4 & 7 & 15 \\ \text { No } & 0 & 0 & 0 & 0 \\ \text { Don't know } & 0 & 0 & 1 & 1\end{array}$

7. What is the normal occupancy of your building?

Orange Putnam Westchester Al1 Counties

$\begin{array}{lcccc}\text { Range } & 425-1800 & 100-1600 & 300-2300 & 100-2300 \\ \text { Mean } & 1062 & 621 & 966 & 887\end{array}$

8. What is the capacity of your parking lots? (automobiles)

\begin{tabular}{|c|c|c|c|c|}
\hline & Orange & Putnam & Westchester & Al1 Counties \\
\hline Range & 250-unlimited & $40-500$ & $40-600$ & 40-unlimited \\
\hline Mean & -- & 142 & --- & - \\
\hline
\end{tabular}

9. Are there showers in the your building?

Orango Putnam Westchester All Counties

Yes

$\begin{array}{lll}3 & 3 & 5 \\ 1 & 2 & 3\end{array}$

11

No 
Table 4 (Cont'd)

9a. How many showers are there in the building? ${ }^{f}$

Orange Putnam Westchester All Counties

\begin{tabular}{|c|c|c|c|c|c|}
\hline \multirow{2}{*}{ Male } & (Range & $10-29$ & $3-10$ & $2-12$ & $2-29$ \\
\hline & Mean & 18 & 7 & 9 & 11 \\
\hline \multirow{2}{*}{ Female } & (Range & $12-33$ & $3-10$ & $0-12$ & $0-33$ \\
\hline & (Mean & 20 & 7 & 8 & 11 \\
\hline
\end{tabular}

10. Approximately how many toilets are there in the building? ${ }^{f}$

Orange Putnam Westchester All Counties

Fale $\left\{\begin{array}{lcccc}\text { Range } & 10-30 & 8-30 & 8-20 & 8-30 \\ \text { Mean } & 18 & 16 & -- & -- \\ \text { Range } & 10-33 & 8-30 & 8-20 & 8-33 \\ \text { Mean } & 23 & 16 & --- & ---\end{array}\right.$

11. In the event of a radiological emergency at the Indian Point Nuclear Generating Station, who is in charge of operations at the congregate care center?

Orange Putnam Westchester All Counties

$\begin{array}{llllr}\text { Civil defense } & 0 & 0 & 1 & 1 \\ \text { Red Cross } & 0 & 0 & 1 & 1 \\ \text { Other } & 1 & 1 & 1 & 3 \\ \text { Don't know } & 3 & 4 & 5 & 12\end{array}$

12. Do you have any plans for your own students if you are notified that your school will be used as a congregate care center? (Asked only for congregate care centers located in schools.)

Orange Putnam Westchester All Counties

$\begin{array}{lllll}\text { Yes } & 4 & 2 & 3 & 9 \\ \text { No } & 0 & 2 & 5 & 7 \\ \text { Not applicable } & 0 & 1 & 0 & 1\end{array}$

\footnotetext{
${ }^{a}$ Confidence interval $=(0.33,0.92)$, confidence level $=93 \%$; confidence interval $=(0.25,0.92)$, confidence leve $1=100 \%$.

${ }^{\mathrm{b}}$ Confidence interval $=(0.07,0.77)$, confidence leve $1=90 \%$; confidence interval $=(0.07,0.90)$, confidence level $=100 \%$.

${ }^{c}$ Confidence interval $=(0.47,0.97)$, confidence level $=90 \%$; confidence interval $=(0.08,0.97)$, confidence 1 evel $=100 \%$.

${ }^{\mathrm{d}}$ Confidence interval $=(0.47,0.95)$, confidence 1 eve $1=90 \%$; confidence interval $=(0.09,0.95)$, confidence leve $1=100 \%$.

Multiple responses were given by some facilities.

fumber of unspecified facilities is divided equally between male and female.
} 


\section{Westchester County}

of the eight schools sampled in Westchester County, respondents at six were aware that their buildings were designated as coigregate care centers in the CRERP. Five respondents did not know who would notify them if it became necessary to activate their buildings as congregate care centers. Three of the schools had plans for student: if their buildings were to be activaced as congregate care centers.

\subsection{PUBLIC SCHOOLS WITHIN THE EPZ}

Of the 50 public schools within the EPZ, ten were chosen for the sample and nine responded to the survey. of these nine schools,

- Eight ( $89 \%$ ) had been contacted regarding the CRERP,

- Two (22\%) had personnel with some training in evacuation procedures,

- Two (22\%) had such training scheduled, and

- $\operatorname{Six}(67 \%)$ had tone alert radios.

Table 5 lists the questions and numericai results of the public school survey.

\section{כrange County}

Three orange County public schools within the EPZ were chosen in a rand om sample of all such schools in the county. Two of these three schools had been contacted regarding their roles in the CRERP, two had staff trained in procedures for evacuating the schools, and two had tone alert radios.

\section{$\underline{\text { Putnam County }}$}

In Putnam County, two public schools within the EPZ were included in the survey. Both of the schools had been contacted regarding their roles in the CRERP. Neither of the schools had staff trained in procedures for evacuating the schools. One school had a tone alert ratio.

\section{Westchester County}

Five Westchester County public schools within the EPZ were questioned in the survey. Respondents at four of these schools were willing to answer questions on the telephone. The respondent at the other public school preferred to submit written responses to the questions and consequently this school is not included in the findings discussed here. Each of the remaining four schools had: an contacted regarding its role in the CRERP. None of the schools had staff trained in procedures for evacuating the schools. Three schools had tone alert radios. 
Table 5 Results of the Survey of Public Schools within the EPZ

1. How many students attend your school?

$\begin{array}{cccc}\text { Orange } & \text { Putnam } & \text { Westchester } & \text { All Counties } \\ \begin{array}{cccc}250-650 & 262-775 & 420-2000 & 250-2000 \\ 387 & 519 & 1023 & 699\end{array}\end{array}$

3. Have you or someone in your school been contacted to discuss your role in the Indian Point Radiological Emergency Response plan?

\begin{tabular}{|c|c|c|c|}
\hline Orange & Putnam & Westchester & Al 1 Counties \\
\hline $2^{a}$ & $2^{b}$ & $4^{c}$ & $8^{d}$ \\
\hline 1 & 0 & 0 & 1 \\
\hline
\end{tabular}

3a. LE yes, who contacted your schooi? ${ }^{e}$

Orange Putnam Westchester All Counties

County

State

Board of Education

Civil defense

von't know

()ther

$\begin{array}{ll}0 & 0 \\ 0 & 0 \\ 1 & 0 \\ 0 & 1 \\ 0 & 1 \\ 1 & 0\end{array}$

3b. It yes, when was your school contacted?

Urange Putnam Westchester All Counties

$\begin{array}{lllll}1983 & 0 & 0 & 1 & 1 \\ 1482 & 2 & 0 & 1 & 3 \\ \text { Don't know } & 0 & 2 & 2 & 4\end{array}$

4. Have you or any of your staff received any training in procedures for evacuating your school?

Orange Putnam Westchester All Counties

$\begin{array}{lllll}\text { Yes } & 2^{\mathrm{a}} & 0^{\mathrm{f}} & 0^{\mathrm{g}} & 2^{\mathrm{h}} \\ \text { No } & 1 & 2 & 4 & 7\end{array}$

5. Are any training sessions planned?

Orange Putnam Westchester All Counties

Yes

No

20

Don't know

$\begin{array}{ll}1 & 2 \\ 0 & 0\end{array}$

0

$2 \quad 3 \quad 6$

2 
Table 5 (Cont'd)

6. Who will contact you to tell you that your school is to be evacuated? Orange Putnam Westchester All Counties

District office

Civil defense

County

Don't know

$\begin{array}{llll}0 & 0 & 3 & 3 \\ 1 & 1 & 0 & 2 \\ 1 & 0 & 0 & 1 \\ 1 & 1 & 1 & 3\end{array}$

7. How will you be contacted? ${ }^{\mathrm{e}}$

Urange Putnam Westchester All Counties

Telephone

Rad io

In person

Don't know

$\begin{array}{llll}2 & 2 & 2 & 6 \\ 1 & 0 & 2 & 3 \\ 0 & 0 & 1 & 1 \\ 1 & 0 & 0 & 1\end{array}$

8. Do you have a tone alert radio in your school?

Orange Putnam Westchester All Counties

Yes

$2^{\mathrm{a}} \quad 1^{\mathrm{i}}$

$3^{\mathrm{j}}$

$6^{\mathrm{k}}$

No

11

1

3

9. Are you responsible for contacting any other schools or facilities in your area to inform them that they are to be evacuated?

Orange Putnam Westchester All Counties

Yes

No

Don't know

$\begin{array}{llll}1 & 0 & 0 & 1 \\ 2 & 1 & 3 & 6 \\ 0 & 1 & 1 & 2\end{array}$

10. Have you been informed who will provide buses if evacuation becoms necessary?

Orange Putnam Westchester All Counties

Westpoint Tours

School district

Vanguard

Other

Don't know

$\begin{array}{ll}2 & 0 \\ 1 & 1 \\ 0 & 0 \\ 0 & 0 \\ 0 & 1\end{array}$

0

2
2
2
1
2


Table 5 (Cont'd)

11. Have you been informed where your students will be taken initially if your school is evacuated?

Orange Putnam Westchester All Counties

$Y \in S$

No

$2 \quad 2$

$2 \quad 4$

8

${ }^{a}$ Confidence interval $=(0.40,0.80)$, confidence 1 level $=100 \%$

${ }^{b}$ Contidence interval $=(0.50,1.00)$, confidence level $=100 \%$.

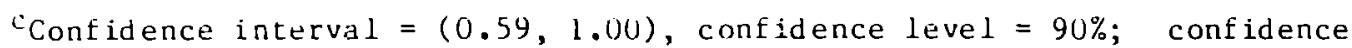
interval $=(0.10,1.00)$, confidence leve $1=100 \%$.

${ }^{\mathrm{d}}$ Confidence interval $=(0.66,0.98)$, confidence level $=90 \%$; confidence interval $=(0.16,0.98)$, confidence leve $1=100 \%$.

Multiple responses were given by some facilities.

$\mathrm{f}_{\text {Confidence intervid }}=(0.00,0.50)$, confidence level $=100 \%$.

SConfidence interva $L=(0.00,0.41)$, confidence level $=90 \%$; confidence interval $=(0.00,0.90)$, confidence level $=100 \%$.

$\mathrm{h}_{\text {Confidence interval }}=(0.04,0.46)$, confidence level $=89 \% ;$ confidence interval $=(0.04,0.86)$, confidence level $=100 \%$.

$\dot{i}_{\text {Confidence }}$ interval $=(0.25,0.75)$, confidence level $=100 \%$.

j Confidence interval $=(0.34,0.98)$, confidence level $=89 \%$; confidence interval $=(0.07,0.98)$, confidence level $=100 \%$.

$\mathrm{k}_{\text {Confidence }}$ interval $=(0.36,0.88)$, confidence level $=90 \%$; confidence interval $=(0.12,0.94)$, confidence level $=100 \%$.

\subsection{NONPUBLIC SCHOOLS, NURSERY SCHOOLS, AND DAY CARE CENTERS} WI THIN THE EPZ

Nine of the 41 nonpublic schools, nursery schools, and day care centers within the EPZ were sampled. Of the nine schools surveyed,

- Eight ( $89 \%)$ had been contacted regarding the CRERP,

- Two (22\%) had personnel with some training in evacuation procedures, 
- None had training sessions planned, and

- Seven ( $78 \%)$ had tone alert radios.

Table 6 lists the questions and numerical results of this survey.

\section{Orange County}

Two Urange County nonpublic schools, nursery schools, or day care centers within the EPZ were included in the sample. One of the two schools had been contacted regarding its role in the CRERP. The staff of one school had received some training in procedures for evacualing the school. One facility had a tone alert $r$ adio, and the respondent at this facility expected to be contacted by radio in an emergency. The other facility had not recelved a tone alert radio, and the respondent there expected to be contacted by relephone.

\section{$\underline{\text { Putnam County }}$}

In Putnam County, two nonpublic schools, nursery schools, or day care centers within the EPZ were included in the sample. Each of the schools had been contacted regarding its role in the CRERP. The staft of one school had received some training in procedures for evacuating the school. One of the schools hac a tone alert radio and the respondent expected to be contacied by radio in an emergency. The other school did not have a tone alert radio, and the respondent there expected to be contacted by telephone.

\section{Westchester County}

Five Westchester County nonpublic schools, nursery schools, or day care centers within the EPZ were included in the sample. Each of the five schools had been contacted regarding its role in the CRERP. The staff of one of the five schools had received some training in procedures for evacuating the school. All five schools had tone alert radios in the buildings, and $a 11$ respondents expected to be contacted by radio in an emergency.

\subsection{SCHOOL DISTRICTS WITHIN THE EPZ}

Eight of the school districts with schools within the EPZ were sampled. Of the eight districts surveyed;

- Seven ( $88 \%)$ had been contacted by the state or county,

- Two (25\%) had personnel with some training in evacuation procedures, 
Table 6 Results of the Survey of Nonpublic Schools, Nursery Schools, and Day Care Centers within the EPZ

1. How many students attend your school?

$\begin{array}{lccccc} & \text { Orange } & \text { Putnam } & \text { Westchester } & \text { All Counties } \\ \text { Range } & 17-129 & 40-100 & & 62-425 & 17-425 \\ \text { Mean } & 73 & 70 & & 217 & 152\end{array}$

3. Have you or someone in your school been contacted to discuss your role in the Indian Point Radiological Emergency Response Plan? Orange Putnam Westchester All Counties

$\begin{array}{lllll}\text { Yes } & 1^{\mathrm{a}} & 2^{\mathrm{b}} & 5^{\mathrm{c}} & 8^{\mathrm{d}} \\ \text { No } & 0 & 0 & 0 & 0 \\ \text { Don }{ }^{\mathrm{t} t} \text { know } & 1 & 0 & 0 & 1\end{array}$

3a. If yes, who contacted your school?

Orange Putnam Westchester All Counties

Utility

Don't know

$\begin{array}{llll}0 & 0 & 1 & 1 \\ 1 & 2 & 4 & 7\end{array}$

3b. If yes, when was your school contacted?

Orange Putnam Westchester All Counties

$\begin{array}{lllll}1982 & 0 & 0 & 3 & 3 \\ 198: & 0 & 0 & 2 & 2 \\ \text { Don't know } & 1 & 2 & 0 & 3\end{array}$

4. Have you or any of your staff received any training in procedures for evacuating your school?

Orange Putnam Westchester All Counties

$\begin{array}{lllll}\text { Yes } & 1^{\mathbf{a}} & 0^{\mathrm{e}} & { }_{1}^{\mathrm{f}} & 2^{\mathrm{g}} \\ \text { No } & 0 & 1 & 4 & 5 \\ \text { Don 't know } & 1 & 1 & 0 & 2\end{array}$

5. Are any training sessions planned?

Orange Putnam Westchester All Counties

$\begin{array}{lllll}\text { Yes } & 0 & 0 & 0 & 0 \\ \text { No } & 1 & 1 & 5 & 7 \\ \text { Don't. kn ow } & 1 & 1 & 0 & 2\end{array}$


Table 6 (Cont'd)

6. Who will contact you to tell you that your school is to be evacuated? Orange Putnam Westchester All Counties

Civil defense

Police

other school

Radio

Don't know

0
1
1
0
0

$\begin{array}{ll}0 & 1 \\ 0 & 1 \\ 0 & 1 \\ 5 & 5 \\ 0 & 1\end{array}$

7. How will you be contacted? ${ }^{\mathrm{h}}$

Orange Putnam Westchester All Counties

Telephone

Radio

$\begin{array}{ll}1 & 1 \\ 1 & 1\end{array}$

0

2

$5 \quad 7$

8. Do you have a tone alert radio in your school?

Orange Putnam Westchester All Counties

$\begin{array}{lllll}\text { Yes } & 1^{\mathrm{a}} & 1^{\mathrm{a}} & 5^{\mathrm{c}} & 7^{\mathrm{m}} \\ \text { No } & 1^{\mathrm{m}} & 1 & 0 & 2^{2}\end{array}$

9. Are you responsible for contacting any other schools or facilities in your area to inform them that they are to be evacuated?

Orange Putnam Westchester All Counties

$\begin{array}{lllll}\text { Yes } & 0 & 0 & 1 & 1 \\ \text { No } & 2 & 2 & 4 & 8\end{array}$

10. Have you been informed who will provide buses if evacuation becomes necessary ${ }^{\mathrm{h}}$

Orange Putnam Westchester All Counties

West Point Tours

Vanguard

100

Omnivan

Don't know

$0 \quad 0$

$0 \quad 0$

0

$3 \quad 4$

$0 \quad 0$

$\begin{array}{llll}1 & 2 & 2 & 5\end{array}$

11. Have you been informed where your students will be taken initially if your school is evacuated?

Orange Putnam Westchester All Counties

$\begin{array}{lllll}\text { Yes } & 2 & 2 & 4 & 8 \\ \text { No } & 0 & 0 & 1 & 1\end{array}$


${ }^{\mathrm{a}}$ Confidence interval $=0.50$, confidence level $=100 \%$.

${ }^{\mathrm{b}}$ Confidence interval $=1.00$, confidence leve $1=100 \%$.

${ }^{c}$ Confidence interval $=(0.64,1.00)$ confidence leve $1=91 \%$; confidence inter:al $=(0.14,1.00)$ confidence level $=100 \%$.

${ }^{\mathrm{d}}$ Confidence interval $=(1.66,0.98)$, cont idence level $=90 \%$; contidence interval $=(0.20,0.98)$, confidence level $=100 \%$.

${ }^{e}$ Confidence incerval $=0.00$, confidence level $=100 \%$.

${ }^{\mathrm{f}}$ Confidence interval $=(0.03,0.56)$, confidence level $=89 \%$; confidence interval $=(0.03,0.89)$, confidence level $=100 \%$.

$\mathrm{g}_{\text {conf idence interval }}=(0.05,0.46)$, confidence level $=90 \%$; confidence interval $=(0.05,0.83)$, confidence level $=100 \%$.

hMltiple responses were given by some facilities.

i cortidence interval $=(0.54,0.95)$, confidence level $=90 \%$; confidence interva $1=(0.17,0.95)$, confidence level $=100 \%$.

- Two (25\%) had such training scheduled, and

- Six (75\%) had an official who knew who would contact the district if schools needed to be evacuated.

Table 7 lists the questions and numerical results of the school districr survey.

vrange County

Both Orange County school districts within the EYZ were included in the sample. Une district had been contacted by the state or county. The staff of one of the school districts had received some training in procedures for evacuating its schools. Neither district had a tone alert radio in the district office.

Putnam County

In Putnam County, two school districts within the EPZ were surveyed. Both districts had been contacted by the state or county. The staffs of the two school districts had not received any training in procedures for evacuating their schools. One of the districts had a tone alert radio in the district office.

Westchester County

Four Westchester County school districts within the EPZ were included in the survey. Each of the school districts in the sample had been contacted by the state or county. The staff of one district had received some training in procedures for evacuating its schools. Two of the sampled districts had tone alert radios in the district offices. 
Table 7 Results of the Survey of School Districts within the EPZ

1. How many schools are in this district which are within the plume exposure emergency planning zone?

Orange Putnam Westchester All Counties

One school

Two schools

Three schools

Five schools

Ten schools

$\begin{array}{ll}1 & 1 \\ 0 & 1 \\ 1 & 0 \\ 0 & 0 \\ 0 & 0\end{array}$

$\begin{array}{ll}1 & 3 \\ 0 & 1 \\ 1 & 2 \\ 1 & 1 \\ 1 & 1\end{array}$

2. Have you or someone on your staff been contacted by the state or county to discuss your role in Indian Point Radiological Emergency Response Plan?

Orange Putnam Westchester All Counties

$\begin{array}{lllll}\text { Yes } & 1^{\mathrm{a}} & 2^{\mathrm{b}} & 4^{c} & 7^{\mathrm{d}} \\ \text { No } & 1 & 0 & 0 & 1^{\mathrm{c}}\end{array}$

2a. If yes, who contacted you concerning the plan?

Orange Putnam Westchester All Counties

County

Civil defense

Utility

Other

Don't know

$\begin{array}{llll}1 & 0 & 1 & 2 \\ 0 & 2 & 0 & 2 \\ 0 & 0 & 1 & 1 \\ 0 & 0 & 2 & 2 \\ 0 & 0 & 1 & 1\end{array}$

2b. If yes, when were you contacted concerning the plan?

Orange Putnam Westchester All Counties

1983

1982

$\begin{array}{llll}0 & 0 & 3 & 3 \\ 1 & 2 & 1 & 4\end{array}$

3. Have you or any of your staff received any training in procedures for evacuating the schools in your district?

Orange Putnam Westchester All Counties

$\begin{array}{lllll}\text { Yes } & 1^{\mathrm{a}} & 0^{\mathrm{e}} & 1^{\mathrm{f}} & 2^{\mathrm{g}} \\ \text { No } & 1^{\mathrm{f}} & 2 & 3^{2} & 6^{2}\end{array}$

4. Are any training sessions planned?

Orange Putnam Westchester All Counties

$\begin{array}{lllll}\text { Yes } & 1 & 0 & 1 & 2 \\ \text { No } & 0 & 1 & 3 & 4 \\ \text { Don' } t \text { know } & 1 & 1 & 0 & 2\end{array}$


Table 7 (Cont'd)

5. Who will contact you to tell you that some or all of the schools in your district are to be evacuated?

Orange Putnam Westchester All. Counties

Superintendent of Hendrick

0

2

Hud son School District

Civil defense

other

Don't know

0
1
1

1
0
0

1

2

2

b. How will you be contacted ?h

Orange Putnam Westchester All Counties

Telephone

Radio

Don't know
1

$0+1$

10
4

0

0
7

1

1

7. Is there a tone alert radio in the district offices?

Orange Putnam Westchester All Counties

$\begin{array}{lllll}\text { Yes } & j & 1 & 2 & 3 \\ \text { No } & 2 & 1 & 2 & 5\end{array}$

8. Are you responsible for contacting any other schools or facilities in your area to inform them that they are to be evacuated?

Orange Putnam Westchester All Counties

$\begin{array}{lllll}\text { Yes } & 1 & 0 & 3 & 4 \\ \text { No } & 1 & 2 & 0 & 3 \\ \text { Don' } t \text { know } & 0 & 0 & 1 & 1\end{array}$

\footnotetext{
${ }^{a}$ Confidence interval $=0.50$, confidence leve $1=100 \%$.

${ }^{b_{C}}$ onfidence interval $=(0.67,1.00)$, confidence level $=100 \%$.

${ }^{c}$ Confidence interval $=(0.62,1.00)$, confidence leve $1=92 \%$; confidence interval $=(0.5,1.00)$, confidence level $=100 \%$.

${ }^{\mathrm{d}}$ Confidence interval $=(0.69,0.92)$, confidence level $=88 \%$; confidence interval $=(0.54,0.92)$, confidence level $=100 \%$.

${ }^{e}$ Confidence interval $=(0.00,0.33)$, confidence level $=100 \%$.

${ }^{\mathrm{f}}$ Confidence interval $=(0.125,0.625)$, confidence level $=100 \%$.

$g_{\text {Confidence interval }}=(0.15,0.46)$, confidence level $=91 \%$; confidence interval $=(0.15,0.54)$, confidence level $=100 \%$.

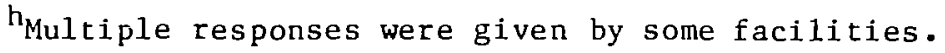




\subsection{HOSPITALS AND NURSING HOMES WITHIN THE EPZ}

Seven of the 23 hospitals and nursing homes within the EPZ were surveyed. Of the facilities surveyed;

- Six $(86 \%)$ had been contacted by the state or county,

- Three (43\%) had personnel with some training in evacuation procedures, and

- All ( $100 \%)$ had tone alert radios.

Respondents at three ( $43 \%)$ said that they did not know where residerts would be taken it if became necessary to evacuate the facilities. Table $\gamma$ lists the questions and numerical results of the hospital and nursing home survey.

\section{Orange County}

One hospital and no nursing homes in orange County are within the EPZ, so the survey is based on a $100 \%$ sample. The hospital had not been contacted by the state or county concerning the CRERP, had no personnel trained in evacuation procedures, and had no evacuation training sessions planned. The respondent did not know who would contact the hospital if an evacuation were necessary or where residents would be taken during an evacuation. The hospital did have a tone alert radio and sufficient vehicles to execute an evacuation.

\section{$\underline{\text { Putnam County }}$}

In Putnam County, one hospital and one nursing home are within the EPZ, and each was surveyed. Both facilities had been contacted by the state or county concerning the CRERP. Neither facility had personnel trained in evacuation procedures, but training sessions were planned for one. One respondent knew who would contact the facility if an evacuation were necessary, ard both facilities had tone alert radios. Neither respondent knew how many atdizional vehicles were needed for an evacuation. One respondent knew where its residents would be taken during an evacuation.

\section{Westchester County}

Four of the 20 hospitals and nursing homes in Westchester County wituin the EPZ were surveyed. All of these facilities had been contacted by the state or county concerning the CKERP, and the staff of three facilities had received some training in procedures for evacuating the residents of their facilities. Three facilities reported that additional training sessions were planned. One respondent knew who would contact the facility if an evacuation were necessary. Each facility had a tone alert radio. All of the respondents indicated that additional vehicles were needed for an evacuation and three knew where residents would be taken during an evacuation. 
Table 8 Results of the Survey of Hospitals and Nursing Homes to be Evacuated

1. How many patients and residents do you have, on average?

Orange Putnam Westclester All Counties

$\begin{array}{lcccc}\text { Range } & 80 & 15-36 & 56-190 & 15-190 \\ \text { Mean } & 80 & 26 & 96 & 74\end{array}$

2a. On average, how many are ambulatory?

Orange Putnam Westchester All Counties

Kange

$75 \quad 14-20$

$8-150$

$8-150$

Mean

75

17

65

53

2b. On average, how many require a wheelchair?

Orange Putnam Westchester All Counties

$\begin{array}{lcccc}\text { Range } & 5 & 1-8 & 0-78 & 0-78 \\ \text { Mean } & 5 & 5 & 27 & 18\end{array}$

2c. On average, how many require a stretcher?

Orange Putnam Westchester All Counties

$\begin{array}{lcccc}\text { Kange } & 0 & 0-8 & 0-14 & 0-14 \\ \text { Mean } & 0 & 4 & 4 & 3\end{array}$

3. Have you been contacted by the state or county to discuss your role in the Indian Point Radiological Emergency Response Plan?

Orange Putnam Westchester All Counties

$\begin{array}{lllll}\text { Yes } & 0^{\mathrm{a}} & 2^{\mathrm{b}} & 4^{\mathrm{c}} & 6^{\mathrm{d}} \\ \text { No } & 1 & 0 & 0 & 1\end{array}$

3a. If yes, who contacted you? ${ }^{\mathrm{e}}$

Orange Putnam Westchester All Counties

Health department

Civil defense

$\begin{array}{ll}--- & 0 \\ --- & 1 \\ --- & 0 \\ --- & 0 \\ --- & 1\end{array}$

1

County

l

0

2

1

Utility

1

Don't know 
Table 8 (Cont'd)

3b. If yes, when were you contacted?

Orange Putnam Westchester All Counties

1982

Several times

Don't know

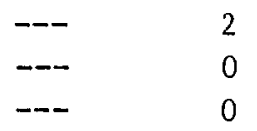

1

3

$2 \quad 2$

Don't know

4. Have you or your staff received any training in procedures for evacuating the residents in your facility?

Orange Putnam Westchester All Counties

$\begin{array}{lllll}\text { Yes } & 0^{\mathrm{a}} & 0^{\mathrm{b}} & 3^{\mathrm{f}} & 3^{\mathrm{g}} \\ \text { No } & 1 & 2 & 1 & 4\end{array}$

5. Are training sessions planned?

Orange Putnam Westchester All Counties

$\begin{array}{lllll}\text { Yes } & 0 & 1 & 3 & 4 \\ \text { No } & 1 & 1 & 1\end{array}$

6. Who will contact you to tell you that your facility is to be evacuated? Orange Putnam Westchester All Counties

Sheriff

other

Don't know

0
0
1

$1 \quad 1$

$0 \quad 0$

13

0

2

0

5

7. How will you be contacted? ${ }^{e}$

Orange Putnam Westchester All Counties

Telephone

Rad io

0

1

3

1

2

3

5

8. Is there a tone alert radio in your facility?

Orange Putnam Westchester All Counties

Yes

No

12

4

7

0

0

0

0 
Table 8 (Cont'd)

9. How many facility-owned vehicles do you have available for evacuation of your residents?

Orange Putnam Westchester All Counties

\begin{tabular}{|c|c|c|c|c|c|}
\hline \multirow{2}{*}{ Buses } & f Range & -- & 0 & 0 & 0 \\
\hline & TMean & --- & 0 & 0 & --- \\
\hline \multirow{2}{*}{ Vans } & f Range & -- & $0-1$ & $1-2$ & $0-2$ \\
\hline & Mean & -- & 1 & 1 & --- \\
\hline \multirow{2}{*}{ Ambulances } & Range & --- & $0-3$ & 0 & $0-3$ \\
\hline & Mean & --- & 2 & 0 & --- \\
\hline \multirow{2}{*}{ Other } & f Range & 5 & $0-1$ & $0-1$ & $0-5$ \\
\hline & Me an & 5 & 1 & 0 & 1 \\
\hline
\end{tabular}

10. If this number is inadequate, how many additional vehicles would be needed?

Orange Putnam Westchester All Counties

$\begin{array}{lllll}2 \text { buses } & 0 & 0 & 1 & 1 \\ 3 \text { buses } & 0 & 0 & 1 & 1 \\ \text { Don't know } & 0 & 2 & 2 & 4 \\ \text { None } & 1 & 0 & 0 & 1\end{array}$

11. What facility will act as the reception center for your residents?

Orange Putnam Westchester All Counties

White Plains

Beacon

$0 \quad 0$

$\begin{array}{lll}0 & 2 & 2\end{array}$

Cannon

Don't know

0

0

1

10

1

$\begin{array}{ll}1 & 1\end{array}$

${ }^{\mathrm{a}}$ Confidence interval $=0.00$, confidence 1 eve $1=100 \%$.

${ }^{b}$ Confidence interval $=1.00$, confidence level $=100 \%$.

${ }^{c}$ Confidence interval $=(0.60,1.00)$, confidence level $=90 \%$; confidence interval $=(0.20,1.00)$, confidence level $=100 \%$.

$\mathrm{d}_{\text {Confidence }}$ interval $=(0.57,0.96)$, confidence level $=92 \%$; confidence interval $=(0.26,0.96)$, confidence leve $1=100 \%$.

eMuliple responses were given by some facilities.

${ }^{\mathrm{F}}$ Confidence interval $=(0.35,0.95)$, confidence leve $1=90 \%$; confidence interval $=(0.15,0.95)$, confidence level $=100 \%$.

Gonfidence interval $=(0.13,0.70)$, confidence 1 evel $=91 \%$; confidence interval $=(0.13,0.83)$, confidence 1 evel $=100 \%$. 


\subsection{HOSPITALS CAPABLE OF TREATING RADIOLOGICALLY CONTAMINATED PATIENTS}

Each of the six hospitals listed in the CRERP as being capable of treating radiologically contaminated patients was surveyed. Of the hospitals listed in the CRERP,

- Five (83\%) had respondents who were aware that their hospitals may be used for the emergency treatment of patients if there is an emergency at the Indian Point Nuclear Power Station,

- Four (67\%) had staffs trained for radiological emergencies, and

- All (100\%) had standard operating procedures for treating contaminated patients.

Table 9 lists the questions and numerical results of this survey.

\section{Orange County}

Two hospitals are listed in the Orange County CRERP as being capable of treating radiologically contaminated patients, and both were included in the sample. Respondents at both hospitals were aware that their facilities may be used for the emergency treatment of radioactively contaminated patients if there is an emergency at Indian Point, and both had been contacted by the state or county. One respondent knew who would notify the hospital to prepare for contaminated patients. The staff of each hospital was trained for radiological emergencies, and each hospital had standard operating procedures for treating contaminated patients.

\section{Putnam County}

The one hospital in Putnam County that is listed in the CRERP was surveyed. Although the hospital had been contacted by the county, the survey respondent was not aware that the facility may be used for the emergency treatment of radioactively contaminated patients if there is an emergency at Indian Point. The respondent also did not know who would notify the hospital to prepare for such patients. The hospital staff has not been trained for radiological emergencies, but there were standard operating procedures for treating contaminated patients.

\section{Westchester Courity}

Westchester County has three hospitals listed in the CRERP to treat radioactively contaminated patients and each facility was surveyed. All of the respondents were aware that their hospitals may be used for the emergency treatment of patients if there is an emergency at Indian Point, and two had been contacted by the state or county. Each responded differently when asked 
Table 9 Results of the Survey of Hospitals Capable of Treating Radiologically Contaminated Patients ${ }^{a}$

1. Do you know that this hospital may be used for the emergency treatment of patients if there is an emergency at the Indian Point Nuclear Power Station?

Orange Putnam Westchester All Counties

Yes

$2 \quad 0$

5

No

$0 \quad 1$

3

1

2. Who would notify you that your hospital should prepare for potentially contaminated injured patients?

Orange Putnam Westchester All Counties

County

County sheriff

Police department

Don't know

$\begin{array}{ll}0 & 0 \\ 1 & 0 \\ 0 & 0 \\ 1 & 1\end{array}$

1

0

1

1
1

1

1

3

3. How would you be notified ?

Orange Putnam Westchester All Counties

Telephone

Radio

Other

Don't know

0
1
0
1

0
0
0
1

2

2

2

1

2

4. Have you been contacted by the state or county to discuss your role in responding to an emergency at the Indian Point Nuclear Power Station? Orange Putnam Westchester All Counties

Yes

No

Don' $t$ know

$\begin{array}{ll}2 & 1 \\ 0 & 0 \\ 0 & 0\end{array}$

0

4a. If yes, who contacted you?

Orange Putnam Westchester All Counties

\section{County}

Office of Natural Disaster:

Other

Don'c know

$\begin{array}{ll}1 & 0 \\ 1 & 0 \\ 0 & 0 \\ 0 & 1\end{array}$

$\begin{array}{ll}2 & 5 \\ 0 & 0 \\ 1 & 1\end{array}$

5

0

1 
Table 9 (Cont'd)

4b. If yes, when were you contacted?

Orange Putnam Westchester All Counties

Dec. 1982

Over a year ago

Don't know

$\begin{array}{llll}0 & 0 & 1 & 1 \\ 1 & 1 & 0 & 2 \\ 1 & 0 & 1 & 2\end{array}$

5. Is the staff of this facility trained for radiological emergencies that may take place at a nuclear power station?

Orange Putnam Westchester Ali Counties

$\begin{array}{lllll}\text { Yes } & 2 & 0 & 2 & 4 \\ \text { No } & 0 & 1 & 1 & 2\end{array}$

5a. Are the following personnel on the staff at the facility?

Orange Putnam Westchester All Counties

Health Physicist

Health Physias Technician

$\mathrm{X}-\mathrm{ray}$ Technician with

$\begin{array}{llll}2 & 0 & 3 & 5\end{array}$

$\begin{array}{llll}0 & 0 & 2 & 2\end{array}$

health physics training

0

$3 \quad 3$

6. Are dosimeters provided for personnel who will be caring for contaminated injured persons?

Orange Putnam Westchester All Counties

$\begin{array}{lllll}\text { Yes } & 1 & 1 & 3 & 5 \\ \text { No } & 0 & 0 & 0 & 0 \\ \text { Don' } t \text { know } & 1 & 0 & 0 & 1\end{array}$

6a. If yes, what type of dosimeters are used?

Orange Putnam Westchester Al 1 Counties

Pocket self reading

Eilm badge

0

$1 \quad 1$

$\begin{array}{ll}0 & 2\end{array}$

2

Thermoluminescent

$0 \quad 0$

35 
Table 9 (Cont'd)

7. Are there survey instruments available?

Orange Putnam Westchester All Counties

$\begin{array}{lllll}\text { Yes } & 2 & 0 & 2 & 4 \\ \text { No } & 0 & 1 & 0 & 1 \\ \text { Don't know } & 0 & 0 & 1 & 1\end{array}$

7a. If yes, what type of survey instruments are available?

Orange Putnam Westchester All Counties

Geiger counters

$2 \quad 0 \quad 2$

4

8. Can an area be set aside for the treatment of radioactively contaminated patients that is separate from normal hospital operations?

Orange Putnam Westchester All Counties

$\begin{array}{lllll}\text { Yes } & 2 & 0 & 3 & 5 \\ \text { No } & 0 & 0 & 0 & 0 \\ \text { Don 't know } & 0 & 1 & 0 & 1\end{array}$

9. Are there sinks, showers, and change areas?

Orange Putnam Westchester All Counties

$\begin{array}{lllll}\text { Yes } & 2 & 0 & 2 & 4 \\ \text { No } & 0 & 0 & 1 & 1 \\ \text { No answer } & 0 & 1 & 0 & 1\end{array}$

10a. Are there facilities for solid waste containment and/or disposal?

Orange Putnam Westchester All Counties

$\begin{array}{lllll}\text { Yes } & 2 & 0 & 3 & 5 \\ \text { No } & 0 & 1 & 0 & 1\end{array}$

10b. Are there facilities for liquid waste containment and/or disposal?

Orange Putnam Westchester A11 Counties

Yes

No

$2 \quad 0$

3

No

0

1


Table 9 (Cont'd)

10c. Can facilities for waste containment and/or disposal be disposed?

Orange Putnam Westchester All Counties

$\begin{array}{lllll}\text { Yes } & 1 & 0 & 2 & 3 \\ \text { No } & 0 & 1 & 0 & 1 \\ \text { Don't know } & 1 & 0 & 1 & 2\end{array}$

11. Are communications available to communicate with fixed and mobile facilities?

$\begin{array}{cccc}\text { Orange } & \text { Putnam } & \text { Westchester } & \text { Al. Counties } \\ 2 & 1 & 2 & 5 \\ 0 & 0 & 1 & 1\end{array}$

11a. If yes, what commuications systems are used?

Orange Putnam Westchester All Counties

$\begin{array}{lllll}\text { Radio } & 2 & 1 & 2 & 5\end{array}$

12. Are there standard operating procedures for hospital personnel treating patients who have radioactively contaminated wounds, gross contamination, or gross gamma whole body exposures?

Orange Putnam Westchester All Counties

$\begin{array}{lllll}\text { Yes } & 2 & 1 & 3 & 6 \\ \text { No } & 0 & 0 & 0 & 0\end{array}$

${ }^{a}$ Sirce all of the hospitals listed in the plans as being capable of treating radiologically contaminated patients were surveyed, no statistical analysis needed to be performed on the results.

bultiple responses were given by some facilities. 
who would notify the hospital to prepare for contaminated patients. Two hospitals had staff trained for radiological emergencies. All of the hospiLals had standard operating procedures for treating contaminated patients.

\subsection{AMBULANCES}

of the 89 ambulance companies and volunteer ambulance corps listed in the CRERP, 14 were included in the sample. Of those 14, three no longer exist; one was not operating at the time of the survey; and one is still operating, but repeated attempts to reach an official from this company were unsuccessful. From the completed nine surveys,

- Five (56\%) of the companies were aware that they were designated to respond to radiological emergencies,

- Six (67\%) had been contacted by the state or county,

- None had ambulances equipped with monitoring devices or potassium iodide (KI),

- Seven (78\%) had ambulance crews that had been trained for radiological emergencies,

- Three (33\%) had crews that had been trained in the care and treatment of radiologically injured or contaminated patients, and

- Two (22\%) had standard operating procedures for ambulance crews treating radiologically injured patients.

Table 10 lists the questions and numerical results of the ambulance company survey.

\section{Orange County}

Five ambulance companies were included in the sample for orange County. Of these five, one had been disbanded and a second was also assumed to be disbanded because surveyors were unable to contact anyone who was aware of its existence. From the remaining three companies, one respondent was aware that the CRERP had designited the company to respond to radiological emergencies at Indian Point. One company had been contacted by the county. The ambulance crews of two of the three companies were trained for radiological emergencies. No ambulances were equipped with monitoring devices or KI. 
Table 10 Results of the Survey of Ambulance Companies

1. Are you aware that your company is designated to respond to radiological emergencies in the Indian Point Radiological Emergency Response Plan?

Orange Putnam Westchester All Counties

$\begin{array}{lllll}\text { Yes } & 1^{a} & 3^{b} & 1^{c} & 5^{d} \\ \text { No } & 2 & 1 & 1 & 8^{e, f}\end{array}$

2. Who would notify you that your company is to provide services?

Orange Putnam Westchester All Counties

Sheriff/police

Civil defense

County

Don't know

$\begin{array}{ll}2 & 2 \\ 2 & 1 \\ 0 & 1 \\ 0 & 0\end{array}$

125

$0-3$

$0-1$

3. How would you be notified that your company is to provide services? Orange Putnam Westchester All Counties

Radio

Te lephone

Police

$\begin{array}{ll}3 & 3 \\ 2 & 1 \\ 0 & 0\end{array}$

$3-1$

1

7

0

1

3

4. Have you been contacted by the state or county to discuss your role in responding to an emergency at the Indian Point Nuclear Power Station? Orange Putnam Westchester All Counties
Yes
$1^{\mathrm{a}} \quad 3^{\mathrm{b}}$
$2^{\text {h }}$
No
2
1
0
$6^{i}$
$7^{e, t}$

4a. If yes, who contacted the company?

Orange Putnam Westchester All Counties

County

Civil defense

Don't know

$\begin{array}{ll}0 & 1 \\ 1 & 2 \\ 0 & 0\end{array}$

1
0
1

2

3

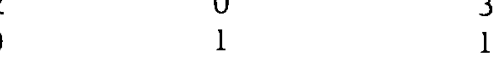

4b. If yes, when was the company contacted?

Orange Putnam Westchester All Counties

1983

1982

Don't know

$\begin{array}{ll}0 & 0 \\ 1 & 0 \\ 0 & 3\end{array}$

2

2

$0 \quad 0 \quad 1$ 
Table 10 (Cont'd)

5. Are ambulance crews of this facility trained for radiological emergencies that may take place at a nuclear power plant?

Orange Putnam Westchester All Counties

$\begin{array}{lllll}\text { Yes } & 2^{j} & 4^{\mathrm{k}} & 1^{\mathrm{c}} & 7^{\mathrm{l}} \\ \text { No } & 1 & 0 & 1 & 6^{\mathrm{e}}, \mathrm{f}\end{array}$

6. What type of equipment is there to communicate with fixed and mobile facilities?

Orange Putnam Westchester All Counties

Rad io

Walkie-talkie

Radio pager

$\begin{array}{lll}3 & 4 & 2 \\ 1 & 0 & 0 \\ 1 & 0 & 0\end{array}$

9

$0 \quad 1$

1

7. Are ambulances equipped with monitoring devices?

Orange Putnam Westchester All Counties

Yes

No

Don' $t$ know

0

3

0

8. Are ambulance

crews trained in the use of monitoring equipment and d os ime ters?

Orange Putnam Westchester All Counties

Yes

No

Don't know
$1 \quad 0$

$2 \quad 2$

10
0 $12^{\mathrm{e}, \mathrm{f}}$ 1

9. Does the ambulance have the following equipment? (number of companies answering yes)

Orange Putnam Westchester All Counties

Gloves

Blankets

Waste containers

Batteries

Labels

$\begin{array}{ll}2 & 3 \\ 2 & 4 \\ 2 & 2 \\ 1 & 2 \\ 2 & 2\end{array}$

2
2
1
0
2

7

8

5

3 
Table 10 (Cont'd)

10. Are ambulance crews trained in the care and treatment of radiologically injured or contaminated patients?

Orange Putnam Westchester All Counties

$\begin{array}{llllr}\text { Yes } & 1 & 2 & 0 & 3 \\ \text { No } & 2 & 2 & 2 & 10^{\mathrm{e}, \mathrm{F}}\end{array}$

11. Are there standard operating procedures for ambulance crews treating patients that have radioactive wounds, gross contamination, or gross gamma whole body exposures?

Orange Putnam Westchester All Counties

$\begin{array}{llllc}\text { Yes } & 1 & 1 & 0 & 2 \\ \text { No } & 2 & 3 & 2 & 11 \text { e, f }\end{array}$

12. Are ambulance crews trained in the use of potassium iodide and is it available for use?

Orange Putnam Westchester All Counties

$\begin{array}{llllc}\text { Yes } & 0 & 0 & 0 & 0 \\ \text { No } & 3 & 4 & 2 & 13^{\mathrm{e}, \mathrm{f}}\end{array}$

13. Where do ambulance drivers transport patients?

Orange Putnam Westchester All Counties

Westchester County

Medical Center $\quad 0 \quad 002$

Putnam Commity Hospital $\quad 0 \quad 11$

Butterfield Hospital $\quad 0 \quad 1 \quad 1$

St. Anthony's Hospital $\quad 1 \quad 0001$

Arden Hill Hospital $\quad 1 \quad 00001$

Nearest hospital $\quad 2 \quad 10002$

Don't know

$0 \quad 2$

02

\footnotetext{
${ }^{\mathrm{a}}$ Confidence interval $=(0.0 \%, 0.78)$, confidence level $=89 \%$; confidence interval $=(0.04,0.93)$, confidence level $=100 \%$.

${ }^{b}$ Confidence interval $=(0.36,0.91)$, confidence level $=91 \%$; confidence interval $=(0.27,0.91)$, confidence level $=100 \%$.

${ }^{c}$ Confidence interval $=(0.02,0.80)$, confidence level $=91 \%$; confidence interval $=(0.02,0.96)$, confidence level $=100 \%$.

${ }^{\mathrm{d}}$ Confidence interval $=(0.18,0.63)$, confidence level $=90 \%$; confidence interval $=(0.06,0.91)$, confidence level $=100 \%$.
} 
eIncludes one company that no longer exists and one company that commenced operations in Feb. 1983.

${ }^{\mathrm{f}}$ Includes one company that has been disbanded and one company that apparently no longer exists.

gultiple responses were given by some companies.

$\mathrm{h}_{\text {Confidence }}$ interval $=(0.31,1.00)$, confidence l€vel $=91 \%$; confidence interval $=(0.04,1.00)$, confidence level $=100 \%$.

${ }^{i}$ Confidence interval $=(0.24,0.70)$, confidence level $=90 \%$; confidence interval $=(0.07,0.92)$, confidence level $=100 \%$.

$j_{\text {Confidence }}$ interval $=(0.22,0.96)$, confidence level $=89 \%$; confidence interval $=(0.07,0.96)$, confidence level $=100 \%$.

${ }^{k}$ Confidence interval $=(0.64,1.00)$, confidence level $=91 \%$; confidence interva $1=(0.36,1.00)$, confidence level $=100 \%$.

${ }^{1}$ Confidence interval $=(0.30,0.76)$, confidence level $=90 \%$; confidence interval $=(0.08,0.93)$, confidence level $=100 \%$

\section{Putnam County}

In Putnam County, four ambulance companies were surveyed. All were associated with local fire departments. Three of the respondents questioned were aware that their companies were designated in the CRERP to respond to radiological emergencies at Indian Point, and three had been contacted by the state or county. All of the ambulance crews had received training for radiological emergencies. No ambulances were equipped with monitoring devices or KI.

\section{Westchester County}

Five ambulance companies in westchester County were chosen to be sampled. One of these no longer exists, a second was not operating at the time of the survey, and surveyors were unable to reach an official from a third company, despite repeated attempts to do so. One of the other two company respondents was aware that the CRERP designated the company to respond to radiological emergencies at Indian Point, and both of these companies had been contacted by the state or county. One company had crews that had been trained for radiological emergencies. No ambulances were equipped with monitoring devices or KI.

\subsection{PERSONNEL MONITORING CENTERS}

Based upon an examination of the orange, Westchester, and revised Putnam CRERPs, it was determined that personnel monitoring centers will be established as needea and where needed during a radiological emergency. Attachment 11 in Sec. 3 (Health) of the Orange CRERP reads in part: 
During a radiological emergency, the County Commissioner of Health is responsible for the radiological exposure control of emergency response personnel. Activities associated with this responsibility include, but are not limited to, the following: - . 7. Establishing facilities for the decontamination of exposed emergency personnel.

The revised Putnam CRERP states:

Personnel monitoring centers will be established at the time of an emergency outside but near the 10-mile EPZ. Locacions will be communicated at the time to emergency team leaders anc supervisors. (Attachment 12, County Radiological officer)

Accordingly, since no sites in Orange County or Putnam County have been designated as personnel monitoring centers, it was impossible to survey such centers.

At the time of the verification analysis, the Westchester CRERP $d i d$ not indicate where personnel monitoring centers will be located. Subsequent revisions to the plan state:

2.1 Appropriate personnel monitoring centers will be established and operational unless the determination is made by the County Chief Executive that none are needed because of the absence of a release of radioactive material sufficient to cause a contamination problem.

2.2 Personnel monitoring centers [PMCs] will be activated at the time of an emergency outside the 10-mile EPZ. Activation and locations will be communicated to emergency team leaders and supervisors and Commissioner/Sheriff in the event traffic control is required at PMC locations. The PMC for County Emergency Workers is currently the Westchester County Fire Training Center, Dana Road, Valhalla, N.Y. (Section 3, Attachment 13)

Since the facility at the Westchester County Fire Training Center was not originally included in the CRERP, the verification analysis could not include the facility. 
APPENDIX A

QUEST LONNAIRES USED IN THE SURVEY 
BUS COMPANIES

B.C. Interview I.D. 非

Interviewer

Verified by:

Date Completed

Telephone

Letter (received)

Field Visit

FEMA/REP VERIFICATION FORM

Indian Point Nuclear Generating Station

I. ORGANIZATION VERIFICATION DATA

Information taken from Plan

1. Company Information

Company Name

General Manager

Telephone Number

Business Address

2. Garage Information

Garage Address

Telephone Number

Person in Charge

Title
Verification Data

(if same as plan, ind icate "Same") 
II. QUESTIONNAIRE

PLAN

1. Information source being verified (check one )

New York Scate Plan County Plan

(Name of County)

2. How many buses and vans do you have in your garage?

Buses

Vans

3. On an average day, how many buses and vans do you have in working condicion?

Buses

Vans

4. What is the average capacicy of the buses and vans that you have in working condition on an average day?

Buses

Vans

5. How many of your vehicles are equipred to transport handicapped, nonambulatory ind ividuals?

6. How many licensed bus and van drivers do you employ?
B.C Interview I.D. \# Interviewe $r^{\prime} s$ Initials

VER IF ICATION

(enter response; put D.K. if respondent does not know) 
C. Interview L.D. \#

Interviewer's Initials

II. QUESTIONNAIRE (Cont 'd)

PLAN

VERIFICATION

7. How many vehicles do you use on an ordinary daily basis when schools are in session?

For schools (public and private)

For general population

For special facilities

8. How many vehicles do you use on an ordinary daily basis when schools are not in session? (weekends, vacations, summers, etc.)

Not in use

For general population For special facilities other (specify)

9. Approximately how many of your vehicles are equipped with mobile cornmunications equipment?

10. Have you or someone in your organization been contacted by State or County representatives to discuss your role in the Indian Point Radiological Emergency Response Plan?
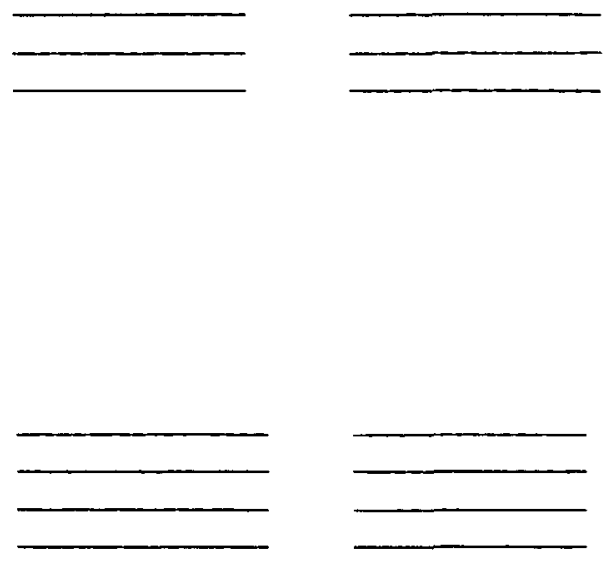
Yes No

Who When

11. Does your organization have a formal agreement to supply vehicles in the event of a radiological emergency at the Indian Point Nuclear Generating Station?

Yes

No
Yes

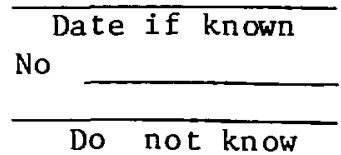


B.C. Interview I.D. \# Interviewer's Initials

II. QUESTIONNAIRE (Cont 'd)

PLAN

VERIFICATION

i2. Who would contact you

and tell you to deploy

your vehicles in the

event an evacuation

became necessary?

13. How would you be contacted?

(e.g. phone, radio, etc.)

14. How would you notify your vehicle drivers to report

to the garage in the event they were needed for an evacuation?

15. Is your garage located within the $10 \mathrm{mile}$

Emergency Planning Zone?

No Yes (if yes, ask: How will you comminicate with your drivers if there is a total evacrition and your dispatcher must leave the garage?)

16. How many vehicles will you use if evacuation becomes necessary?
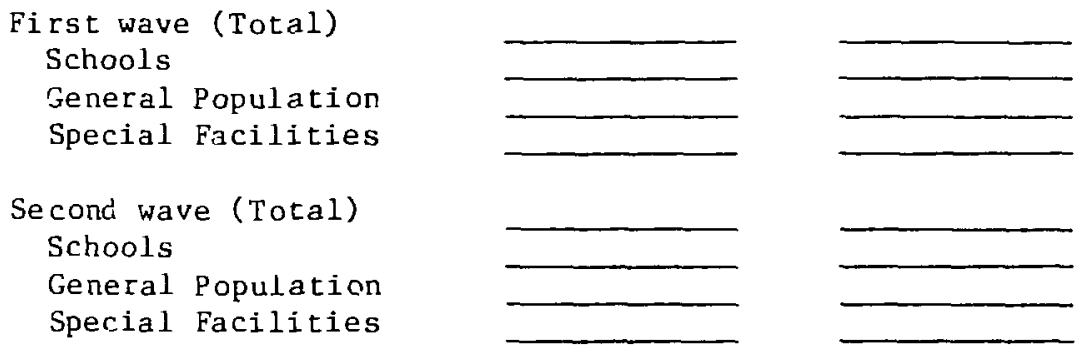
B.C. Interview I.D. 非 Interviewer's Initials

II. QUSTIONNAIRE (Cont'd)

PLAN

VERIFICATION

17. Do you have maps or 1ists of evacuee pickup locations available for distribution to your vehicle drivers?

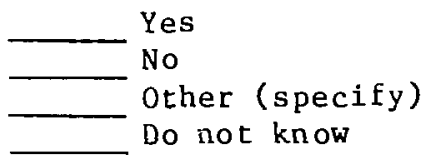

18. How many of your vehicle drivers have received formal training on radiological emergency response preparedness (including dosimetry, evacuation routes, etc.)

19. Are your vehicle drivers scheduled to receive radiological emergency response training in the future?

Yes Date (if known)
No not know
Do not

20. How many dosimeters do you have available for distribution to your drivers?

$$
\begin{aligned}
& \text { Low range self reading } \\
& \text { High range self reading } \\
& \text { Film badges } \\
& \text { Total Dosimeters } \\
& \text { No. of bus drivers }
\end{aligned}
$$

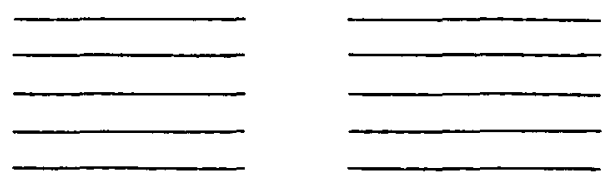

21. Where are your dosimeters stored? 


\section{RECEPTION CENTERS}

R.C. Interview I.D. \#

Interviewer

Verified by:

Date Completed

Telephone

Letter

Field Visit

FEMA/REP VERIEICATIUN FORM

Indian Point Nuclear Generating Station

I. ORGANIZATION VERIFICATION DATA

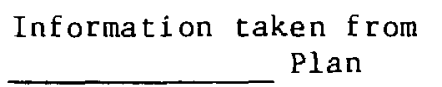

Verification Data

(if same pian,

ind icate "same")

1. Building Name

2. Address

3. Telephone Number

4. Eerson in Charge of Building

5. Person in charge of Congregate Care Center

Telephone Number

6. Is this a school?

Yes

No 


\section{QUESTIONNAIRE}

Questions to be asked of person in charge of normal building operations:

1. Are you aware that your

building is designated as a

Reception Center

in the Indian Point

Radiological Emergency

Response Plan?

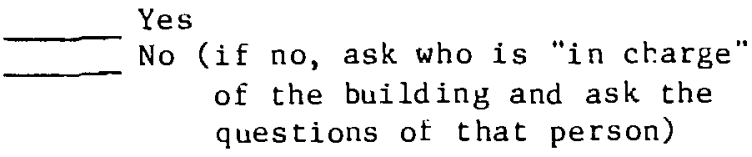

2. Who would notify you that

your building is to be activated

as a Reception Center?

Name

Don't know

3. How would you be notified that your

building is to be activated as

a Reception Center?

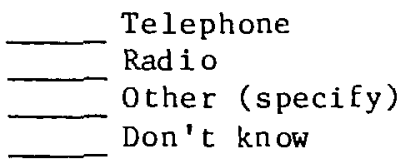

4. Is your building utilized 12

months a year?

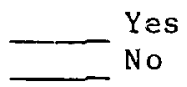

5. Who is authorized to open the building after working hours

(and weekends, vacations, summers

if applicable) in case it is

needed as a Reception

Center during a radiological

eme rgency?

Don't know

6. Is there a back-up person name

available in case the regular

person isn't available?

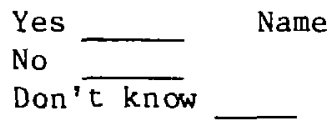


II. QUESTIONNAIRE (Cont'd)

7. What is the normal daily occupancy of your building?

persons

8. What is the capacity of your parking lot?

automobiles buses/vans

9. Are there showers in your building?

$$
\begin{aligned}
& \text { Yes }-\quad \text { How many male? } \\
& \text { No } \longrightarrow \text { How many female? }
\end{aligned}
$$

10. Approximately how many

toilets are there $i n$ your building?

Male Female

11. In the event of a radiological emergency at the Indian Point Nuclear Generating Station, who is in charge of operations at the Reception Center to be located in your building?

Name

$$
\text { Title }
$$
Address

Telephone Numbers Business Home

(Ask only for a reception center located in a school)

12. Do you have any plans for your own scudents if you are notified that your school will be used as a reception center?

$$
\text { Yes — If yes, briefly describe them. }
$$


III. QUESTIONNAIRE

Questions to be asked of person in charge of reception center at

(if respondent does not know, indicate with D.K.)

1. Who would notify you that your Reception center is to be activated.

2. How would you receive this notification?

Telephone

Radio Other

3. How many staff are assigned to the facility?

4. Are there enough personnel to staff more than one shift?

Yes

No

5. Are ail personnel assigned to work in the facility trained in hand ling mass evacuees?

Yes

No

6. Do you have forms for registering people who come to the facility?

Yes No

7. Is there a capability for decontamination and radiation monitoring?

Yes No

(Ask questions $8,9,10$ and 11 only if yes to 7 )

8. Are you able to:

Monitor people?

Decontaminate people?

Monitor vehicles?

Yes

Yes

Yes

Yes

No

No

No

Decontaminate vehicles?

No

9. Do you have procedures to hand le waste generated during contamination of people and vehicles?

Solid waste?

Liquid waste?
Yes

Yes

No

No 
III. QUESTIONNAIRE (Cont'd)

10. Do you have a supply of clothing for use in place of contaminated clothing?

$$
\text { Yes_ No }
$$

11. Where can additional supplies be obtained?

12. How would the Reception center maintain communications with the county Emergency Operations Center?

Te lephone

Radio

Other (Specify)

13. How would the Reception center maintain communications with Congregate Care Center?

Te lephone

Radio

Same location

other (Specify)

14. From whom would you receive notifications on the status of the emergency?

County EOC

EBS reports

Other (Specify) 
CONGREGATE CARE RELOCATION CENTERS

C.C.R.C. Interview I.D. \# Interviewer

Verified by:

Telephone

Let ter

Field Visit

FEMA/REP VERIFICATION FORM

Indian Point Nuclear Generating Station

I. ORGANIZATION VERIFICATION DATA

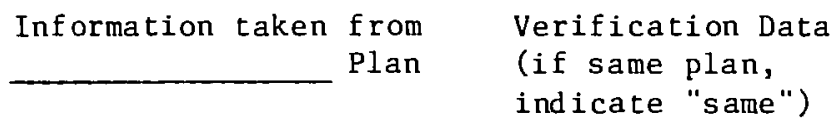

l. Building Name

2. Add ress

3. Telephone Number

4. Person in Charge of Building

5. Person in Charge of Congregate Care Center

Telephone Number

6. Is this a school?

Yes

No 
II. QUESTIONNAIRE

Questions to be asked of person in charge of normal building operations:

(if respondent does not know, indicate with D.K.)

1. Are you aware that your

building is designated as

a Congregate Care Center

in the Indian Point

Radiological Emergency

Response Plan?

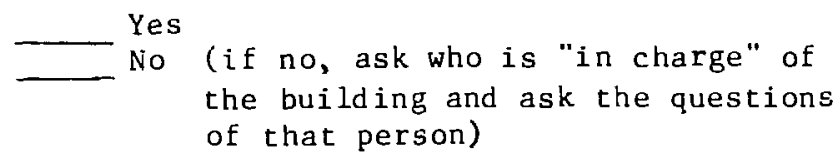

2. Who would notify you that your

building is to be activated as

a Congregate Care Center?

Name

Don't know

3. How would you be notified that your

building is to be activated as a

Congregate Care Center?

Telephone

Radio

other (specify)

4. Is your building utilized 12 months

a year?

Yes

No

5. Who is authorized to open the building after working hours (and weekends, vacations, summers, if applicable) in case it is needed as a Congregate Care Center during a radiological emergency?

6. Is there a back-up person available

in case the regular person isn't available?

$\simeq_{\text {No }}^{\text {Yes }} \quad$ Name


I I. QUESTIONNAIRE (Cont 'd )

7. What is the normal daily occupancy of your building?

persons

8. What is the capacity of your parking lot?

Automobiles buses/vans

Q. Are there showers in your build ing?

Yes - How many male?
No $\quad$ How many female?

10. Approximately how many toilets are there in your building?

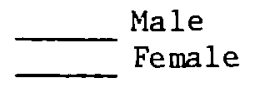

11. In the event of a radiological emergency at the Indian Point Nuclear Generating Station, who is in charge of operations at the Congregate Care Center to be located in your building?

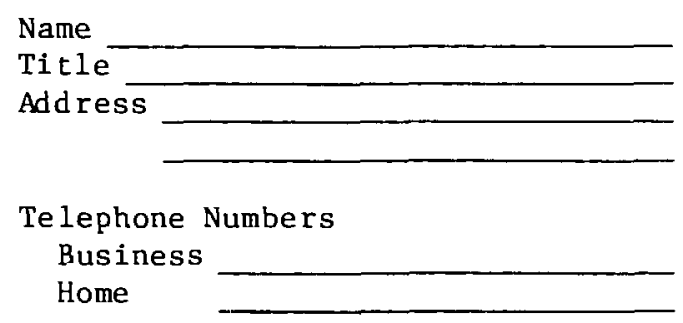

12. Do you have any plans for your students if you are notified that your school will be used as a reception center:

No
Yes If yes, please briefly describe them. 


\section{I. QUESTIONNAIRE}

Questions to be asked of person in charge of Congregate Care Center at

(if respondent does not know, indicate with D.K.)

1. Who would notify you that your Congregate Care center is to be activated?

2. How would you receive this notification?

Te lephone Rad io

EBS Message

Other

3. What is the capacity of the facility?

4. How many personnel are assigned to the facility?

5. Are there enough personnel to staff more than one shift?

Yes No

b. Are all personnel assigned to work in the facility trained in hand ling mass evacuees?

Yes _ No

If no, how many individuals have been trained?

7. Do you have procedures for handling people arriving without papers indicating that they have been processed at a reception center?

Yes

8. If yes, what are your proceciures:

9. (If yes to 7) Can your facility be configured to maintain a separation between people who have been processed through a reception center and those who have not?

Yes_ No Don't know

10. Are sleeping accommodations (beds, cots, blankets) provided?

Yes _ No If yes, how many

11. How would the Congregate Care Center maintain communications with the County Emergency Operation Center?

Telephone

Rad io

Other (specify) 
III. QUESTIONNAIRE (Cont' $d$ )

12. How would the center maintain communications with the Reception Center? Telephone Rad io Same location Other (specify)

13. From whom would you receive emergency notification on the status of the emergency?

County EOC

EBS Reports

Other (Specify) 


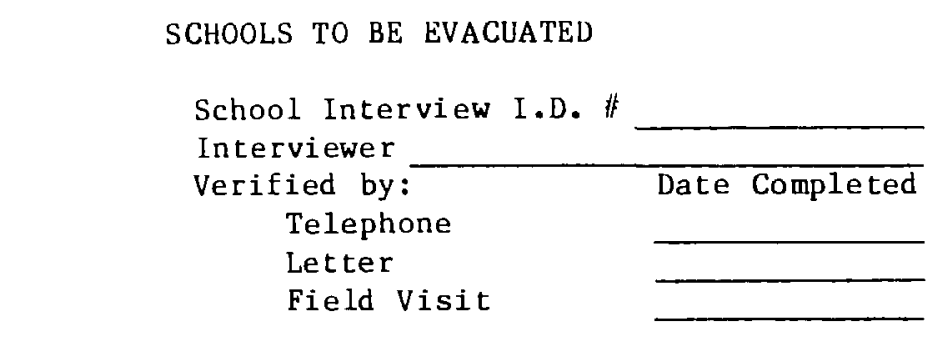

FEMA/REP VERIFICATION FORM

Indian Point Nuclear Generating Station

I. ORGANIZATION VERIFICATION DATA

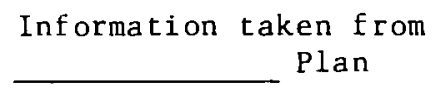

Plan

1. School Name

2. Address

3. Person in Charge of School

4. Telephone Number

5. Is school still in operation?
Verification Data

(if same plan, ind icate "same")
Yes

No 
II. QUESTIONNAIRE'

1. How many students attend your school?

2. What hours is your school in session?

3. Have you or someone in your school been contacted to discuss your role in the Indian Point Radiological Emergency Response Plan?

Yes_ No Don't know

If yes,

Who (name)

Title/Organization

When

4. Have you or any of your staff received any training in procedures for evacuating your school?
Yes
No
Don't know

If yes, what?

5. Are any training sessions planned?

Yes_ No_ Don't know

If yes, details (what, when)

6. Who will contact you to tell you that your school is to be evacuated? Name Title

7. How will you be contacted?

Telephone

Tone alert radio

Other (specify)

8. Do you have a tone alert radio in your school?
Yes
No
Don't know

9. Are you responsible for contacting any other schools or facilities in your area to inform them that they are to be evacuater?

$$
\text { Yes_ No_ Don't know }
$$

If so, which one(s)? 
II. QUESTIONNAIRE (Cont'd)

10. Have you been informed who will provide buses if evacuation becomes necessary?

$$
\text { Yes_ No_ Don't know }
$$

If yes, who?

11. Have you been informed where your students will be taken initially if your school is evacuated?

$$
\text { Yes_ No_ Don't know }
$$

If yes, where? 
SCHOOL DISTRICTS WITHIN

THE PLUME EXPOSURE EPZ

School District Interview I.D. \# Interviewer

Verified by:

Telephone

Letter

Field Visit

FEMA/REP VERIFICATION FORM

Indian Point Nuclear Power Station

\section{ORGANIZATION VERIFICATION DATA}

1. School District Name

2. Address

3. Superintendent of Schools

4. Telephone Number 


\section{QUESTICNNAIRE (Cont'd)}

1. How many schools are in this district which are within the plume exposure emergency planning zone?

2. Have you or someone on your staff been contacted by the state or county to discuss your role in the Indian Point Radiological Emergency Response Plan?

$$
\text { Yes_ No Don't know }
$$

If yes,

Who (name) When

Title/Organization

3. Have you or any of your staff received any training in procedures for evacuating the schools in your district?

$$
\text { Yes__ No__ Don't know }
$$

If yes, please briefly describe.

4. Are any training sessions planned?

$$
\text { Yes_ No Don't know }
$$

If yes, please give details (when, what)?

5. Who will contact you to tell you that some or all of the schools in your district are to be evacuated?

Name

Title

6. How will you be contacted?

Telephone

- Tone alert radio

Other (specify)

7. Is there a tone alert radio in the district offices?

$$
\text { Yes___ No___ Don't know }
$$


8. Are you responsible for contacting any other schools or facilities in your area to inform them that they are to be evacuated?

Yes__ No___ Don't know____

If so, which ones(s)? 
SPECIAL FACILITIES TO BE EVACUATED

S. F. Interview I.D. \# Interviewer

Verified by:

Date Completed

Telephone

Letter

Field Visit

FEMA/REP VERIFICATION FORM

Indian Point Nuclear Power Station

I. ORGANIZATION VERIFICATION DATA

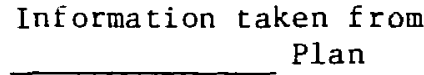
Plan

Nursing Home Hospital

1. Facility Type other (specify)

Verification Data (if same plan, ind icate "same")

2. Facility Name

3. Address

4. Person in charge of facility

5. Title/Position

6. Telephone Number 


\section{QUESTIONNAIRE}

1. How many patients and residents do you have, on average?

2. On average, how many:

$$
\begin{aligned}
& \text { are ambulatory? } \\
& \text { require a wheelchair? } \\
& \text { require a stretcher? }
\end{aligned}
$$

3. Have you been contacted by the state or county to discuss your role in the Indian Point Radiological Emergency Response Plan?

$$
\text { Yes___ No___ Don't know }
$$

If yes,

Who , When

Title/Organization

4. Have you or your staff received any training in procedures for evacuating the residents in your facility?

$$
\text { Yes_ No___ Don't know }
$$

If yes, describe briefly:

$\therefore$ Are training sessions planned:

$$
\text { Yes_ No___ Don't know }
$$

If yes, please describe briefly:

6. Who will contact you to tell you that your facility is to be evacuated?

Name Title

7. How will you be contacted?

Telephone

Tone alert radio

Other (specify)

8. Is there a tone alert radio in your facility?

$$
\text { Yes_ No___ Don't know }
$$


II. QUEST IONNAIRE (Cont 'd)

9. How many facility-owned vehicles do you have available for evacuation of your residents?

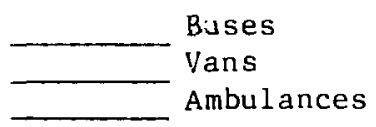

10. If this number is inadequate, how many additional vehicles would be need ed?

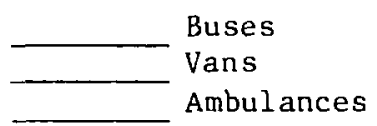

Who will pruvide them?

11. What facility will act as the reception center for your residents? Name Location 
HOSPITALS

H. Interview I.D. \#

Interviewe $\mathbf{r}$

Verified by:

Date Completed

Telephone

Letter

Field Visit

FEMA/REP VERIFICATION FORM

Indian Point Nuclear Generating Station

I. ORGANIZATION VERIFICATION DATA

$\begin{array}{cl}\text { Information taken from } & \text { Verification Data } \\ \text { Plan } & \text { (if same plan, } \\ \text { indicate "same") }\end{array}$

1. Hospital Name

2. Add ress

3. Telephone Number

4. Person in Charge Radiological

Emergency Response 
I I. QUESTIONNAIRE

Questions to be asked of person in charge of Radiological Emergency Response at the facility:

1. Do you know that this hospital may be used for emergency treatment of patients if there is an emergency at the Indian Point Nuclear Power Station?

$$
\text { Yes_ No_ Don't know }
$$

2. Who would notify you that your hospital should prepare for potentially contaminated injured patients?

Name

$\overline{\text { Don't }^{\prime} \mathrm{know}}$

3. How would you be notified?

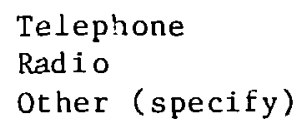

4. Have you been contacted by the state or county to discuss your role in responding to an emergency at the Indian Point Nuclear Power Stations:
Yes
No
Don't know

If Yes,

By Whom When

Title/Organization

5. Is the staff of this facilicy trained for Radiological Emergencies that may take place at a nuclear power station?

$$
\text { Yes_ No___ Don't know }
$$

If Yes,

Is there a Health Physicist on the staff Yes

Is there a Health Physics Technician Yes

An $\mathrm{X}$-kay technician with H.P. training Yes No No No

6. Are dosimeters provided for personnel who will be caring for contaminated injured persons?
Yes
No
Don't know 
II. QUESTIONNAiRE (Cont'd)

If Yes,

What type of dosimeters are used,

Pocket self reading

Film Badge

TLDS

7. Are there survey instruments available?

Yes_ No___ Don't know

If yes,

What type? explain briefly

8. Can an area be set aside for the treatment of radioactive contaminated patients that is separate from normal hospital operations?

Yes_ No___ Don't know

9. Are there sinks, showers and change areas?

Yes_ No D__ Don't know

10. Are there facilities for waste containment and/or disposal?

Yes___ No

Solids?

Liquids?

Can they be disposed?

11. Are commications available to communicate with fixed and mobile facilities?

$$
\text { Yes_ No_ Don't know }
$$

If Yes,

What is used?

Telephone

Radio

Radio pagers

12. Are there Standard Operating Procedures for hospital personnel treating patients who have radioactive contaminated wounds, gross contamination or gross gamma whole body exposures?

Yes_ No___ Don't know 
II. QUESTIONNAIRE (Cont'd)

If this facility cannot treat contaminated patients, what hospitals with capabilities for doing blood chemistry and whole body scanning are mentioned in the SOP's? 
AMBULANCE COMPANIES

A.C. Interview I.D. \# Interviewe $r$

Verified by:

Date Completed

Telephone

Let ter

Field Visit

FEMA/REP VERIFICATION FORM

Indian Point Nuclear Generating Station

I. ORGANIZATION VERIFICATION DATA

$$
\begin{array}{cl}
\text { Information taken from } & \text { Verification Data } \\
\text { Plan } & \text { (if same plan, } \\
\text { indicate "same") }
\end{array}
$$

1. Company Name

2. Address

3. Telephone Number

4. Person in Charge of Company 
II. QUESTIONNAIRE

Questions to be asked of person in charge of Radiological Emergency Response at Ambulance Services.

1. Are you aware that your company is designated to respond to radiological emergencies in the Indian Point Radiological Emergency Response Plan?

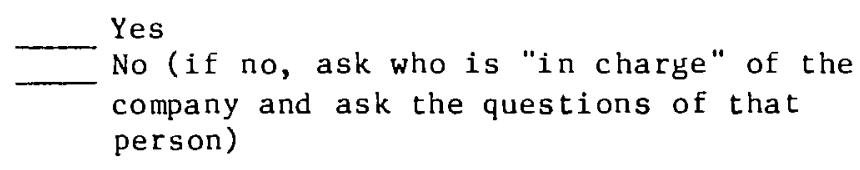

2. Who would notify you that your company is to provide services? Name Don't know

3. How would you be notified that your company is to provide services? Telephone Rad io Uther (specity)

4. Have you been contacted by the state or county to discuss your role in responding to an emergency at the Indian Point Nuclear Power Station?

$$
\text { Yes }
$$

No

Don't know

If Yes,

By Who

When

Title/Organization

5. Are the ambulance crews of this facility trained for Radiological Emergencies that may take place at a nuclear power plant?

If Yes,

By whom

When

Title/Organization

6. Is there equipment to communicate with fixed and mobile facilities?

$$
\text { Yes__ No___ Don't know }
$$

If Yes, What type?

Radio

Radio pagers

Walkie-talkie 
II. QUESTIONNAIRE (Cont'd)

7. Are ambulances equipped with monitcring devices?

Yes_ No____ Don't know

If Yes,

What type?

Survey meters

Dosimeters, pocket self reading

TLDs or film badges

8. Are ambulance crews trained in the use of monitoring equipment and dosime ters?
Yes
No
Don't know

If Yes,

By Whom

When

Title/Organization

9. Does the ambulance have the following equipment?

Gloves (rubber or plastic)

Blankets or coverings (plastic or paper)

Plastic bags or large metal cans for wastes

Batteries for survey instruments

Tags, labels, tape

10. Are ambulance crews trained in the care and treatment of radiologically injured or contaminated patients?
Yes
No
Don't know

If Yes,

By Whom

When

Title/Organization

11. Are there standard operating procedures for ambulance crews treating patients that have radioactive wounds, gross contamination or gross gamma whole body exposures?
Yes
No
Don't know

12. Potassium iodide (KI) as a radioactive iodine blocker is used for protection against the uptake radioactive iodine that may be present during an accident at nuclear power stations. Are ambulance crews trained in the use of this drug and is it available for use?

Yes

No

Don't know 
II. QUESTIONNAIRE (Cont'd)

13. Where do ambulance drivers transport patients?

Don't know

Place 
APPENDIX B

CONFIDENCE INTERVALS 


\section{Introduction}

In many practical situations, statistical and probability theory can be used to analyze the information obtained by surveys. In particular, a confidence interval can be placed around an estimate of the presence or absence of some characteristic in a population by taking random samples of only a portion of that poulation.* For example, a confidence interval can be placed around the estimated number of institutions prepared to meet a radiological emergency by randomly sampling only a fraction of these institutions. For this and similar situations in which sampling all members of the population is expensive or impossible, statistical and probability theory is used to interpret information from a given set of samples. This theory allows one, for example, to estimate the characteristic of interest and place a " $\mathrm{C} \times 100 \%$ " conficlence interval around that estimate. The general theory further states that $C x$ $100 \%$ of all such confidence intervals so constructed will in fact contain the "true" value. The confidence limits are upper and lower bounds.

Theory

Consider a population of $\mathrm{N}$ objects, $K$ of which are "successes" (prepared, for example), and $N$ - $K$ of which are "not successes" (not prepared). If a rand om sample of size NS is taken from the population of $N$, then the hypergeometric probability function provides the probability that $X$ objects of those NS zandomly sampled without replacement will be successes, given that $\mathrm{K}$ of the $\mathrm{N}$ objects in the whole population are successes. The hypergeometric probability function is defined as

$$
f(X ; N, N S, K)=\frac{\left(\begin{array}{l}
K \\
X
\end{array}\right)\left(\begin{array}{l}
N-K \\
N S-X
\end{array}\right)}{\left(\begin{array}{l}
N \\
N S
\end{array}\right)}
$$

where the "zombination" or "binomial coefficient" expression is

$$
\left(\begin{array}{l}
a \\
b
\end{array}\right)=\frac{a !}{(a-b) ! b !}
$$

and the factorial is defined as

$$
a !=a(a-1)(a-2)(a-3) \ldots(3)(2)(1)
$$

\footnotetext{
*A confidence interval is a range of values which may or may not include the parameter of interest. The degree of belief (which should not be interpreted as a probability) that the confidence interval actually contains the true value is the confidence level.
} 
The cumulat. $\cdots$ hypergeometric distribuition function is defined as the probability of $f$ nil $1 r_{i} X$ or fewer successes in a random sample of NS objects from a population s $N$ objects. Mathematically this is wrilten as:

$$
F(x ; N, N S, K)=\sum_{r=0}^{X} \frac{\left(\begin{array}{l}
K \\
r
\end{array}\right)\left(\begin{array}{l}
N-K \\
N S-r
\end{array}\right)}{\left(\begin{array}{l}
N \\
N S
\end{array}\right)}=\sum_{r=0}^{X} f(r ; N, N S, K)
$$

The tables of Apnendix $C$ provide individual and cumulative values of the hypergeometric distribution for $N=2$ to 12 , for all possible combinations of NS, $k$ and $x_{0} *$

To illustrate the use of the tables, consider the first page of Appendix $C$; the first entry in the right-hand column indicates that there is a 0.60 probability of having 1 success out of 2 items selected randomly from a population of 5 in which there are a total of 3 successes. There is also a 0.70 probability of selecting either 0 or 1 successful item under the same conditions.

These tables can be used to construct an approximate C $x \quad 100 \%$ confidence interval around an estimate of $\mathrm{K}$. The confidence intervals will generally be approximate due to the discrete nature of the hypergeometric cistribution. Denote $K_{u}$ as the upper limit and $K_{\ell}$ as the lower $l i n i t$ for the estimate of $K$ where:

$$
k_{u}=\text { smallest } K \text { such that } F(X ; N, N S, K) \leq(1-C) / 2
$$

and

$$
K_{\ell}=\text { largest } K \text { such that } F(X-1 ; N, N S, K) \geq(1+C) / 2
$$

When the above equation yields a value of $K$ iess than $x$, due to the discrete nature of the hypergeometric distribution and the definition of confidence intervals, $K_{\ell}$ is taken to be $x$.

$\mathrm{K}_{\mathrm{e}}$ and $\mathrm{K}_{\ell}$ provide a $C \times 100 \%$ confidence int $\mathrm{C}$. successes, namely, $K_{\ell} / N, K_{u} / N$; the observed proportion of successes is $X / N S$. It follows that $K_{\ell} / N=X / N S \leq K_{u} / N$.

Example

Consider a case in which $N=11, N S=5, X=1$ and $C=0.80$. That is, the statistician wants $80 \%$ confidence that the true value of $K$ lies between

\footnotetext{
*Additional values for those cases where $F(\bullet) \leq 0.20$ or $F ! \cdot) \geq 0.80$ were also cabulated and can be obtained on microfiche from Ron Whitfield, Argonne National Laboratory.
} 
the values $K_{\ell}$ and $K_{u}$, given that 1 out of 5 samples was successful from a total population of 11 . Using the tables, the following is found:

$\begin{array}{lll}\underline{K} & \mathrm{~F}(1 ; 11,5, \mathrm{~K}) & \mathrm{F}(0 ; 11,5, \mathrm{~K}) \\ 1 & 1.000 & 1.00 \\ 2 & 0.818 & 0.545 \\ 3 & 0.516 & 0.273 \\ 4 & 0.348 & 0.121 \\ 5 & 0.175 & 0.045 \\ 6 & 0.067 & \\ 7 & 0.015 & \end{array}$

$K_{u}$ is determined by $f$ inding the smallest value of $K$ such that $F(1 ; 11$, $5, K) \leq 0.1$; this value is $K_{u}=6 . K_{\ell}$ is determined by finding the largest value of $K$ such that $F(0 ; 11,5, K) \geq 0.9$; this value is 0 , but is less than the observed number of successes; therefore $K_{\ell}=1$. As a result, the statistician is approximately $80 \%$ confident that the true value of the number of successes in a population of 11 is between $l$ and 6 , given that 1 success was found in 5 rand om samples drawn from these 11. To ie more precise, the interval 2 to 8 is a $93.3 \%$ confidence interval. Similarly, the interval 1 to 5 is an $82.5 \%$ confidence interval.

A $93.3 \%$ confidence interval on the proportion of successes is 0.09 to 0.55 ; the observed proportion is 0.20 .

Choice of Confidence Intervals

Confidence intervals are constructed by first observing that the hypergeometric distribution properly describes the probabilities of observing the various outcomes while sampling (without replacement) fewer than all of the members of a finite population. It is important to use this distribution when the population of interest is small or the percent sampled is large (both usually apply here) in order to obtain correct results and conclusions. The theory of confidence intervals is used to construct upper and lower bound $\mathrm{s}$ or the estimated parameters. These bounds are influenced by the size of the population of interest, the number of samples taken, and the observed results.

When confidence intervais are stated in this report, usually both an approximate $90 \%$ and a $100 \%$ confidence interval are given. The $100 \%$ confidence interval is not a statistical device, but represents the possible minimum and maximum values implied by the sample. The approximate $90 \%$ confidence intervals are statistical devices; they are approximate due to the discrete nature of the hypergeometric distribution (i.e., it deals with integer numbers). It is not possible or a aningful to construct an approximate $90 \%$ confidence interval when the population of interest is too small. This problem does arise if all or almost all of the population can be sampled; in such a case, an exact (or nearly exact) estimate can be obtained. 
Confidence intervals usually can be located at any number of places in the allowable interval (i.e., the $100 \%$ confidence interval). The following principles were used to set the confidence intervals listed in this report:

- The confidence level was chosen to be as close as possible เo $90 \%$.

- If moving the confidence interval a small distance to the right of the lowest possible value $(0.07$ in Fig. 1) decreases the maximum confidence level below about $85 \%$, then the $l$ ow end of the confidence interval is set at the lowest pussible value (i.e., the $86 \%$ confidence interval is appropriate).

- A similar argument applies to locating the confidence interval if the observed proportion is near 1.00 , as illustrated in Fig. 2 . The $88 \%$ confidence interval, which has its high end at the highest possible value $(0.87)$, is the appropriate choice.

- When possible, the confidence interval is "shortened" at both ends, as illustrated in Fig. 3. In this case, there is $95 \%$ confidence that the true proportion is greater than or equal to $0.18,95 \%$ confidence that it is less than or equal to 0.63 , and therefore $90 \%$ confidence that it is in the range 0.18 to 0.63 . A qualitative argument for preferring the $90 \%$ confidencf: interval to the $89 \%$ confidence interval in Fig. 3 is that the $90 \%$ confidence interval is more conservative in estimating the upper bound on the proportion. This conservative interval seems to be appropriate since the observed proportion is 0.38 . 
Population Size

15

Sample Size

9

Number Answering "Yes" 1

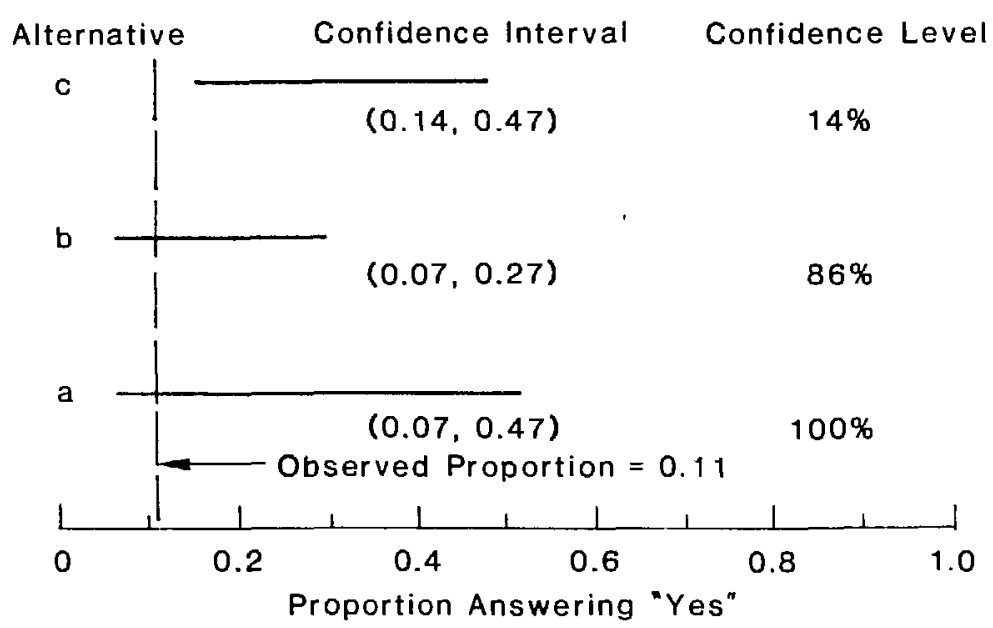

Fig. I Choice of Confidence Intervals for the Bus Company Category -- Low Proportion Observed

$\begin{array}{lr}\text { Population Size } & 15 \\ \text { Sample Size } & 9 \\ \text { Number Answering "Yes" } & 7\end{array}$

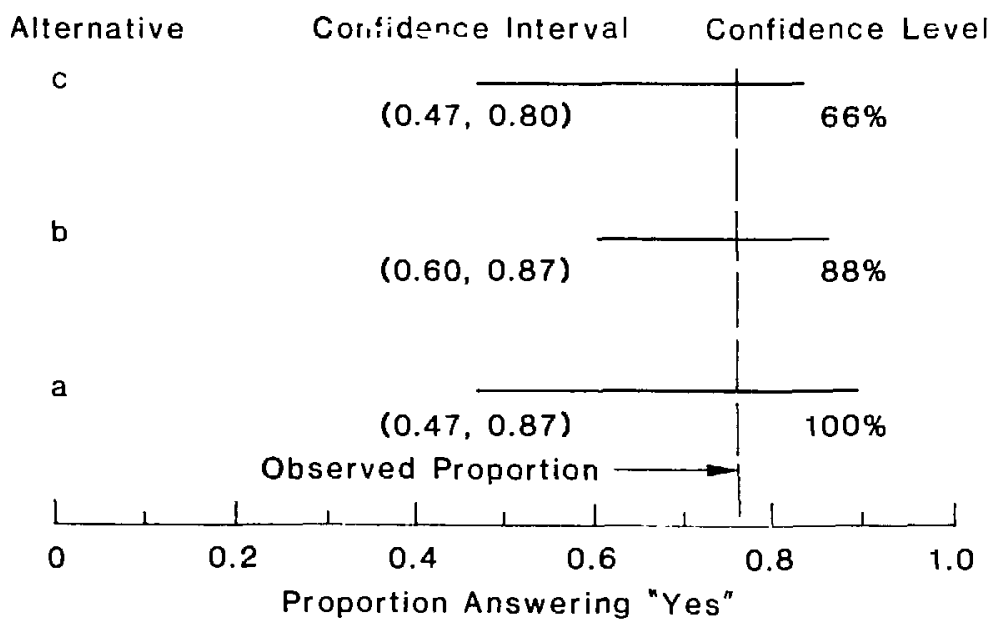

Fig. 2 Choice of Confidence Intervals for the Bus Company Category -- High Proportion Observed 


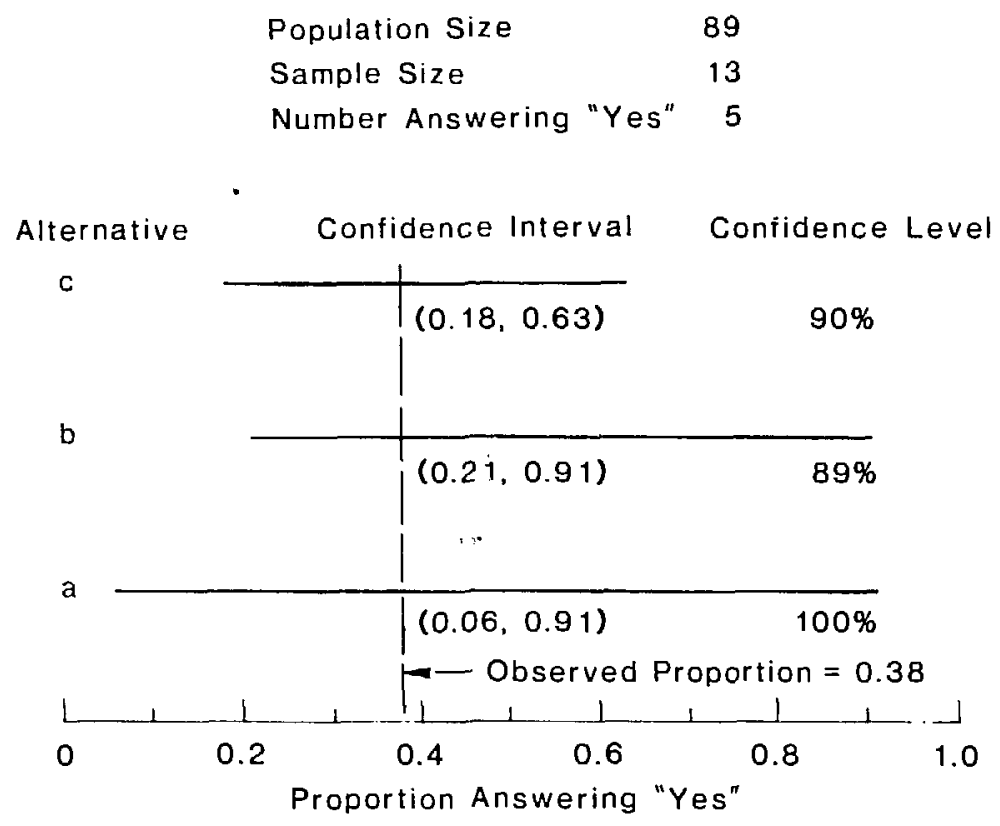

Fig. 3 Choice of Confidence Intervals for the Ambulance Companies Category 
APPENDIX C

INDIVIDUAL AND CUMULATIVE

PROBABILITIES

FOR THF

HYPERGEOMETRIC DISTRIBUTION

FOR

$$
\begin{aligned}
N & =2, \ldots, 12 \\
N S & =1, \ldots, N-1 \\
K & =1, \ldots, N \\
X & =0, \ldots, N S
\end{aligned}
$$




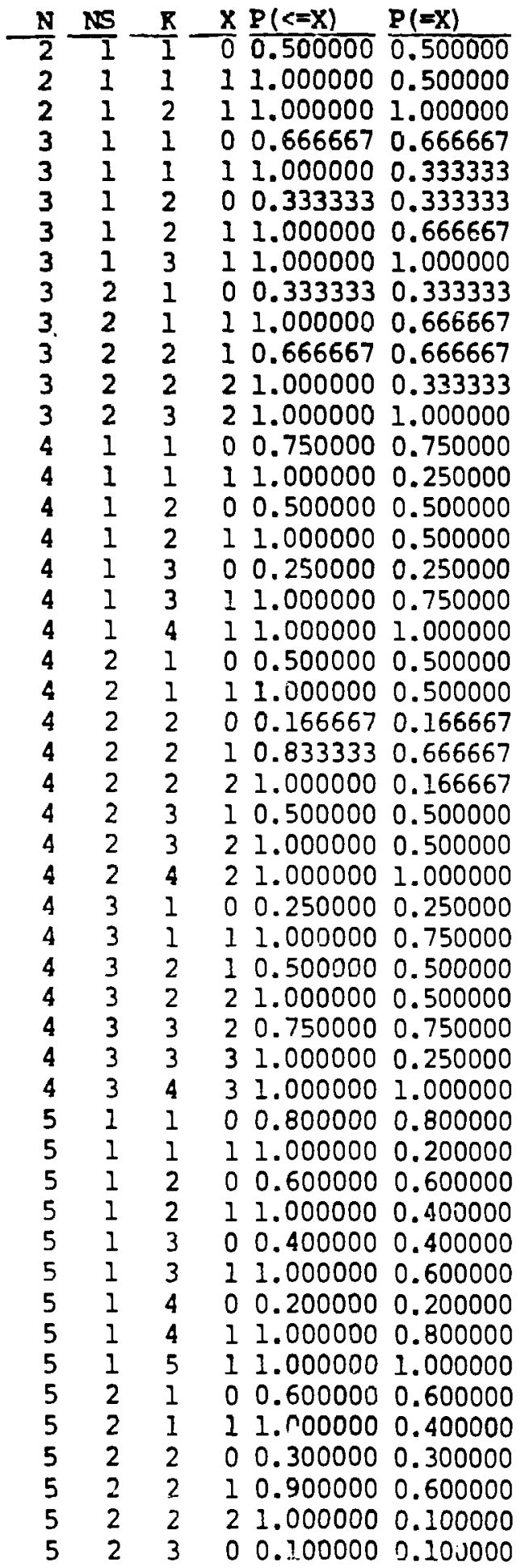

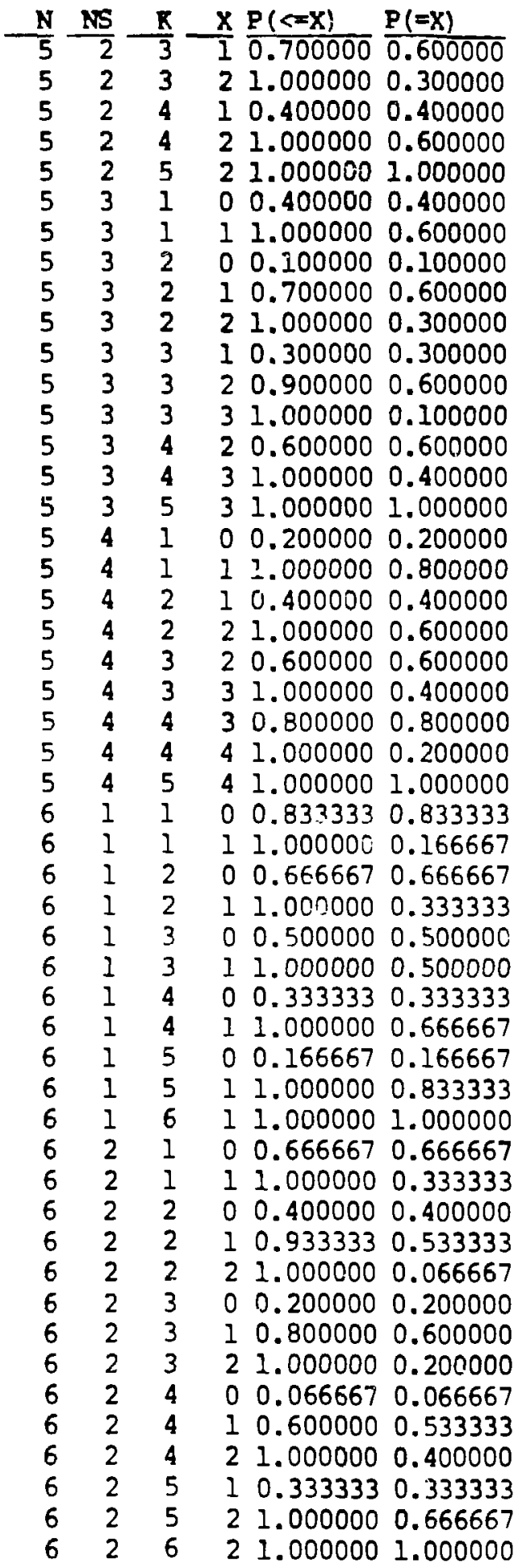




\begin{tabular}{|c|c|c|c|c|}
\hline $\mathbf{N}$ & NS & $\mathbf{R}$ & $\mathrm{X} P(<=\mathrm{X})$ & $P(=X)$ \\
\hline 6 & 3 & $\overline{1}$ & $0 \overline{0.500000}$ & 0.500000 \\
\hline 6 & 3 & 1 & 11.000000 & 0.500000 \\
\hline 6 & 3 & 2 & 00.200000 & 0.200000 \\
\hline 6 & 3 & 2 & 10.800000 & 0.600000 \\
\hline 6 & 3 & 2 & 21.000000 & 0.200000 \\
\hline 6 & 3 & 3 & 00.050000 & 0.050000 \\
\hline 6 & 3 & 3 & 10.500000 & 0.450000 \\
\hline 6 & 3 & 3 & 20.950000 & 0.450000 \\
\hline 6 & 3 & 3 & 31.000000 & 0.050000 \\
\hline 6 & 3 & 4 & 10.200000 & 0.200000 \\
\hline 6 & 3 & 4 & 20.800000 & 0.600000 \\
\hline 6 & 3 & 4 & 31.000000 & 0.200000 \\
\hline 6 & 3 & 5 & 20.500000 & 0.500000 \\
\hline 6 & 3 & 5 & 31.000000 & 0.500000 \\
\hline 6 & 3 & 6 & 31.000000 & 1.000000 \\
\hline 6 & 4 & 1 & 00.333333 & 0.333333 \\
\hline 6 & 4 & 1 & 11.000000 & 0.666667 \\
\hline 6 & 4 & 2 & 00.066667 & 0.066667 \\
\hline 6 & 4 & 2 & 10.600000 & 7.533333 \\
\hline 6 & 4 & 2 & 21.000000 & 0.400000 \\
\hline 6 & 4 & 3 & 10.200000 & 0.200000 \\
\hline 6 & 4 & 3 & 20.800000 & 0.600000 \\
\hline 6 & 4 & 3 & 31.000000 & 0.200000 \\
\hline 6 & 4 & 4 & 20.400000 & 0.400000 \\
\hline 6 & 4 & 4 & 30.933333 & 0.533333 \\
\hline 6 & 4 & 4 & 41.000000 & 0.066667 \\
\hline 6 & 4 & 5 & 30.666667 & 0.666667 \\
\hline 6 & 4 & 5 & 41.000000 & 0.333333 \\
\hline 6 & 4 & 6 & 41.000000 & 1.000000 \\
\hline 6 & 5 & 1 & 00.166667 & 0.166667 \\
\hline 6 & 5 & 1 & 11.000000 & 0.833333 \\
\hline 6 & 5 & 2 & 10.333333 & 0.333333 \\
\hline 6 & 5 & 2 & .000000 & 0.666667 \\
\hline 6 & 5 & 3 & 20.500000 & 0.500000 \\
\hline 6 & 5 & 3 & 31.000000 & 0.500000 \\
\hline 6 & 5 & 4 & 30.666667 & 0.666667 \\
\hline 6 & 5 & 4 & 41.000000 & 0.333333 \\
\hline 6 & 5 & 5 & 40.833333 & 0.833333 \\
\hline 6 & 5 & 5 & 51.000000 & 0.166667 \\
\hline 6 & 5 & 6 & 51.000000 & 1.000000 \\
\hline 7 & 1 & 1 & 00.857143 & 0.857143 \\
\hline 7 & 1 & 1 & 11.000000 & 0.142857 \\
\hline 7 & 1 & 2 & 00.714286 & 0.714286 \\
\hline 7 & 1 & 2 & 11.000000 & 0.285714 \\
\hline 7 & 1 & 3 & 00.571429 & 0.571429 \\
\hline 7 & 1 & 3 & 11.000000 & 0.428571 \\
\hline 7 & 1 & 4 & 00.428571 & 0.428571 \\
\hline 7 & 1 & 4 & 11.000000 & 0.571429 \\
\hline 7 & 1 & 5 & 00.285714 & 0.285714 \\
\hline 7 & 1 & 5 & 11.000000 & 0.714286 \\
\hline
\end{tabular}

\begin{tabular}{|c|c|c|c|c|}
\hline $\mathbf{N}$ & NS & $\mathbf{R}$ & $\mathrm{X} P(\leqslant \mathrm{X})$ & $P(=x)$ \\
\hline & 1 & 6 & $\overline{0} \overline{0.142857}$ & 0.142857 \\
\hline 7 & 1 & 6 & 11.000000 & 0.857143 \\
\hline 7 & 1 & 7 & 11.000000 & 1.000000 \\
\hline 7 & 2 & 1 & 00.714286 & 0.714286 \\
\hline 7 & 2 & 1 & 11.000000 & 0.285714 \\
\hline 7 & 2 & 2 & 00.476190 & 0.476190 \\
\hline 7 & 2 & 2 & 10.952381 & 0.476190 \\
\hline 7 & 2 & 2 & 21.000000 & 0.047619 \\
\hline 7 & 2 & 3 & 00.285714 & 0.285714 \\
\hline 7 & 2 & 3 & 10.857143 & 0.571429 \\
\hline 7 & 2 & 3 & 21.000000 & 0.142857 \\
\hline 7 & 2 & 4 & $\begin{array}{ll}0 & 0.142857\end{array}$ & 0.142857 \\
\hline 7 & 2 & 4 & 10.714286 & 0.571429 \\
\hline 7 & 2 & 4 & 21.000000 & 0.285714 \\
\hline 7 & 2 & 5 & 00.047619 & 0.047619 \\
\hline 7 & 2 & 5 & 10.523810 & 0.476190 \\
\hline 7 & 2 & 5 & 21.000000 & 0.476190 \\
\hline 7 & 2 & 6 & 10.285714 & 0.285714 \\
\hline 7 & 2 & 6 & 21.000000 & 0.714286 \\
\hline 7 & 2 & 7 & 21.000000 & 1.000000 \\
\hline 7 & 3 & 1 & $0 \quad 0.571429$ & 0.571429 \\
\hline 7 & 3 & 1 & 11.000000 & $0.4285 ? 1$ \\
\hline 7 & 3 & 2 & $0 \quad 0.285714$ & 0.285714 \\
\hline 7 & 3 & 2 & 10.857143 & 0.571429 \\
\hline 7 & 3 & 2 & 21.000000 & 0.142857 \\
\hline 7 & 3 & 3 & 00.114286 & 0.114286 \\
\hline 7 & 3 & 3 & 10.628571 & 0.514286 \\
\hline 7 & 3 & 3 & $\approx 0.971429$ & 0.342857 \\
\hline 7 & 3 & 3 & 31.000000 & 0.028571 \\
\hline 7 & 3 & 4 & 00.028571 & 0.028571 \\
\hline 7 & 3 & 4 & 10.371429 & 0.342857 \\
\hline 7 & 3 & 4 & 0.885714 & 0.514286 \\
\hline 7 & 3 & 4 & 31.000000 & 0.114286 \\
\hline 7 & 3 & 5 & 10.142857 & 0.142857 \\
\hline 7 & 3 & 5 & 20.714286 & 0.571429 \\
\hline 7 & 3 & 5 & 31.000000 & 0.285714 \\
\hline 7 & 3 & 6 & 20.428571 & 0.428571 \\
\hline 7 & 3 & 6 & 31.000000 & 0.571429 \\
\hline 7 & 3 & 7 & 31.000000 & 1.000000 \\
\hline 7 & 4 & 1 & $0 \quad 0.428571$ & 0.428571 \\
\hline 7 & 4 & 1 & 11.000000 & 0.571429 \\
\hline 7 & 4 & 2 & 00.142857 & 0.142857 \\
\hline 7 & 4 & 2 & 10.714286 & 0.571429 \\
\hline 7 & 4 & 2 & 21.000000 & 0.285714 \\
\hline 7 & 4 & 3 & 00.028571 & 0.028571 \\
\hline 7 & 4 & 3 & 10.371429 & 0.342857 \\
\hline 7 & 4 & 3 & 20.885714 & 0.514286 \\
\hline 7 & 4 & 3 & 31.000000 & 0.114286 \\
\hline 7 & 4 & 4 & 10.114286 & 0.114286 \\
\hline 7 & 4 & 4 & 20.628571 & 0.514286 \\
\hline
\end{tabular}




\begin{tabular}{|c|c|c|c|c|}
\hline$\frac{N}{2}$ & Ns & $\mathbf{R}$ & $x P(<=x)$ & $P(=X)$ \\
\hline & & $\overline{4}$ & 30.971429 & 0.342857 \\
\hline 7 & 4 & 4 & 41.000000 & 0.028571 \\
\hline 7 & 4 & 5 & 20.285714 & 0.285714 \\
\hline 7 & 4 & 5 & 30.857143 & 0.571429 \\
\hline 7 & 4 & 5 & 41.000000 & 0.142857 \\
\hline 7 & 4 & 6 & 30.571429 & 0.571429 \\
\hline 7 & 4 & 6 & 41.000000 & \\
\hline 7 & 4 & 7 & 41.000000 & 1.000000 \\
\hline 7 & 5 & 1 & $0 \quad 0.285714$ & 0.285714 \\
\hline 7 & 5 & 1 & 11.000000 & 0.714286 \\
\hline 7 & 5 & 2 & 00.047619 & 0.0 \\
\hline 7 & 5 & 2 & 10. & 0.476190 \\
\hline 7 & 5 & 2 & 21.000000 & 0.476190 \\
\hline 7 & 5 & 3 & 10.142857 & 0.142857 \\
\hline 7 & 5 & 3 & 20 & 0.571429 \\
\hline 7 & 5 & 3 & 31.0 & 0.28 \\
\hline 7 & 5 & 4 & 20.2 & $0.285^{\circ}$ \\
\hline 7 & 5 & 4 & 57143 & 0.571 \\
\hline 7 & 5 & 4 & 00000 & 0.142857 \\
\hline$f$ & 5 & 5 & 30.476190 & 0.476190 \\
\hline$f$ & 5 & 5 & 40.952381 & 0.476190 \\
\hline 1 & 5 & 5 & 51.000000 & 0.047615 \\
\hline$i$ & 5 & 6 & 40.714286 & 0.71428 \\
\hline 7 & 5 & 6 & 51.000000 & 0.28571 \\
\hline & 5 & 7 & 51.000000 & 1.000000 \\
\hline 7 & 6 & 1 & 00.142857 & 0.142857 \\
\hline 7 & 6 & 1 & 11.000000 & 0.857143 \\
\hline 7 & 6 & 2 & 10.285714 & 0.28571 \\
\hline$?$ & 6 & 2 & 21.000000 & 0.71428 \\
\hline 7 & 6 & 3 & 20.42 & 0.4 .2857 \\
\hline 7 & 6 & 3 & 31.000000 & 0.571429 \\
\hline 7 & 6 & 4 & 30.57 & 0. \\
\hline 7 & 6 & 4 & 41.000000 & 0.428 \\
\hline 7 & 6 & 5 & 86 & 0. \\
\hline 7 & 6 & 5 & 00 & 0.2 \\
\hline 7 & 6 & 6 & 50. & 0. \\
\hline 7 & 6 & 6 & 61. & 0.14 \\
\hline 7 & 6 & 7 & 61. & \\
\hline 8 & 1 & 1 & 00.875000 & 0.875000 \\
\hline 8 & 1 & 1 & 11.000000 & 0.12500 \\
\hline 8 & 1 & 2 & 00.750000 & 0.75000 \\
\hline 8 & 1 & 2 & 11.000000 & 0.25000 \\
\hline 8 & 1 & 3 & 00. & 2500 \\
\hline 8 & 1 & 3 & 11.000000 & 0.37500 \\
\hline 8 & 1 & 4 & 00.500000 & 0.50000 \\
\hline 8 & 1 & 4 & 11.000000 & 0.50000 \\
\hline 8 & 1 & 5 & 00.37 & 0.37500 \\
\hline 8 & 1 & 5 & 11.000000 & 0.62500 \\
\hline 8 & 1 & 6 & 00. & \\
\hline 3 & 1 & 6 & 11. & \\
\hline
\end{tabular}

\begin{tabular}{|c|c|c|c|c|}
\hline $\mathbf{N}$ & NS & $\mathbf{R}$ & $X P(s=x)$ & $P(=X)$ \\
\hline$\overline{8}$ & $I$ & 7 & $\overline{0.125000}$ & 0.125000 \\
\hline 8 & 1 & 7 & 11.000000 & 0.875000 \\
\hline 8 & 1 & 8 & 11.000000 & 1.000000 \\
\hline 8 & 2 & 1 & 00.750000 & 0.750000 \\
\hline 8 & 2 & 1 & 11.000000 & 0.250000 \\
\hline 8 & 2 & 2 & 00.535714 & 0.535714 \\
\hline 8 & 2 & 2 & 10.964286 & 0.428571 \\
\hline 8 & 2 & 2 & 21.000000 & 0.035714 \\
\hline 8 & 2 & 3 & $\begin{array}{lll}0 & 0.357143\end{array}$ & 0.357143 \\
\hline $\begin{array}{l}8 \\
8\end{array}$ & $\begin{array}{l}2 \\
2\end{array}$ & $\begin{array}{l}3 \\
3\end{array}$ & $\begin{array}{ll}1 & 0.892857 \\
2 & 1.000000\end{array}$ & $\begin{array}{l}0.535714 \\
0.107143\end{array}$ \\
\hline 8 & 2 & 4 & 00.214286 & 0.214286 \\
\hline 8 & 2 & 4 & 10.785714 & 0.571429 \\
\hline 8 & 2 & 4 & 21.000000 & 0.214286 \\
\hline 8 & 2 & 5 & 00.107143 & 0.107143 \\
\hline 8 & 2 & 5 & 10.542857 & 0.535714 \\
\hline 8 & 2 & 5 & 21.000000 & $0.35714 ?$ \\
\hline 8 & 2 & 6 & 00.035714 & 0.035714 \\
\hline 8 & 2 & 6 & 10.464286 & 0.428571 \\
\hline 8 & 2 & 6 & 21.000000 & 0.535714 \\
\hline 8 & 2 & 7 & 10.250000 & 0.250000 \\
\hline 8 & 2 & 7 & 21.000000 & 0.750000 \\
\hline 8 & 2 & 8 & 21.000000 & 1.000000 \\
\hline 8 & 3 & 1 & 00.625000 & 0.625000 \\
\hline 8 & 3 & 1 & 11.000000 & 0.375000 \\
\hline 8 & 3 & 2 & 00.357143 & 0.357143 \\
\hline 8 & 3 & 2 & 10.892857 & 0.535714 \\
\hline 8 & 3 & 2 & 21.000000 & 0.107143 \\
\hline 8 & 3 & 3 & 00.178571 & 0.178571 \\
\hline 8 & 3 & 3 & 10.714286 & 0.535714 \\
\hline 8 & 3 & 3 & 20.982143 & 0.267857 \\
\hline 8 & 3 & 3 & 31.000000 & 0.017857 \\
\hline 8 & 3 & 4 & 00.071429 & 0.071429 \\
\hline 8 & 3 & 4 & 10.500000 & 0.428571 \\
\hline 8 & 3 & 4 & 20.928571 & 0.428571 \\
\hline 8 & 3 & 4 & 31.000000 & 0.071429 \\
\hline 8 & 3 & 5 & 00.017857 & 0.017857 \\
\hline 8 & 3 & 5 & 10.285714 & 0.267857 \\
\hline 8 & 3 & 5 & 20.821429 & 0.535714 \\
\hline 8 & 3 & 5 & 31.000000 & 0.178571 \\
\hline 8 & 3 & 6 & 10.107143 & 0.107143 \\
\hline 8 & 3 & 6 & 20.642857 & 0.535714 \\
\hline 8 & 3 & 6 & 31.000000 & 0.357143 \\
\hline 8 & 3 & 7 & 20.375000 & 0.375000 \\
\hline 8 & 3 & 7 & 31.000000 & 0.625000 \\
\hline 8 & 3 & 8 & 31.000000 & 1.000000 \\
\hline 8 & 4 & 1 & 00.500000 & 0.500000 \\
\hline 8 & 4 & 1 & 11.000000 & 0.500000 \\
\hline 8 & 4 & 2 & 00.214286 & 0.214285 \\
\hline 8 & 4 & 2 & 10.785714 & 0.571429 \\
\hline
\end{tabular}




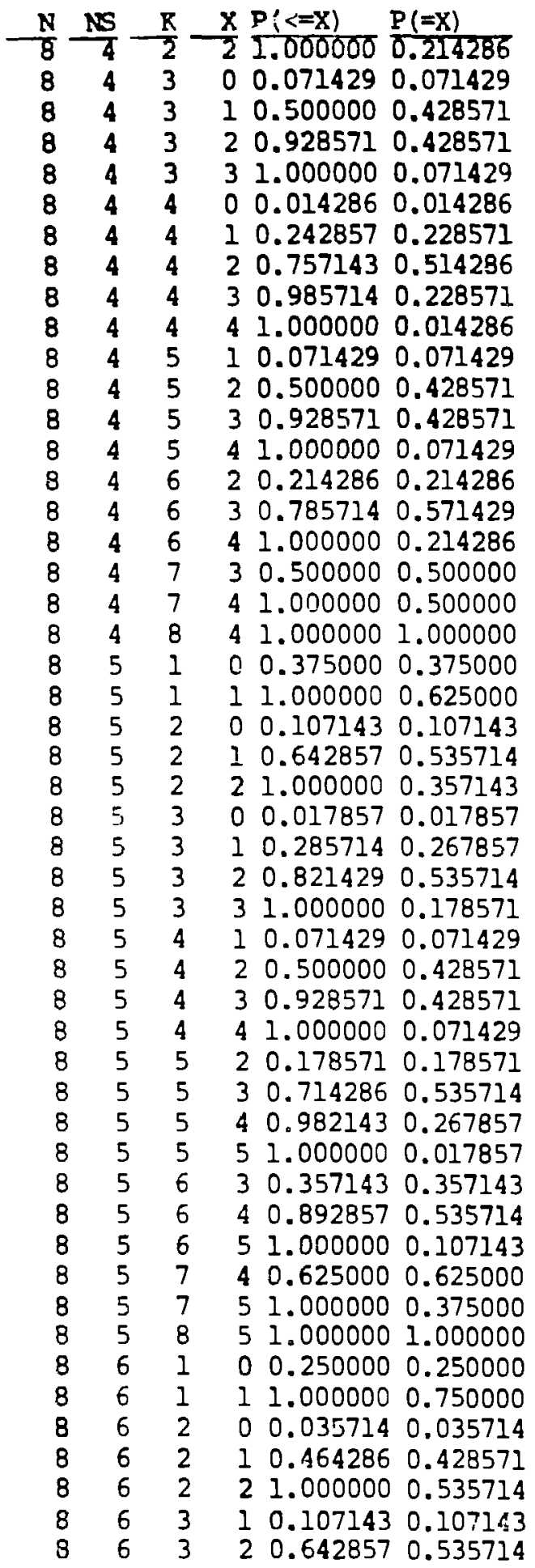

\begin{tabular}{|c|c|c|c|c|}
\hline$\underset{N}{N}$ & NS & $\mathbf{K}$ & $X P(<=X)$ & $P(=X)$ \\
\hline & 6 & $\frac{\pi}{3}$ & 31.000000 & 0.357143 \\
\hline 8 & 6 & 4 & 20.214286 & 0.214286 \\
\hline 8 & 6 & 4 & 30.785714 & 0.571429 \\
\hline 8 & 6 & 4 & 41.000000 & 0.214286 \\
\hline 8 & 6 & 5 & 30.357143 & 0.357143 \\
\hline 8 & 6 & 5 & $\begin{array}{ll}4 & 0.892857\end{array}$ & 0.535714 \\
\hline $\begin{array}{l}8 \\
8\end{array}$ & $\begin{array}{l}6 \\
6\end{array}$ & $\begin{array}{l}5 \\
6\end{array}$ & $\begin{array}{l}51.000000 \\
4 \\
4\end{array}$ & $\begin{array}{l}0.107143 \\
0.535714\end{array}$ \\
\hline 8 & 6 & 6 & 50.964286 & 0.428571 \\
\hline 8 & 6 & 6 & 61.000000 & 0.035714 \\
\hline B & 6 & 7 & 50.750000 & 0.750000 \\
\hline 8 & 6 & 7 & 61.000000 & 0.250000 \\
\hline 8 & 6 & 8 & 61.000000 & 1.000000 \\
\hline 8 & 7 & 1 & 00.125000 & 0.125000 \\
\hline 8 & 7 & 1 & 11.000000 & 0.875000 \\
\hline 8 & 7 & - & 10.250000 & 0.250000 \\
\hline 8 & 7 & 2 & 21.000000 & 0.750000 \\
\hline 8 & 7 & 3 & 20.375000 & 0.375000 \\
\hline 8 & 7 & 3 & 31.000000 & 0.625000 \\
\hline 8 & 7 & 4 & 30.500000 & 0.500000 \\
\hline 8 & 7 & 4 & 1.000000 & 0.500000 \\
\hline 8 & 7 & 5 & 0.625000 & 0.625000 \\
\hline 8 & 7 & 5 & 1.000000 & 0.375000 \\
\hline 8 & 7 & 6 & 50.750000 & 0.750000 \\
\hline 8 & 7 & 6 & 61.000000 & 0.250000 \\
\hline 8 & 7 & 7 & $\begin{array}{ll}6 & 0.875000\end{array}$ & 0.875000 \\
\hline 8 & 7 & 7 & 1.000000 & 0.125000 \\
\hline 8 & 7 & 8 & 71.000000 & 1.000000 \\
\hline 9 & 1 & 1 & 00.888889 & 0.888889 \\
\hline 9 & 1 & 1 & 1.000000 & 0.111111 \\
\hline 9 & 1 & 2 & $0 \quad 0.777778$ & 0.777778 \\
\hline 9 & 1 & 2 & 11.000000 & 0.222222 \\
\hline 9 & 1 & 3 & $0 \quad 0.666667$ & 0.666667 \\
\hline 9 & 1 & 3 & 11.000000 & 0.333333 \\
\hline 9 & 1 & 4 & 00.555556 & 0.555556 \\
\hline 9 & 1 & 4 & 11.000000 & 0.444444 \\
\hline 9 & 1 & 5 & $0 \quad 0.444444$ & 0.444444 \\
\hline 9 & 1 & 5 & 11.000000 & 0.555556 \\
\hline 9 & 1 & 6 & 00.333333 & 0.333333 \\
\hline 9 & 1 & 6 & 11.000000 & 0.666667 \\
\hline 9 & 1 & 7 & $0 \quad 0.222222$ & 0.222222 \\
\hline 9 & 1 & 7 & 11.000000 & 0.777778 \\
\hline 9 & 1 & 8 & 00.111111 & 0.111111 \\
\hline 9 & 1 & 8 & 11.000000 & 0.888889 \\
\hline 9 & 1 & 9 & 11.000000 & 1.000000 \\
\hline 9 & 2 & 1 & $\begin{array}{ll}0 & 0.777778\end{array}$ & 0.777778 \\
\hline 9 & 2 & 1 & 11.000000 & 0.222222 \\
\hline 9 & 2 & 2 & 00.583333 & 0.583333 \\
\hline 9 & 2 & 2 & 10.972222 & \\
\hline 9 & 2 & 2 & 21.000000 & 0.0277 \\
\hline
\end{tabular}




\begin{tabular}{|c|c|c|c|c|}
\hline $\mathrm{N}$ & NS & $\mathbf{K}$ & $X P(<x)$ & $P(=x)$ \\
\hline & 2 & $\frac{\pi}{3}$ & 00.416667 & 0.416667 \\
\hline 9 & 2 & 3 & 10.916667 & 0.500000 \\
\hline 9 & 2 & 3 & 21.000000 & 0.083333 \\
\hline 9 & 2 & 4 & 00.277778 & 0.277778 \\
\hline 9 & 2 & 4 & 10.833333 & 0.555556 \\
\hline 9 & 2 & 4 & 21.000000 & 0.166667 \\
\hline 9 & 2 & 5 & 00.166667 & 0.166667 \\
\hline 9 & 2 & 5 & 10.722222 & 0.555556 \\
\hline 9 & 2 & 5 & 21.000000 & 0.277778 \\
\hline 9 & 2 & 6 & 00.083333 & 0.083333 \\
\hline 9 & 2 & 6 & 10.583333 & 0.500000 \\
\hline 9 & 2 & 6 & 21.000000 & 0.416667 \\
\hline 9 & 2 & 7 & 00.027778 & 0.027778 \\
\hline 9 & 2 & 7 & 10.416667 & 0.388889 \\
\hline 9 & 2 & 7 & 21.000000 & 0.583333 \\
\hline 9 & 2 & 8 & 10.222222 & 0.222222 \\
\hline 9 & 2 & 8 & 21.000000 & 0.777778 \\
\hline 9 & 2 & 9 & 21.000000 & 1.000000 \\
\hline 9 & 3 & 1 & 00.666667 & 0.666667 \\
\hline 9 & 3 & 1 & 11.000000 & 0.333333 \\
\hline 9 & 3 & 2 & 00.416667 & 0.416667 \\
\hline 9 & 3 & 2 & 10.916667 & 0.500000 \\
\hline 9 & 3 & 2 & 21.000000 & 0.083333 \\
\hline 9 & 3 & 3 & 00.238095 & 0.238095 \\
\hline 9 & 3 & 3 & 10.773810 & 0.535714 \\
\hline 9 & 3 & 3 & 20.988095 & 0.214236 \\
\hline 9 & 3 & 3 & 31.000000 & 0.011905 \\
\hline 9 & 3 & 4 & 00.119048 & 0.119048 \\
\hline 9 & 3 & 4 & 10.595238 & 0.476190 \\
\hline 9 & 3 & 4 & 20.952381 & 0.357143 \\
\hline 9 & 3 & 4 & 31.000000 & 0.047619 \\
\hline 9 & 3 & 5 & 00.047619 & 0.047619 \\
\hline 9 & 3 & 5 & 10.404762 & 0.357143 \\
\hline 9 & 3 & 5 & 20.880952 & 0.476190 \\
\hline 9 & 3 & 5 & 31.000000 & 0.119048 \\
\hline 9 & 3 & 6 & 00.011905 & 0.011905 \\
\hline 9 & 3 & 6 & 10.226190 & 0.214286 \\
\hline 9 & 3 & 6 & . 0.761905 & 0.535714 \\
\hline 9 & 3 & 6 & 31.000000 & 0.238095 \\
\hline 9 & 3 & 7 & $\therefore 0.083333$ & 0.083333 \\
\hline 9 & 3 & 7 & $\approx 0.583333$ & 0.500000 \\
\hline 9 & 3 & 7 & 31.000000 & 0.416667 \\
\hline 9 & 3 & 8 & 20.333333 & 0.333333 \\
\hline 9 & 3 & 8 & 31.000000 & 0.666667 \\
\hline 9 & 3 & 9 & 31.000000 & 1.000000 \\
\hline 9 & 4 & 1 & 00.555556 & 0.555556 \\
\hline 9 & 4 & 1 & 11.000000 & 0.444444 \\
\hline 9 & 4 & 2 & 00.277778 & 0.277778 \\
\hline 9 & 4 & 2 & 0.833333 & 0.555556 \\
\hline 9 & 4 & 2 & 1.000000 & 0.166667 \\
\hline
\end{tabular}

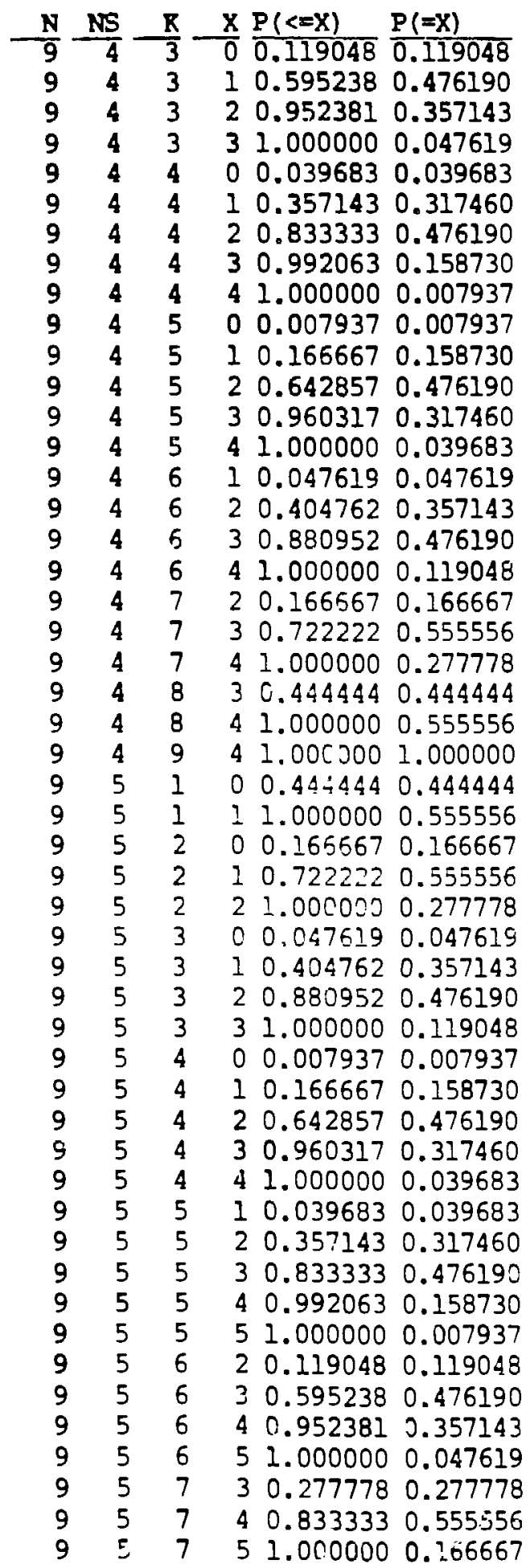




\begin{tabular}{|c|c|c|c|c|}
\hline$N$ & NS & $\mathbf{R}$ & $X P(\Leftrightarrow X)$ & $P(=x)$ \\
\hline$\frac{11}{9}$ & $\frac{5}{5}$ & $\frac{\pi}{8}$ & $\frac{\pi}{4} \frac{1}{0.555556}$ & 0.555556 \\
\hline 9 & 5 & 8 & 51.000000 & 0.444444 \\
\hline 9 & 5 & 9 & 51.000000 & 1.000000 \\
\hline 9 & 6 & 1 & 00.333333 & 0.333333 \\
\hline 9 & 6 & 1 & 11.000000 & 0.666667 \\
\hline 9 & 6 & 2 & 00.083333 & 0.083333 \\
\hline 9 & 6 & 2 & 10.583333 & 0.500000 \\
\hline 9 & 6 & 2 & 000000 & 0.416667 \\
\hline 9 & 6 & 3 & 00.011905 & 0.011905 \\
\hline 9 & 6 & 3 & 10.226190 & 0.214286 \\
\hline 9 & 6 & 3 & 20.761905 & 0.535714 \\
\hline 9 & 6 & 3 & 31.000000 & 0.238095 \\
\hline 9 & 6 & 4 & 10.047619 & 0.047619 \\
\hline 9 & 6 & 4 & 20.404762 & 0.357143 \\
\hline 9 & 6 & 4 & 30.880952 & 0.476190 \\
\hline 9 & 6 & 4 & 41.000000 & 0.119048 \\
\hline 9 & 6 & 5 & 20.119048 & 0.119048 \\
\hline 9 & 6 & 5 & 30.595238 & 0.476190 \\
\hline 9 & 6 & 5 & 40.952381 & 0.357143 \\
\hline 9 & 6 & 5 & 51.000000 & 0.047619 \\
\hline 9 & 6 & 6 & 30.238095 & 0.238035 \\
\hline 9 & 6 & 6 & 40.773810 & 0.535714 \\
\hline 9 & 6 & 6 & $\begin{array}{ll}50.988095\end{array}$ & 0.214286 \\
\hline 9 & 6 & 6 & 61.000000 & 0.011905 \\
\hline 9 & 6 & 7 & 40.416667 & 0.416667 \\
\hline 9 & 6 & 7 & 50.916667 & 0.500000 \\
\hline 9 & 6 & 7 & 61.000000 & 0.083333 \\
\hline 9 & 6 & 8 & $\begin{array}{ll}5 & 0.666667\end{array}$ & 0.666667 \\
\hline 9 & 6 & 8 & 61.000000 & 0.333333 \\
\hline 9 & 6 & 9 & 61.000000 & 1.000000 \\
\hline 9 & 7 & 1 & 00.222222 & 0.222222 \\
\hline 9 & 7 & 1 & 11.000000 & 0.777778 \\
\hline 9 & 7 & 2 & 00.027778 & 0.027778 \\
\hline 9 & 7 & 2 & 10.416667 & 0.388889 \\
\hline 9 & 7 & 2 & 21.000000 & 0.583333 \\
\hline 9 & 7 & 3 & 10.083333 & 0.083333 \\
\hline 9 & 7 & 3 & 20.583333 & 0.500000 \\
\hline 9 & 7 & 3 & 31.000000 & 0.416667 \\
\hline 9 & 7 & 4 & 20.166667 & 0.166667 \\
\hline 9 & 7 & 4 & $\begin{array}{ll}3 & 0.722222\end{array}$ & 0.555556 \\
\hline 9 & 7 & 4 & 41.000000 & 0.277778 \\
\hline 9 & 7 & 5 & 30.277778 & 0.277778 \\
\hline 9 & 7 & 5 & 40.833333 & 0.555556 \\
\hline 9 & 7 & 5 & 51.000000 & 0.166667 \\
\hline 9 & 7 & 6 & 40.416667 & 0.416667 \\
\hline 9 & 7 & 6 & $\begin{array}{ll}5 & 0.916667\end{array}$ & 0.500000 \\
\hline 9 & 7 & 6 & 61.000000 & c. .083333 \\
\hline 9 & 7 & 7 & $\begin{array}{ll}5 & 0.583333\end{array}$ & 0.583333 \\
\hline 9 & 7 & 7 & 0.972222 & 0.388889 \\
\hline 9 & 7 & 7 & 71.000000 & 0.027778 \\
\hline
\end{tabular}

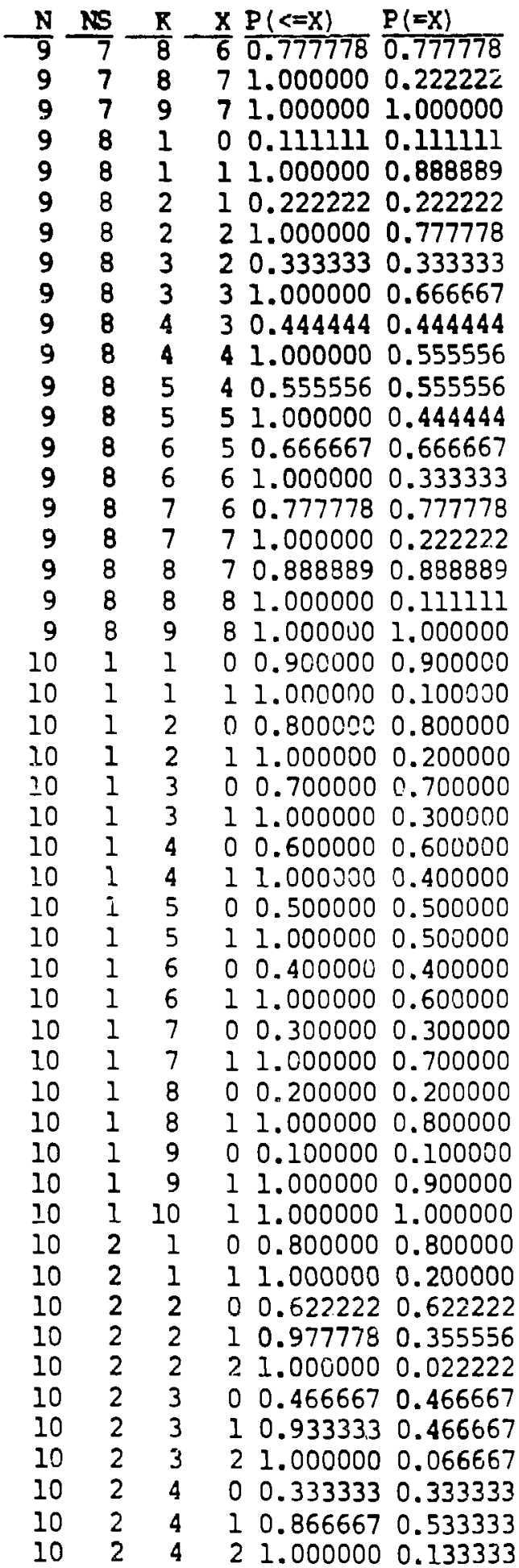




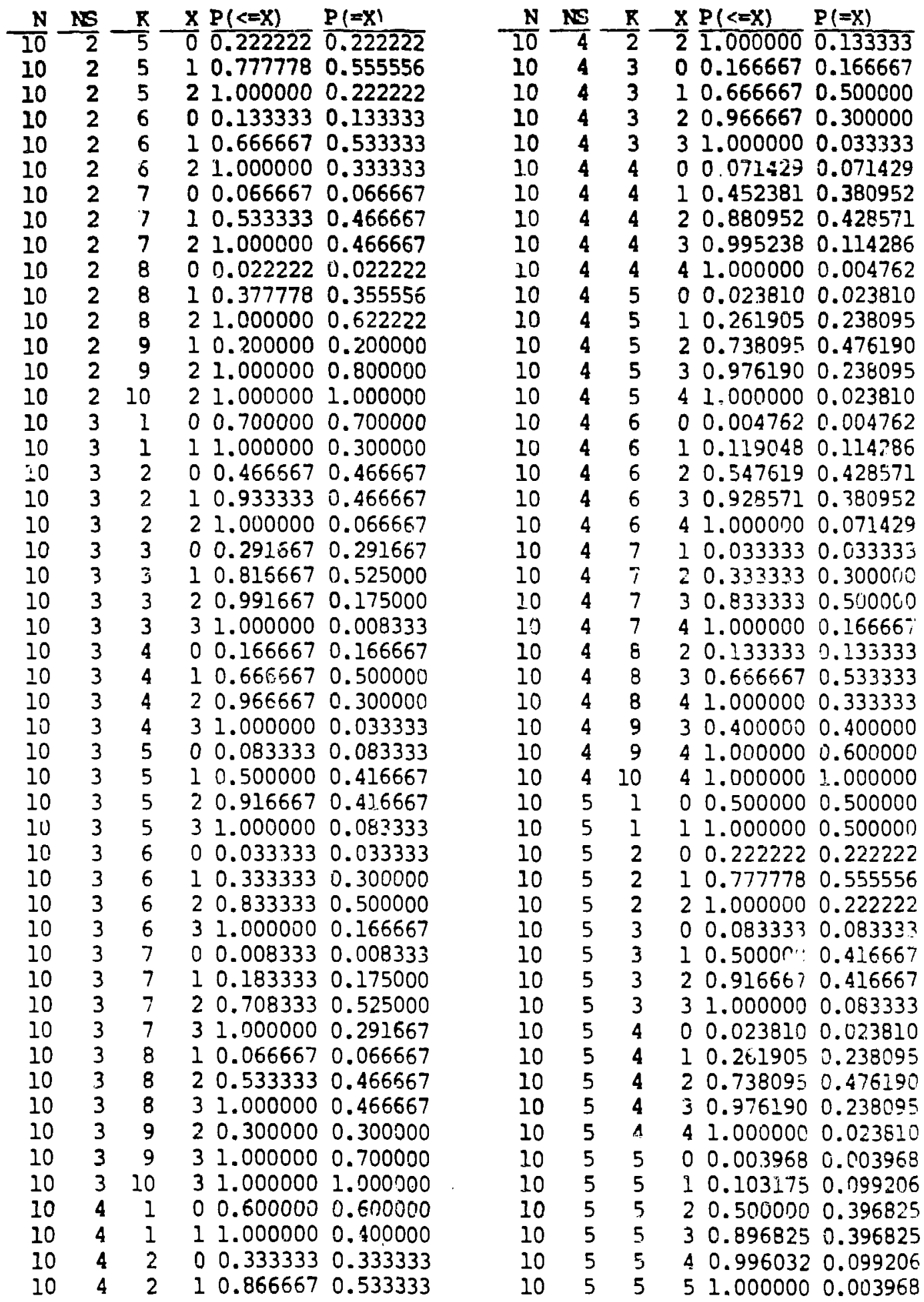




\begin{tabular}{|c|c|c|c|c|}
\hline $\mathrm{N}$ & NS & $\underline{R}$ & $\mathrm{X} \mathrm{P}(<=\mathrm{x})$ & $P(=X)$ \\
\hline$\overline{10}$ & 5 & $\overline{6}$ & $1 \overline{0.023810}$ & $\overline{0.023810}$ \\
\hline 10 & 5 & 6 & 20.261905 & 0.238095 \\
\hline 10 & 5 & 6 & 30.738095 & 0.476190 \\
\hline 10 & 5 & 6 & 40.976190 & 0.238095 \\
\hline 10 & 5 & 6 & 51.000000 & 0.023810 \\
\hline 10 & 5 & 7 & 20.083333 & 0.083333 \\
\hline 10 & 5 & 7 & 30.500000 & 0.416667 \\
\hline 10 & 5 & 7 & 40.916667 & 0.416667 \\
\hline 10 & 5 & 7 & 51.000000 & 0.083333 \\
\hline 10 & 5 & 8 & 30.222222 & 0.222222 \\
\hline 10 & 5 & 8 & 40.777778 & 0.555556 \\
\hline 10 & 5 & 8 & 51.000000 & 0.222222 \\
\hline 10 & 5 & 9 & 40.500000 & 0.500000 \\
\hline 10 & 5 & 9 & 51.000000 & 0.500000 \\
\hline 10 & 5 & 10 & 51.000000 & 1.000000 \\
\hline 10 & 6 & 1 & 00.400000 & 0.400000 \\
\hline 10 & 6 & 1 & 11.000000 & 0.600000 \\
\hline 10 & 6 & 2 & 00.133333 & 0.133333 \\
\hline 10 & 6 & 2 & 10.666667 & 0.533333 \\
\hline 10 & 6 & 2 & 21.000000 & 0.333333 \\
\hline 10 & 6 & 3 & 00.033333 & 0.033333 \\
\hline 10 & 6 & 3 & 10.333333 & 0.300000 \\
\hline 10 & 6 & 3 & 20.833333 & 0.500000 \\
\hline 10 & 6 & 3 & 31.000000 & 0.166667 \\
\hline 10 & 6 & 4 & $00.004>62$ & 0.004762 \\
\hline 10 & 6 & 4 & 10.119048 & 0.114286 \\
\hline 10 & 6 & 4 & 20.547619 & 0.428571 \\
\hline 10 & 6 & 4 & 30.928571 & 0.380952 \\
\hline 10 & 6 & 4 & 41.000000 & 0.071429 \\
\hline 10 & 6 & 5 & 10.023810 & 0.023810 \\
\hline 10 & 6 & 5 & 20.261905 & 0.238095 \\
\hline 10 & 6 & 5 & 30.738095 & 0.476190 \\
\hline 10 & 6 & 5 & 40.976190 & 0.238095 \\
\hline 10 & 6 & 5 & 51.000000 & 0.023810 \\
\hline 10 & 6 & 6 & 20.071429 & 0.071429 \\
\hline 10 & 6 & 6 & 0.452381 & 0.380952 \\
\hline 10 & 6 & 6 & 40.880952 & 0.428571 \\
\hline 10 & 6 & 6 & 0.995238 & 0.114 \\
\hline 10 & 6 & 6 & 1.000000 & 0.004762 \\
\hline 10 & 6 & 7 & 0.166667 & 0.166667 \\
\hline 10 & 6 & 7 & 0.666667 & 0.500000 \\
\hline 10 & 6 & 7 & 0.966667 & 0.300000 \\
\hline 10 & 6 & 7 & 1.000000 & 0.03333 \\
\hline 10 & 6 & 8 & 0.333333 & 0.3 \\
\hline 10 & 6 & 8 & 0.866667 & 0.53 \\
\hline 10 & 6 & 8 & 1.000000 & \\
\hline 10 & 6 & 9 & 0.600000 & 0.600000 \\
\hline 10 & 6 & 9 & 1.000000 & 0.400000 \\
\hline 10 & 6 & 10 & 1.000000 & 00000 \\
\hline 10 & 7 & 1 & 00.300000 & \\
\hline
\end{tabular}

\begin{tabular}{|c|c|c|c|c|}
\hline $\mathbf{N}$ & NS & $\mathbf{R}$ & $\mathbf{X} \underline{\mathbf{P}(<=\mathrm{X})}$ & $P(=x)$ \\
\hline 10 & 7 & $\overline{1}$ & $\overline{1.000000}$ & 0.700000 \\
\hline 10 & 7 & 2 & 00.066667 & 0.066667 \\
\hline 10 & 7 & 2 & 533333 & 0.456667 \\
\hline 10 & 7 & 2 & 000000 & 466667 \\
\hline 10 & 7 & 3 & 008333 & 0.008333 \\
\hline 10 & 7 & 3 & 10.183333 & 0.175000 \\
\hline 10 & 7 & 3 & 20.708333 & 0.525000 \\
\hline 10 & 7 & 3 & 000000 & 0.291667 \\
\hline 10 & 7 & 4 & 10.033333 & 0.033333 \\
\hline 10 & 7 & 4 & 33 & 0000 \\
\hline 10 & 7 & 4 & 30 & 00000 \\
\hline 10 & 7 & 4 & 000000 & 0.166667 \\
\hline 10 & 7 & 5 & 083333 & 0.083333 \\
\hline 10 & 7 & 5 & 500000 & .416667 \\
\hline 10 & 7 & 5 & 40.916667 & 0.416667 \\
\hline 10 & 7 & 5 & 51.000000 & 0.083333 \\
\hline .0 & 7 & 6 & 30 & 6667 \\
\hline 10 & 7 & 6 & 40.666667 & 500000 \\
\hline 10 & 7 & 6 & 50. & 300000 \\
\hline 10 & 7 & 6 & 61.000000 & 0.033333 \\
\hline 10 & 7 & 7 & 40.291667 & 0.291667 \\
\hline 10 & 7 & 7 & 50.816667 & 0.525000 \\
\hline 10 & 7 & 7 & $\begin{array}{ll}6 & 0.991667\end{array}$ & 0.175000 \\
\hline 10 & 7 & 7 & 71.000000 & 0.008333 \\
\hline 10 & 7 & 8 & 50.466667 & 0.466667 \\
\hline 10 & 7 & 8 & 60. & 0.466667 \\
\hline 10 & 7 & 8 & 71.000000 & 0.066667 \\
\hline 10 & 7 & 9 & $\begin{array}{ll}6 & 0.700000\end{array}$ & 0.700000 \\
\hline 10 & 7 & 9 & 71.000000 & 0.300000 \\
\hline 10 & 7 & 10 & 71.000000 & 1.000000 \\
\hline 10 & 8 & 1 & 00.200000 & 0.200000 \\
\hline 10 & 8 & 1 & 11.000000 & 0.800000 \\
\hline 10 & 8 & 2 & $0 \quad 0.022222$ & 0.022222 \\
\hline 10 & 8 & 2 & 10.377778 & 0.355556 \\
\hline 10 & 8 & 2 & 21.000000 & 0.622222 \\
\hline 10 & 8 & 3 & 10.066667 & 0.066667 \\
\hline 10 & 8 & 3 & 20.533333 & 0.466667 \\
\hline 10 & 8 & 3 & 31.000000 & 0.466667 \\
\hline 10 & 8 & 4 & 20.133333 & 0.133333 \\
\hline 10 & 8 & 4 & 30.666667 & 0.533333 \\
\hline 10 & 8 & 4 & 41.000000 & 0.333333 \\
\hline 10 & 8 & 5 & 30.222222 & 0.222222 \\
\hline 10 & 8 & 5 & 40.777778 & 0.555556 \\
\hline 10 & 8 & 5 & 51.000000 & 0.222222 \\
\hline 10 & 8 & 6 & 40.333333 & 0.333333 \\
\hline 10 & 8 & 6 & 50.866667 & 0.533333 \\
\hline 10 & 8 & 6 & 61.000000 & 0.133333 \\
\hline 10 & 8 & 7 & 50.466667 & 0.466667 \\
\hline 10 & 8 & 7 & $\begin{array}{ll}6 & 0.933333\end{array}$ & 0.466667 \\
\hline 10 & 8 & 7 & 71.000000 & 0.066667 \\
\hline
\end{tabular}




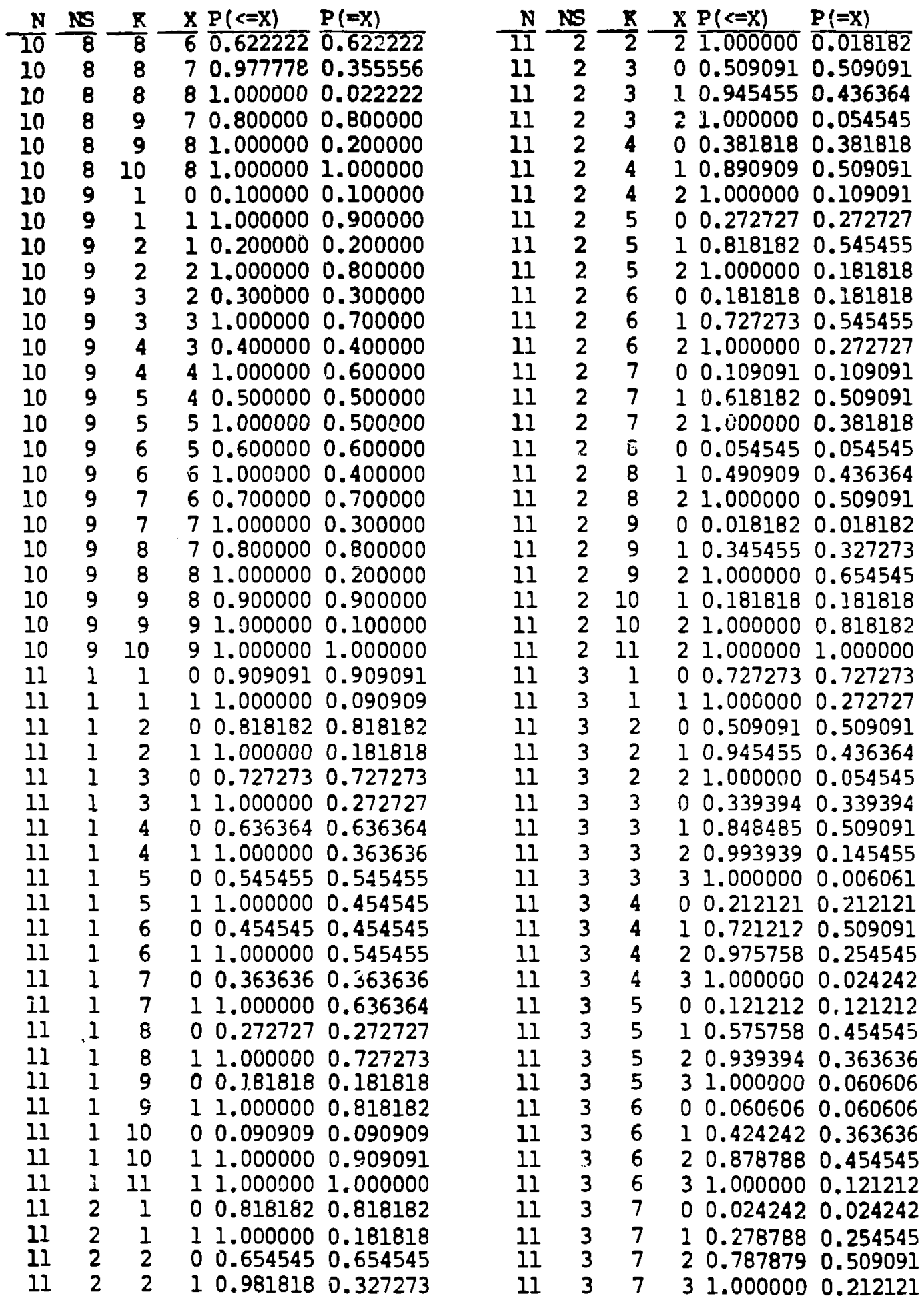




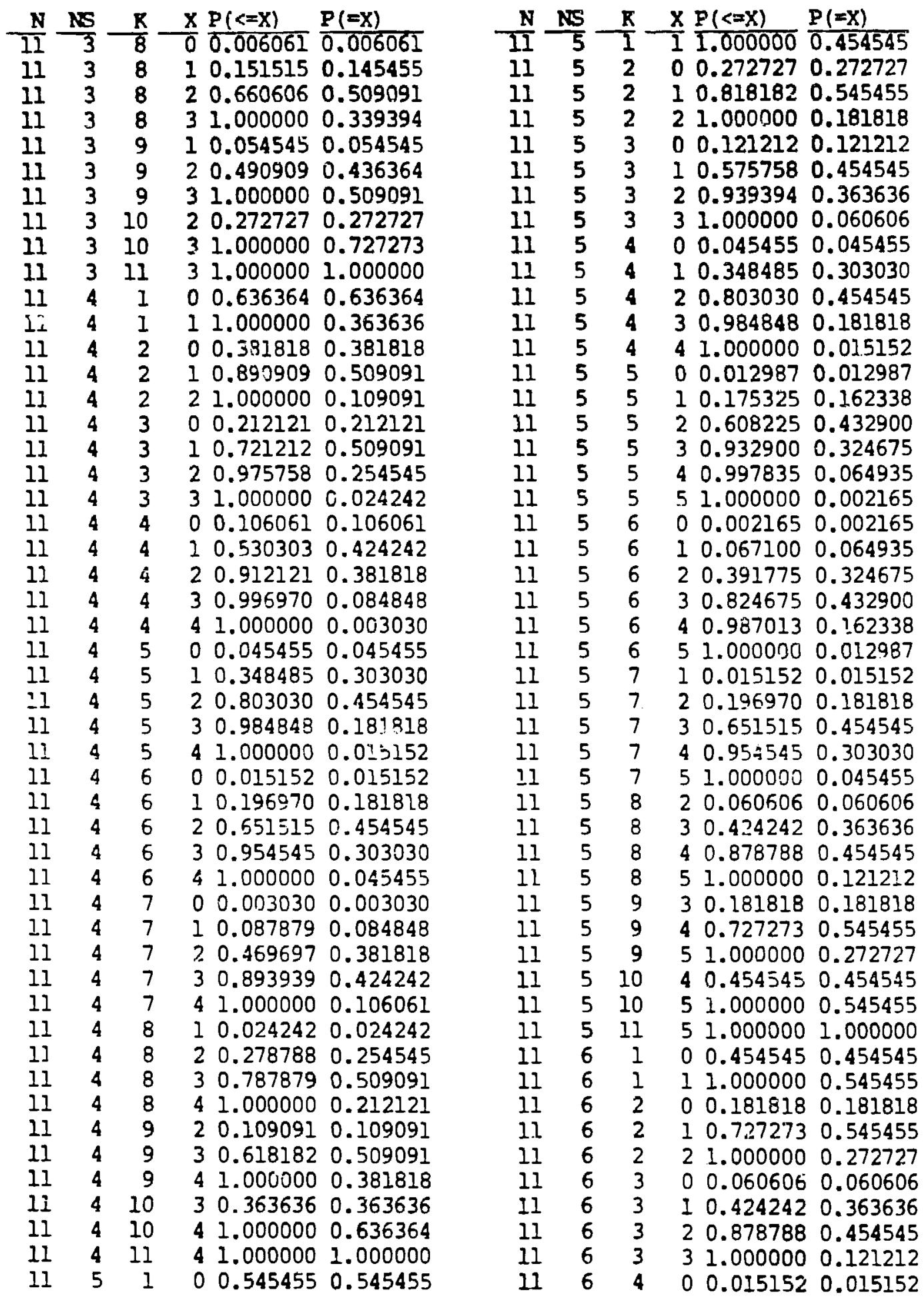




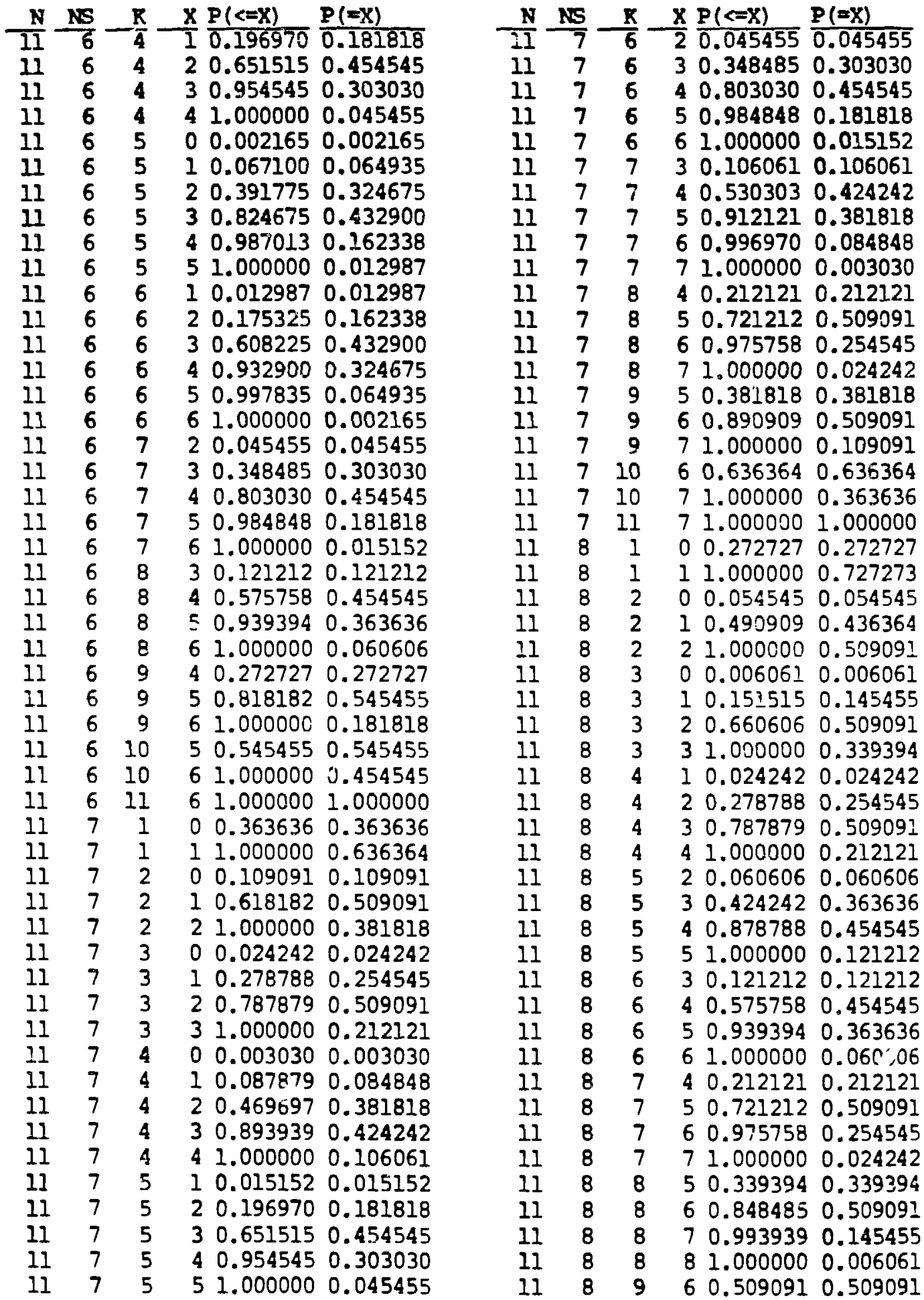




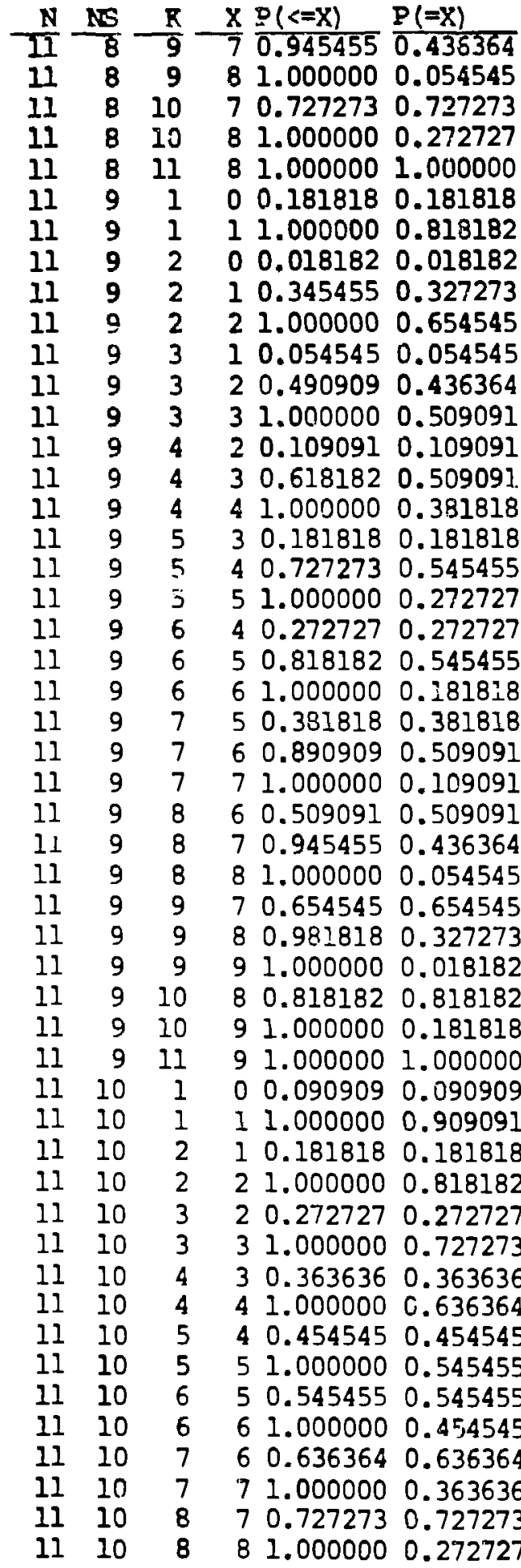

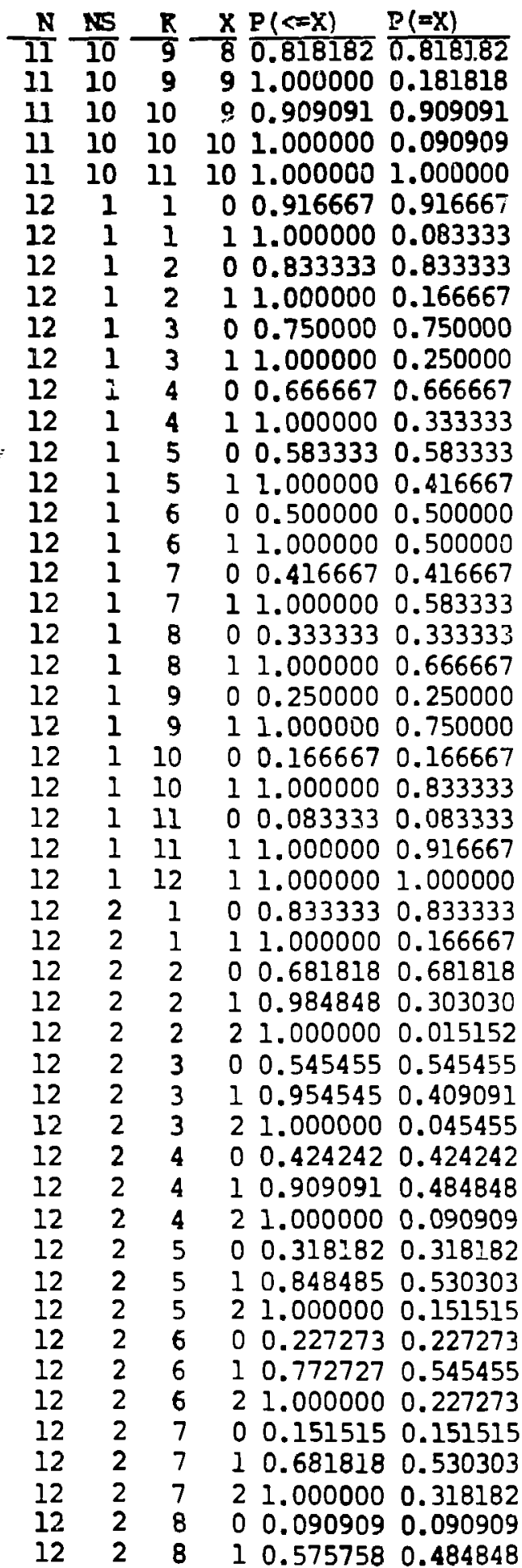




\begin{tabular}{rrr}
$\mathbf{N}$ & $\mathbf{N}$ & $\mathbf{R}$ \\
\cline { 2 - 3 } $\mathbf{1 2}$ & $\mathbf{2}$ & $\mathbf{8}$ \\
12 & 2 & 9 \\
12 & 2 & 9 \\
12 & 2 & 9 \\
12 & 2 & 10 \\
12 & 2 & 10 \\
12 & 2 & 10 \\
12 & 2 & 11 \\
12 & 2 & 11 \\
12 & 2 & 12 \\
12 & 3 & 1 \\
12 & 3 & 1 \\
12 & 3 & 2 \\
12 & 3 & 2 \\
12 & 3 & 2 \\
12 & 3 & 3 \\
12 & 3 & 3 \\
12 & 3 & 3 \\
12 & 3 & 3 \\
12 & 3 & 4 \\
12 & 3 & 4 \\
12 & 3 & 4 \\
12 & 3 & 4 \\
12 & 3 & 5 \\
12 & 3 & 5 \\
12 & 3 & 5 \\
12 & 3 & 5 \\
12 & 3 & 6 \\
12 & 3 & 6 \\
12 & 3 & 6 \\
12 & 3 & 6 \\
12 & 3 & 7 \\
12 & 3 & 7 \\
12 & 3 & 7 \\
12 & 3 & 7 \\
12 & 3 & 8 \\
12 & 3 & 8 \\
12 & 3 & 8 \\
12 & 3 & 8 \\
12 & 3 & 9 \\
12 & 3 & 9 \\
12 & 3 & 9 \\
12 & 3 & 9 \\
12 & 3 & 10 \\
12 & 3 & 10 \\
12 & 3 & 10 \\
12 & 3 & 11 \\
12 & 3 & 11 \\
12 & 3 & 12 \\
12 & 4 & 1 \\
& &
\end{tabular}

$\frac{X}{2} \frac{P(<-X)}{1.000000} \frac{P(=X)}{0.424242}$

$00.045455 \quad 0.045455$

$\begin{array}{lllll}1 & 0.454545 & 0.409091\end{array}$

$\begin{array}{llll}2 & 1.000000 & 0.545455\end{array}$

$0 \quad 0.0151520 .015152$

$\begin{array}{lll}1 & 0.318182 & 0.303030\end{array}$

$\begin{array}{llll}2 & 1.000000 & 0.681818\end{array}$

$\begin{array}{lllll}1 & 0.166667 & 0.166667\end{array}$

$\begin{array}{lll}2 & 1.000000 & 0.833333\end{array}$

21.0000001 .000000

$\begin{array}{llll}0 & 0.750000 & 0.750000\end{array}$

$11.700000 \quad 0.250000$

$\begin{array}{lll}0 & 0.545455 & 0.545455\end{array}$

$\begin{array}{lllll}1 & 0.954545 & 0.409091\end{array}$

$21.000000 \quad 0.045455$

$\begin{array}{llll}0 & 0.381818 & 0.381818\end{array}$

$\begin{array}{lllll}1 & 0.872727 & 0.490909\end{array}$

$\begin{array}{llll}2 & 0.995455 & 0.122727\end{array}$

$\begin{array}{llll}3 & 1.000000 & 0.004545\end{array}$

$\begin{array}{llllllll}0 & 0.254545 & 0.254545\end{array}$

$\begin{array}{lllll}1 & 0.763636 & 0.509091\end{array}$

$\begin{array}{llll}2 & 0.981818 & 0.218182\end{array}$

$\begin{array}{llll}3 & 1.000000 & 0.018182\end{array}$

$\begin{array}{llllllllll}0 & 0.159091 & 0.159091\end{array}$

$\begin{array}{lllll}1 & 0.636364 & 0.477273\end{array}$

$\begin{array}{llll}2 & 0.954545 & 0.318182\end{array}$

$\begin{array}{lll}3 & 1.000000 & 0.045455\end{array}$

$\begin{array}{lll}0 & 0.090909 & 0.090909\end{array}$

$\begin{array}{lllllll}1 & 0.500000 & 0.409091\end{array}$

$\begin{array}{llll}2 & 0.909091 & 0.409091\end{array}$

$\begin{array}{llll}3 & 1.000000 & 0.090909\end{array}$

$\begin{array}{lll}0 & 0.045455 & 0.045455\end{array}$

$\begin{array}{lllll}1 & 0.363636 & 0.318182\end{array}$

$\begin{array}{llll}2 & 0.840909 & 0.477273\end{array}$

$\begin{array}{llll}3 & 1.000000 & 0.159091\end{array}$

$\begin{array}{lll}0 & 0.018182 & 0.018182\end{array}$

$\begin{array}{lllll}1 & 0.236364 & 0.218182\end{array}$

$\begin{array}{llll}2 & 0.745455 & 0.509091\end{array}$

$\begin{array}{lll}3 & 1.000000 & 0.254545\end{array}$

$\begin{array}{lll}0 & 0.004545 & 0.004545\end{array}$

$\begin{array}{llll}1 & 0.127273 & 0.122727\end{array}$

$\begin{array}{llll}2 & 0.618182 & 0.490909\end{array}$

$\begin{array}{llll}3 & 1.000000 & 0.381818\end{array}$

$\begin{array}{llll}1 & 0.045455 & 0.045455\end{array}$

$\begin{array}{lll}2 & 0.454545 & 0.409091\end{array}$

$\begin{array}{lll}3 & 1.000000 & 0.545455\end{array}$

$\begin{array}{llll}2 & 0.250000 & 0.250000\end{array}$

$\begin{array}{llll}3 & 1.000000 & 0.750000\end{array}$

31.0000001 .000000

$\begin{array}{lll}0 & 0.666667 & 0.666667\end{array}$

\begin{tabular}{|c|c|c|c|c|}
\hline $\mathbf{N}$ & NS & $\mathbf{K}$ & $X P(<x)$ & $P(\Sigma X)$ \\
\hline 12 & 4 & $\overline{1}$ & 11.000000 & 0.333333 \\
\hline 12 & 4 & 2 & 00.424242 & 0.424242 \\
\hline 12 & 4 & 2 & 10.909091 & 0.484848 \\
\hline 12 & 4 & 2 & 21.000000 & 0.090909 \\
\hline 12 & 4 & 3 & 00.254545 & 54545 \\
\hline 12 & 4 & 3 & 10.763636 & 9091 \\
\hline 12 & 4 & 3 & 1818 & 8182 \\
\hline 12 & 4 & 3 & 00000 & 182 \\
\hline 12 & 4 & 4 & 00. & 0.141414 \\
\hline 12 & 4 & 4 & 10. & 52525 \\
\hline 12 & 4 & 4 & 33333 & 0.339394 \\
\hline 12 & 4 & 4 & 30 & 0.064646 \\
\hline 12 & 4 & 4 & 00000 & 0.002020 \\
\hline 12 & 4 & 5 & 00.070707 & 0.070707 \\
\hline 12 & 4 & 5 & 10.424242 & 0.353535 \\
\hline 12 & 4 & 5 & 20.848485 & 0.424242 \\
\hline 12 & 4 & 5 & 30.98 & 0.141414 \\
\hline 12 & 4 & 5 & 41.000000 & 0.010101 \\
\hline 12 & 4 & 6 & 00.030303 & 0.030303 \\
\hline 12 & 4 & 6 & 10.272727 & 0.242424 \\
\hline 12 & 4 & 6 & 20.727273 & 0.454545 \\
\hline 12 & 4 & 6 & 30.969697 & 0.242424 \\
\hline 12 & 4 & 6 & 41.000000 & 0.030303 \\
\hline 12 & 4 & 7 & 00.010101 & $0.01010 ?$ \\
\hline 12 & 4 & 7 & 10.151515 & 0.141414 \\
\hline 12 & 4 & 7 & 20.575758 & 0.424242 \\
\hline 12 & 4 & 7 & 30.929293 & 0.35 \\
\hline 12 & 4 & 7 & 41.000000 & 0.070707 \\
\hline 12 & 4 & 8 & 00.002020 & 0.002020 \\
\hline 12 & 4 & 8 & 10.066657 & 0.064646 \\
\hline 12 & 4 & 8 & $20.40606 !$ & 0.339394 \\
\hline 12 & 4 & 8 & 30.858586 & 0.452525 \\
\hline 12 & 4 & 8 & 41.000000 & 0.141414 \\
\hline 12 & 4 & 9 & 10.018182 & 0.018182 \\
\hline 12 & 4 & 9 & 20.236364 & 0.218182 \\
\hline 12 & 4 & 9 & 30.745 & 0.509091 \\
\hline 12 & 4 & 9 & 41.000000 & 0.254545 \\
\hline 12 & 4 & 10 & 20.090909 & 0.090909 \\
\hline 12 & 4 & 10 & 30.575758 & 0.484848 \\
\hline 12 & 4 & 10 & 41. & \\
\hline 12 & 4 & 11 & $\begin{array}{ll}30.333333\end{array}$ & 0.333333 \\
\hline 12 & 4 & 11 & 41.000000 & 0.666667 \\
\hline 12 & 4 & 12 & 41.000000 & 1.000000 \\
\hline 12 & 5 & 1 & 00.583333 & 0.583333 \\
\hline 12 & 5 & 1 & 11.000000 & $C .416667$ \\
\hline 1 & 5 & 2 & 00.318182 & 0.318182 \\
\hline 12 & 5 & 2 & 10.848485 & 0.530303 \\
\hline 12 & 5 & 2 & 21.000000 & 0.151515 \\
\hline 12 & 5 & 3 & 0.159091 & 0.159091 \\
\hline 12 & 5 & 3 & 10. & \\
\hline
\end{tabular}




\begin{tabular}{rrr} 
N & NS & R \\
\cline { 2 - 2 } 12 & 5 & 3 \\
12 & 5 & 3 \\
12 & 5 & 4 \\
12 & 5 & 4 \\
12 & 5 & 4 \\
12 & 5 & 4 \\
12 & 5 & 4 \\
12 & 5 & 5 \\
12 & 5 & 5 \\
12 & 5 & 5 \\
12 & 5 & 5 \\
12 & 5 & 5 \\
12 & 5 & 5 \\
12 & 5 & 6 \\
12 & 5 & 6 \\
12 & 5 & 6 \\
12 & 5 & 6 \\
12 & 5 & 6 \\
12 & 5 & 6 \\
12 & 5 & 7 \\
12 & 5 & 7 \\
12 & 5 & 7 \\
12 & 5 & 7 \\
12 & 5 & 7 \\
12 & 5 & 7 \\
12 & 5 & 8 \\
12 & 5 & 8 \\
12 & 5 & 8 \\
12 & 5 & 8 \\
12 & 5 & 8 \\
12 & 5 & 9 \\
12 & 5 & 9 \\
12 & 5 & 9 \\
12 & 5 & 9 \\
12 & 5 & 10 \\
12 & 5 & 10 \\
12 & 5 & 10 \\
12 & 5 & 11 \\
12 & 5 & 11 \\
12 & 5 & 12 \\
12 & 6 & 1 \\
12 & 6 & 1 \\
12 & 6 & 2 \\
12 & 6 & 2 \\
12 & 6 & 2 \\
12 & 6 & 3 \\
12 & 6 & 3 \\
12 & 6 & 4 \\
& & 3
\end{tabular}

$\mathrm{X} P(<=\mathrm{X}) \quad \mathrm{P}(=\mathrm{X})$

2 0.954545 $\overline{0.318182}$

$31.000000 \quad 0.045455$

$\begin{array}{llll}0 & 0.070707 & 0.070707\end{array}$

10.4242420 .353535

$\begin{array}{llll}2 & 0.848485 & 0.424242\end{array}$

$\begin{array}{llll}3 & 0.989899 & 0.141414\end{array}$

41.0000000 .010101

$\begin{array}{lll}0 & 0.026515 & 0.026515\end{array}$

$\begin{array}{lll}1 & 0.247475 & 0.220960\end{array}$

$\begin{array}{llll}2 & 0.689394 & 0.441919\end{array}$

$\begin{array}{lll}3 & 0.954545 & 0.265152\end{array}$

$\begin{array}{lllll}4 & 0.998737 & 0.044192\end{array}$

$51.000000 \quad 0.001263$

$\begin{array}{llll}0 & 0.007576 & 0.007576\end{array}$

$\begin{array}{llll}1 & 0.121212 & 0.113656\end{array}$

$\begin{array}{llll}2 & 0.500000 & 0.378788\end{array}$

$\begin{array}{llll}3 & 0.878788 & 0.378788\end{array}$

$\begin{array}{llll}4 & 0.992424 & 0.113636\end{array}$

$51.000000 \quad 0.007576$

$\begin{array}{llll}0 & 0.001263 & 0.00 !: 63\end{array}$

$\begin{array}{llll}1 & 0.045455 & 0.044192\end{array}$

$\begin{array}{llll}2 & 0.310606 & 0.265152\end{array}$

$\begin{array}{lll}3 & 0.752525 & 0.441919\end{array}$

$\begin{array}{lll}4 & 0.973485 & 0.220960\end{array}$

$51.000000 \quad 0.026515$

$\begin{array}{llll}1 & 0.010101 & 0.010101\end{array}$

$\begin{array}{llll}2 & 0.151515 & 0.141414\end{array}$

$\begin{array}{lllll}3 & 0.575758 & 0.424242\end{array}$

$\begin{array}{lll}4 & 0.929293 & 0.353535\end{array}$

$\begin{array}{lll}5 & 1.000000 & 0.070707\end{array}$

20.0454550 .045455

$\begin{array}{llll}3 & 0.363636 & 0.318182\end{array}$

40.8409090 .477273

$51.000000 \quad 0.159091$

$\begin{array}{llll}3 & 0.151515 & 0.151515\end{array}$

$40.681818 \quad 0.530303$

$51.000000 \quad 0.318182$

$\begin{array}{llll}4 & 0.416667 & 0.416667\end{array}$

$\begin{array}{llll}5 & 1.000000 & 0.583333\end{array}$

51.0000001 .000000

$0 \quad 0.500000 \quad 0.500000$

$11.000000 \quad 0.500000$

$\begin{array}{llll}0 & 0.227273 & 0.227273\end{array}$

$\begin{array}{lllll}1 & 0.772727 & 0.545455\end{array}$

$\begin{array}{llll}2 & 1.000000 & 0.227273\end{array}$

$\begin{array}{llll}0 & 0.090909 & 0.090909\end{array}$

$\begin{array}{lllll}1 & 0.500000 & 0.409091\end{array}$

$\begin{array}{lll}2 & 0.909091 & 0.409091\end{array}$

$\begin{array}{lll}3 & 1.000000 & 0.090909\end{array}$

00.0303030 .030303

\begin{tabular}{|c|c|c|c|c|}
\hline $\mathbf{N}$ & & & $X \underline{P(<=x)}$ & $P(=X)$ \\
\hline$\overline{12}$ & 6 & $\overline{4}$ & $\overline{1} \overline{0.272727}$ & $\overline{0.242424}$ \\
\hline 12 & 6 & 4 & 20.727273 & 0.454545 \\
\hline 12 & 6 & 4 & 30.969697 & 0.2 \\
\hline 12 & 6 & 4 & 41.000000 & $\begin{array}{l}0.03030 \\
0.0075\end{array}$ \\
\hline $\begin{array}{l}12 \\
12\end{array}$ & $\begin{array}{l}6 \\
6\end{array}$ & $\begin{array}{l}5 \\
5\end{array}$ & $\begin{array}{ll}0 & 0.0075 / 6 \\
1 & 0.121212\end{array}$ & $0.0075 / 6$ \\
\hline 12 & 6 & 5 & 20.500000 & 0.378788 \\
\hline 12 & 6 & 5 & 378788 & 378788 \\
\hline 12 & 6 & 5 & 40.992424 & 0.113636 \\
\hline 12 & 6 & 5 & 51.000000 & 0.007576 \\
\hline 12 & 6 & 6 & 00.001082 & 0.001082 \\
\hline 12 & 6 & 6 & 10.040043 & 0.038961 \\
\hline 12 & 6 & 6 & 20.283550 & 0.243506 \\
\hline 12 & 6 & 6 & 30.716450 & 0.132900 \\
\hline 12 & 6 & 6 & 40.959957 & 0.243506 \\
\hline 12 & 6 & 6 & 50.998918 & 0.038961 \\
\hline 12 & 6 & 6 & 61.000000 & 0.001082 \\
\hline 12 & 6 & 7 & 10.007576 & 0.007576 \\
\hline 12 & 6 & 7 & 20.121212 & 0.113636 \\
\hline 12 & 6 & 7 & 0.500000 & 0.378788 \\
\hline 12 & 6 & 7 & 40.878788 & 0.378788 \\
\hline 12 & 6 & 7 & $\begin{array}{ll}5 & 0.992424\end{array}$ & 0.113636 \\
\hline 12 & 6 & 7 & 61.000000 & 0.007576 \\
\hline 12 & 6 & 8 & 20.030303 & 0.030303 \\
\hline 12 & 6 & 8 & 30.272727 & 0.242424 \\
\hline 12 & 6 & 8 & 40.727273 & 0.454545 \\
\hline 12 & 6 & 8 & 0.969697 & 0.242424 \\
\hline 12 & 6 & 8 & 61.000000 & 0.030303 \\
\hline 12 & 6 & 9 & 30.090909 & 0.090909 \\
\hline 12 & 6 & 9 & 40.500000 & 0.409091 \\
\hline 12 & 6 & 9 & 50.909091 & 0.409091 \\
\hline 12 & 6 & 9 & 61.000000 & 0.090909 \\
\hline 12 & 6 & 10 & 40.227273 & 0.227273 \\
\hline 12 & 6 & 10 & $\begin{array}{ll}5 & 0.772727\end{array}$ & 0.545455 \\
\hline 12 & 6 & 10 & 61.000000 & 0.227273 \\
\hline 12 & 6 & 11 & 50.500000 & 0.500000 \\
\hline 12 & 6 & 11 & 61.000000 & 0.500000 \\
\hline 12 & 6 & 12 & 61.000000 & 1.000000 \\
\hline 12 & 7 & 1 & 00.416667 & 0.416667 \\
\hline 12 & 7 & 1 & 11.000000 & 0.583333 \\
\hline 12 & 7 & 2 & 00.151515 & 0.151515 \\
\hline 12 & 7 & 2 & 10.681818 & 0.530303 \\
\hline 12 & 7 & 2 & 21.000000 & 0.318182 \\
\hline 12 & 7 & 3 & 00.045455 & 0.045455 \\
\hline 3.2 & 7 & 3 & 10.363636 & 0.318182 \\
\hline 12 & 7 & 3 & 20.840909 & 0.477273 \\
\hline 12 & 7 & 3 & 31.000000 & 0.159091 \\
\hline 12 & 7 & 4 & 00.010101 & 0.010101 \\
\hline 12 & 7 & 4 & 10.151515 & 0.141414 \\
\hline 12 & 7 & 4 & 20.575758 & 0.424242 \\
\hline
\end{tabular}




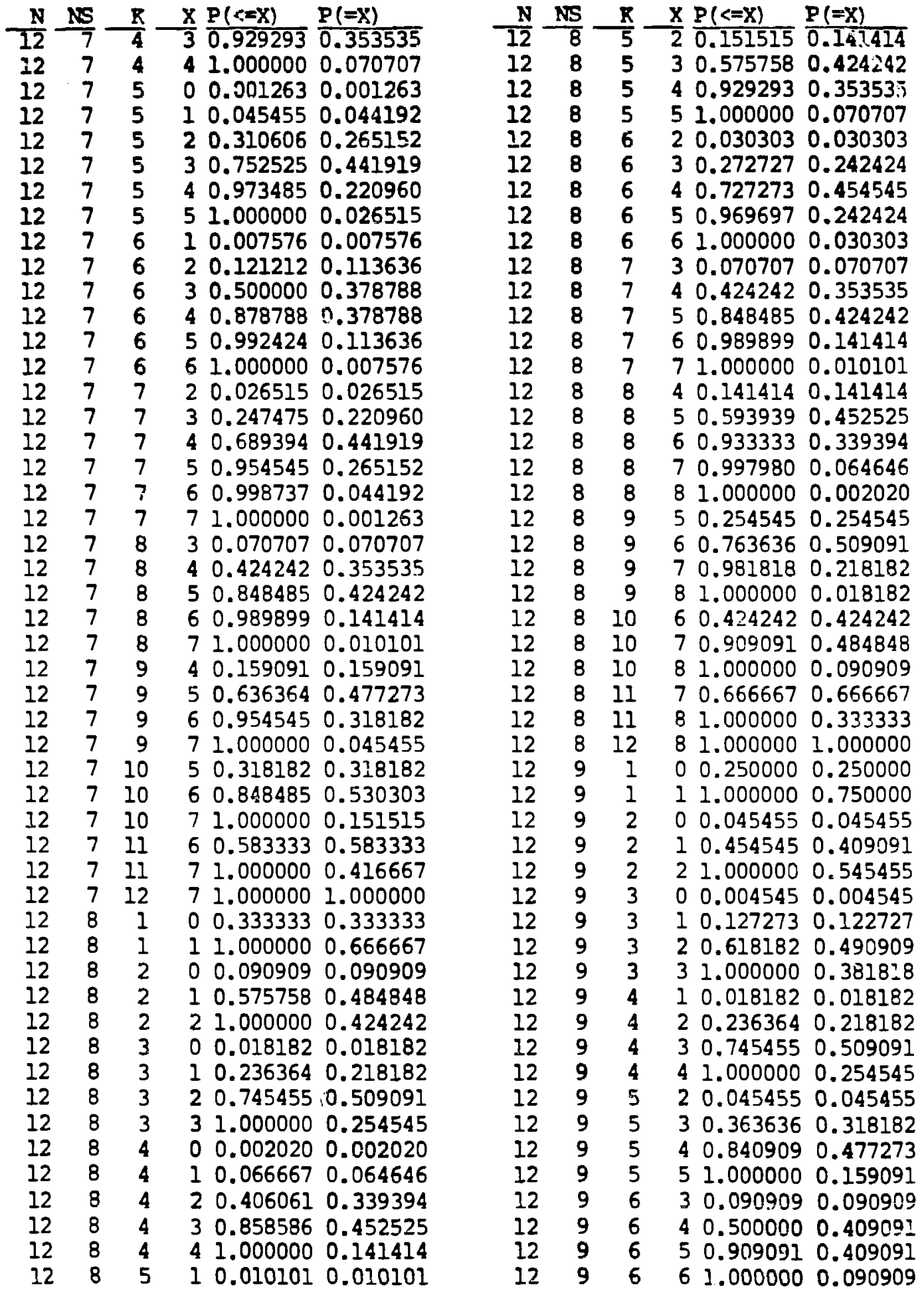




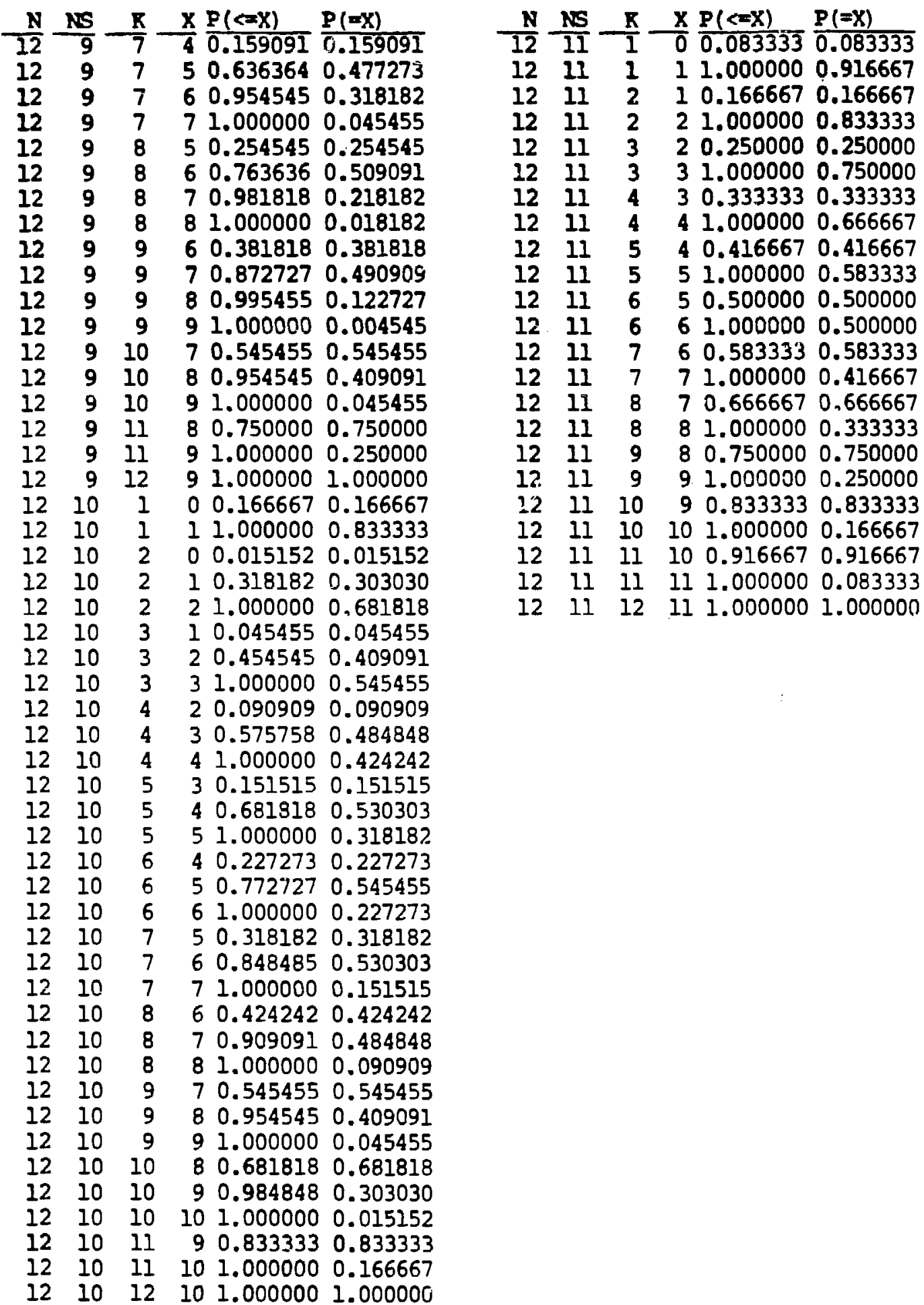

